\title{
Accelerating Net Zero from the perspective of Optimizing a Carbon Capture and
}

\section{Utilization System}

\author{
Zhimian Hao, ${ }^{1}$ Magda H. Barecka, ${ }^{2}$ Alexei A. Lapkin ${ }^{1,2 *}$
}

${ }^{I}$ Department of Chemical Engineering and Biotechnology, University of Cambridge, Cambridge CB3 OAS, UK

${ }^{2}$ Cambridge Centre for Advanced Research and Education in Singapore Ltd, 1 Create Way, CREATE Tower \#05-05, 138602, Singapore

\begin{abstract}
Net zero requires an accelerated transition from fossil fuels to renewables. Carbon capture and utilization (CCU) can be an effective intermediate solution for the decarbonization of fossil fuels. However, many research works contain renewables in the design of CCU systems, which may mislead stakeholders regarding the hotspots of CCU systems. In this work we build a model of a CCU system with no renewables involved, and evaluate its greenhouse (GHG) emissions based on the life cycle assessment with a cradle-to-gate boundary. To pursue the best system performance, an optimization framework is established to digitalize and optimize the CCU system regarding GHG emissions reduction. The optimized CCU can reduce GHG emissions by $13 \%$ compared with the conventional process. Heating is identified as the most significant contributor to GHG emissions, accounting for $60 \%$. Electrifying heating fully by low-carbon electricity can further reduce GHG emissions by $47 \%$, but such extreme conditions will significantly sacrifice the economic benefit. By contrast, the multi-objective optimization can show how the decisions can affect the balance between GHG emissions and profit. Further, this work discusses the dual effect of carbon pricing on the CCU system - raising the cost of raw materials and utilities, but also gaining credits when emissions are reduced in producing valued products.

[ Broader context ]
\end{abstract}

Fossil fuels are essential to supply the global energy demand but cause remarkable $\mathrm{CO}_{2}$ emissions. Carbon capture and utilization $(\mathrm{CCU})$ can be an effective technology to decarbonize the fossil fuel-based heavy industry, e.g. power stations. In many systems proposed for CCU, further conversion of captured $\mathrm{CO}_{2}$ to valued chemicals (utilization) requires extensive input of hydrogen or energy, which are assumed to be generated using surplus renewable electricity. Such an assumption might be challenging to realize in the near future and make the evaluation 
of CCU over-optimistic. Herein, this work focuses on a 'worst condition' (no renewables involved) and shows how optimization can be applied to explore the maximum potential of CCU regarding environmental and economic aspects. Further, the influence of carbon pricing on the deployment of CCU is also discussed.

\section{Highlights}

- Statistical surrogate models ease the task of optimization of large process

- Heating in CCU is identified as the most significant contributor to GHG emissions

- Multi-objective optimization achieves better solutions compared to single-objective

- Carbon pricing has dual effects on the deployment of CCU.

Keywords: multi-objective optimization; carbon capture and utilization; digitalization; carbon pricing; lifecycle GHG emissions

\section{Nomenclature}

\begin{tabular}{ll}
\hline CCUS & Carbon capture, utilization and storage \\
$\mathrm{CCU}$ & Carbon capture and utilization \\
$\mathrm{CCS}$ & Carbon capture and storage \\
$\mathrm{GHG}$ & Greenhouse gas \\
$\mathrm{NGCC}$ & Natural gas combined cycle power plant \\
NGCC-CCS & Natural gas power plant equipped with CCS \\
Low-carbon electricity & Specifically refer to the electricity from NGCC-CCS in this work. \\
$\mathrm{MEA}$ & Monoethanolamine \\
$\mathrm{PSA}$ & Pressure swing adsorption \\
$\mathrm{FT}$ & Fischer-Tropsch \\
$\mathrm{MS}$ & Methanol synthesis \\
$\mathrm{GHG}$ & GHG emissions of the whole CCU system (the industrial park) \\
$\mathrm{GHG}$ & GHG emissions of the reference system (no capture, refinery, MS) \\
$\mathrm{F}$ & Mass flow, ton/h \\
$\alpha$ & Lifecycle GHG emission factors, ton $\mathrm{CO}_{2}$ eq $/$ ton \\
$\mathrm{U}$ & Consumption of utility u in sub-system i, GJ/h \\
$\beta$ & Economic factors, $\$ /$ ton \\
$\gamma_{\mathrm{CO}_{2}}$ & Carbon price, $\$ /$ ton \\
$\mathrm{CAO}_{2}$ \\
$\mathrm{NSGA}$
\end{tabular}




\section{Introduction}

To limit global warming to $1.5 \sim 2{ }^{\circ} \mathrm{C}$ above pre-industrial levels, worldwide countries have pledged to cut the $\mathrm{CO}_{2}$ emissions to nearly zero (or 'net zero') by the mid of $21^{\text {st }}$ century. ${ }^{1} \mathrm{Net}$ zero requires a complete upgrading for the current energy system, since approx. $75 \%$ of GHG emissions result from today's energy sector. ${ }^{2}$ Fossil fuels are essential to supply approx. $80 \%$ of today's worldwide energy demand, and they are projected to play an indispensable role in an immediate timeframe. ${ }^{2}$ Carbon capture is reported as both an effective and scalable technology to decarbonize the fossil fuels-based energy sectors. ${ }^{3}$ Further conversion of captured $\mathrm{CO}_{2}$ to high-value products (or 'utilization') requires an excessive amount of energy to break its chemical bonds, because $\mathrm{CO}_{2}$ is thermodynamically highly stable. If the energy source is purely fossil fuels, carbon capture and utilization (CCU) is reported to cause more emissions than unabated fossil fuels. ${ }^{4-6}$ To address this challenge, it has been proposed to apply renewable energy to power the carbon utilization, thus forming 'power-to-X' (power refers to solar or wind renewable energy source; $\mathrm{X}$ refer to fuels or chemicals, such as methanol, $\mathrm{H}_{2}$, gasoline and polymers). ${ }^{4,5,7-13}$ However, it is complex to immediately scale up these systems due to two facts: (1) a prerequisite is the access to cheap renewable energy, which requires a considerably higher renewable power capacity than todays' installations for solar photovoltaics ${ }^{14}$ and wind turbines; (2) the intermittent renewable electricity requires either cheap battery systems or the feasibility for dynamic operation of the utilization processes. ${ }^{8,11}$ Further, several studies on hybrid systems, i.e. [CCU + renewable $\mathrm{H}_{2} /$ electricity], lead to a conclusion that the inclusion of renewable energy sources are indispensable to achieve emissions reduction, ${ }^{4,5}$ and also the cost of the renewables is considered to be the limiting factor for the economic feasibility of hybrid systems. ${ }^{4,6,15} \mathrm{We}$ anticipate that the involvement of renewables might underestimate the potential of CCU and mislead the hotspot identification for the CCU itself.

We therefore sought to investigate whether CCU can be viable without the input of renewables. To answer this question, we created a hypothetical industrial park, where power plants are integrated with CCU, but no renewables are involved in the initial design. Following this, optimization is applied to explore the maximum potential of CCU regarding the environmental and economic aspects. The proposed strategy is inspired by the net-zero trends and prior works on CCU studies, which will be expanded in this section. 
1.1 'Big picture' - some trends urged by net zero

Transition to net zero requires drastic changes across many industries, which is difficult to realize in a short period of time. ${ }^{16}$ Net zero will not happen spontaneously, and it largely relies on policies. So far, over 130 countries have pledged to their national net-zero targets, ${ }^{1}$ but few pledges are backed up by legislation or detailed policies. From the existing policies to stricter schemes, International Energy Agency (IEA) presents three scenarios ${ }^{2}$ for the prediction of global energy sector through 2050, as shown in Figure 1.
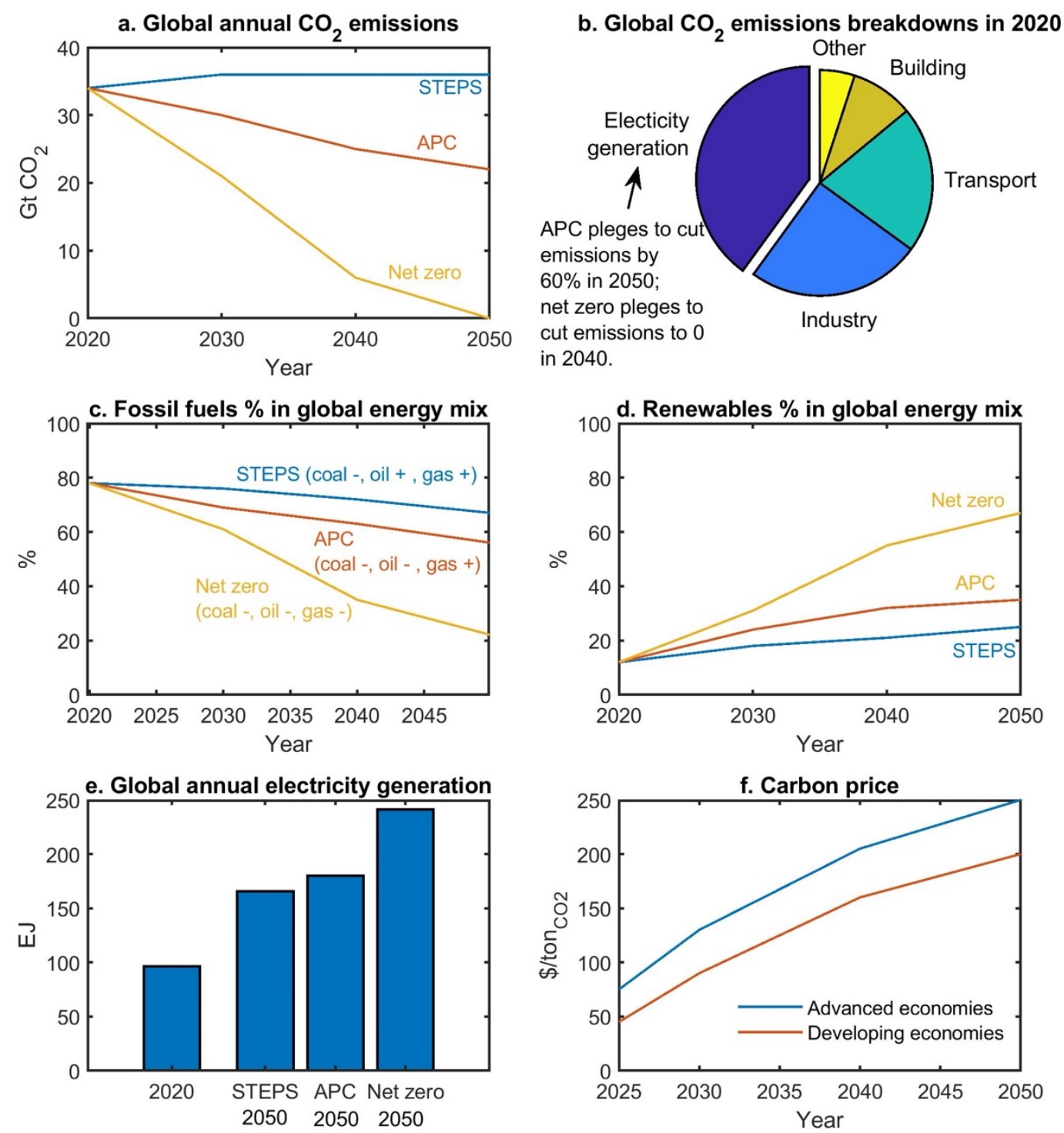

Figure 1. Three scenarios for energy transition, predicted by IEA. ${ }^{2}$ STEPS only considers the existing policies, which can control the temperature increase by $2.7^{\circ} \mathrm{C}$ in 2100 ; (2) APC 
assumes that all the pledged targets will become policies, which can control the temperature increase by $2.1^{\circ} \mathrm{C}$ in 2100 ; (3) net-zero case, corresponds to the temperature increase by $1.5^{\circ} \mathrm{C}$ in 2050. (Note: this net-zero case scenario is proposed by IEA, but not the only scenario path to achieve net-zero emissions.)

Some key points are as follows.

(1) Electricity (generation) sector produces nearly 40\% emissions in 2020 (Figure 1b). ${ }^{2}$

(2) The reliance on fossil will decline to $67 \sim 22 \%$ in 2050 (Figure 1c) but not disappear, because fossil fuels are required to produce carbon-embodied products (e.g., certain polymers $),{ }^{2}$ which cannot be easily replaced by bio-materials based products.

(3) Even if fossil fuels decline to $22 \%$, the potential market of carbon capture is enormous, because around half of fossil fuels are required to equip with carbon capture (4Gt $\mathrm{CO}_{2}$ captured in 2035 , while $7.6 \mathrm{Gt}$ captured in 2050). ${ }^{2}$

(4) The renewable share will grow to $25 \sim 67 \%$ in 2050 (Figure 1d). ${ }^{2}$

(5) Electrification will be the trend across all sectors. ${ }^{2}$ Electricity generation will increase by $170 \sim 150 \%$ (Figure 1e), which lays the foundation for electrification. Regarding the supply of heating utility, fossil fuels should gradually be substituted by low-carbon electricity. $^{2}$

(6) A significant growth in carbon price should be introduced to regulate the GHG emissions (Figure 1f). ${ }^{2}$

Therefore, reducing the power plant emissions is paramount under the net-zero framework. Fossil fuels will continue to play a dispensable role through 2050, while the growth rate of renewables will be subject to a high degree of uncertainty depending on the extent of policy support. As such, there is a need for innovation that supports a stepwise transition from the current fossil-fuels based energy production to the renewable-based future. Hence, [fossil fuels + carbon capture] may be a good intermediate solution to renewables. Additionally, we can consider electrification to enhance $\mathrm{CCU}$ as well as the influence of carbon price.

\subsection{Prior works on $\mathrm{CCU}$}

'Capture' systems described in the literature usually refer to carbon capture, utilization and storage (CCUS). Carbon capture involves capturing $\mathrm{CO}_{2}$ from heavy industries, such as power stations, fertilizer production sites, cement factories, steel plants, or directly from the air. ${ }^{3} \mathrm{CO}_{2}$ storage refers to the captured $\mathrm{CO}_{2}$ being compressed and injected into the underground for permanent storage. ${ }^{3} \mathrm{CO}_{2}$ utilization converts the captured $\mathrm{CO}_{2}$ to valued products, e.g., fuels 
and polymers. ${ }^{3}$ Depending on storage or utilization, the CCUS is divided into CCS (carbon capture and storage) and CCU (carbon capture and utilization). ${ }^{17} \mathrm{CCS}$ deal with the endpoint of $\mathrm{CO}_{2}$, which can directly benefit climate change mitigation ${ }^{17}$ but might deliver limited financial returns depending on the local policies. ${ }^{18}$ By contrast, $\mathrm{CCU}$ regards $\mathrm{CO}_{2}$ as a carbon source for further conversion, which can be highly profitable, as far as the deployed conversion methods are efficient and associated with a minimum additional GHG emissions. ${ }^{17}$ Hence, $\mathrm{CCU}$ is a complex system that requires a techno-economic evaluation at a regional scale, ${ }^{17}$ e.g., an industrial park.

There are various pathways for either capture or utilization. Extensive studies had been done to optimize individual sub-systems of CCU, e.g., pressure swing adsorption, ${ }^{19-22}$ and MEA for $\mathrm{CO}_{2}$ capture, ${ }^{23,24}$ methanol synthesis ${ }^{11,15,25}$ or Fischer-Tropsch ${ }^{26,27}$ for subsequent utilization. However, the performance of these sub-systems depends on each other, and thus individual optimal solutions cannot simultaneously co-exist. When optimizing a sub-system before extending to the whole CCU system, we can only expect to obtain a sub-optimal solution. In a recent review paper, Dieterich et al. also pointed out that the studies on the interaction between CCU sub-systems are still scarce. ${ }^{8}$ Inspiringly, Roh et al. optimized a whole CCU system, where MEA is taken as the only $\mathrm{CO}_{2}$ capture technology, and the 15 utilization pathways coexist to satisfy market demands. ${ }^{5}$ In Roh's work, the competitive interactions among different sub-systems are considered, but the complexity/non-linearity for individual sub-systems is neglected. ${ }^{5}$ To manipulate both high-level system variables and sub-system variables, a more robust method is superstructure optimization, ${ }^{28}$ but this method leads to complex formulations and difficult-to-solve MINLP problems. ${ }^{29}$ An alternative solution is surrogate-based optimization, where sub-systems can be represented by cheap-to-evaluate surrogates. ${ }^{29}$ Surrogates are developed by regression to build a direct relationship between process inputs and outputs. ${ }^{30}$ Still, most prior works limit the surrogate-based optimization to a CCU subsystem (either capture ${ }^{21,22,31-33}$ or utilization ${ }^{15,25}$ ).

Overall, previous works neither deliver a convincing evaluation of an impact of a CCU system in energy transition, nor address the complexity of optimizing a CCU system composed of different carbon capture and utilization technologies. To address both challenges, this work focuses on an overseen scenario: CCU plants without renewable energy input considered in the initial design, and we develop a surrogate-based optimization methodology to assess its maximum potentials regarding emissions reduction and economic gain. Carbon pricing is included in the economic calculation to predict the future potential of this CCU system. 
The remaining sections are structured as follows. Section 2 describes an industrial park where natural gas power plants are integrated with CCU. Section 3 illustrates the digitalization and optimization framework for the whole CCU system. Section 4 presents the single-objective optimization of maximizing the GHG reduction; this is set up to evaluate whether CCU can reduce $\mathrm{CO}_{2}$ effectively, as well as to validate the overall optimization framework. Following this, multi-objective optimization is applied to the whole system concerning GHG reduction and economic gain in Section 5. Section 6 introduces carbon pricing within the economic evaluation. The final section presents conclusions and outlooks. 


\section{Problem statement: an industrial park of power stations integrated with $\mathrm{CCU}$}

To explore the potential for decarbonization of energy and chemicals manufacturing by means of CCU, we sought to investigate all feasible process configurations that include wellunderstood, scalable process options for capture and utilization sections. We illustrate this approach with a case study of a hypothetical industrial park, which is powered by natural gas, and delivers electricity and liquid fuels as main products. In the reference case, where no carbon capture is deployed, all $\mathrm{CO}_{2}$ emissions arising from electricity production are vented to the atmosphere. In case of integration of $\mathrm{CCU}$, these $\mathrm{CO}_{2}$ emissions will be captured and converted to fuels, thus reduce the input of petrochemical resources to the chemical synthesis and consequently decrease the carbon footprint of the industrial park. The industrial park is presumed to contain two natural gas combined cycle (NGCC) power plants. One NGCC is equipped with MEA, while the other is coupled with a PSA, as to capture $\mathrm{CO}_{2}$. The $\mathrm{CO}_{2}$ fraction of flue gas is concentrated from $\sim 4$ to $\sim 90 \%$ by MEA and PSA, respectively. Following this, with the co-feed of $\mathrm{NG}$ and steam, the concentrated $\mathrm{CO}_{2}$ is reformed to syngas, which is further converted to fuels, being reviewed as one of the most promising product type for carbon utilization. ${ }^{17,} 34$ Among different liquid fuels used on large-scales, methanol, gasoline, and diesel are reported as the crucial for the mobility sector, because of their high energy density, ${ }^{8}$ and convenient handling. Hence, we focused on Fischer-Tropsch (FT) and methanol synthesis (MS) to manufacture fuel products (gasoline, diesel, and methanol). Overall, the proposed industrial park can be compatible with the existing industry in: (1) the upstream - by decarbonizing the energy sector, (2) the downstream - by supplying fuels to the mobility sector.

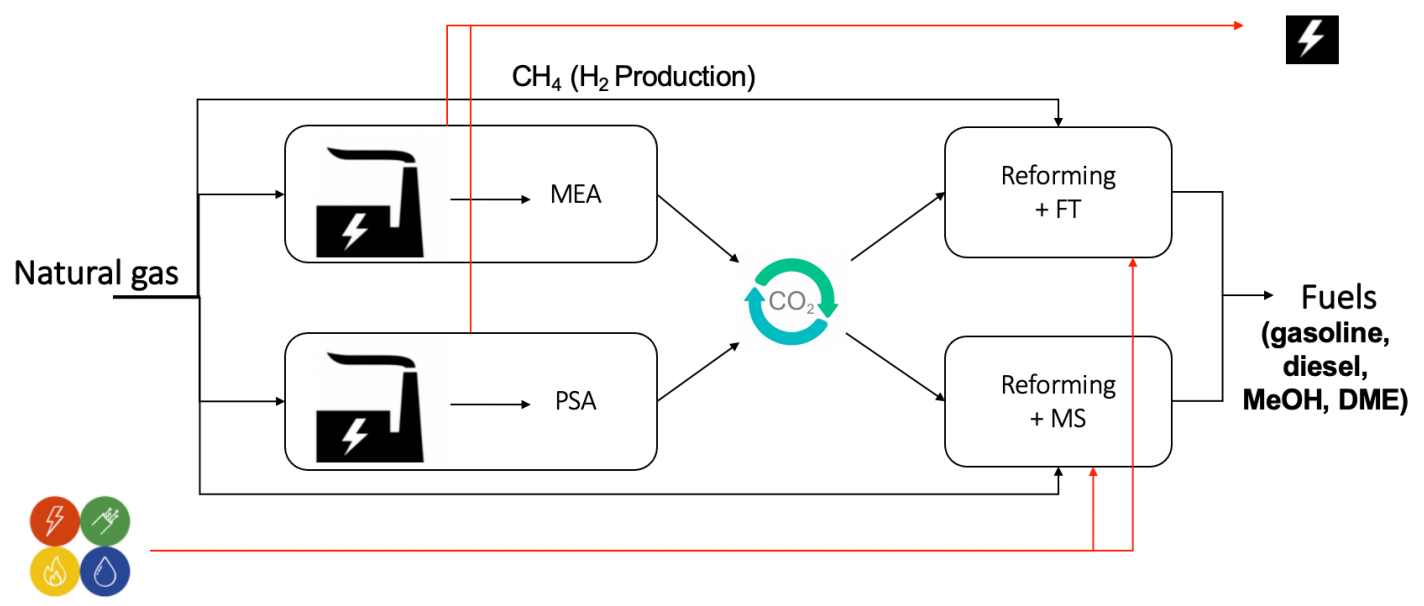

Figure 2. The hypothesized industrial park, where two NG power plants are integrated with carbon capture and fuel production. The industrial park operates as a CCU system, which 
contains four sub-systems: [NGCC+MEA], [NGCC+PSA], [Reforming + FT] and [Reforming $+\mathrm{MS}]$.

The model of the industrial park is based on the following assumptions:

(1) The $\mathrm{CO}_{2}$ captured by PSA is assumed to be temporarily stored in a collection hub, where $\mathrm{CO}_{2}$ is well mixed before utilization. As such, the PSA performance under cyclic steady state ${ }^{32}$ can be equivalent to steady-state. Additionally, the time scale of a PSA cycle $(\sim 10 \mathrm{~min})^{35}$ is much shorter than the start-up of chemical plants ( days) $)^{36}$. Therefore, the overall system can be considered to operate under a steady-state condition.

(2) This PSA system contains two 4-step PSA processes in series to gradually improve the purity of $\mathrm{CO}_{2}$ and guarantee the final purity is over $90 \%$ (SI, Section $\mathrm{S} 1.3$ ).

(3) An NGCC power plant is closely connected to a capture process, forming a sub-system.

(4) The captured $\mathrm{CO}_{2}$ is mixed and then re-distributed to the downstream utilization pathways. The optimal ratio of $\mathrm{CO}: \mathrm{H}_{2}$ is slightly different between $\mathrm{FT}\left(\frac{2 \mathrm{CO}}{\mathrm{H}_{2}}=1\right)$ and MS $\left(\frac{2 \mathrm{CO}+3 \mathrm{CO}_{2}}{\mathrm{H}_{2}}=1\right)$. This is because $\mathrm{CO}_{2}$ can be a carbon source in $\mathrm{MS}\left(\mathrm{CO}_{2}\right.$ is active on MS catalysts ${ }^{37,}{ }^{38}$ ), while $\mathrm{CO}_{2}$ is inactive on $\mathrm{FT}$ catalysts ${ }^{39}, 40$. Hence, $\mathrm{CO}_{2}$ is distributed before reforming, which adjusts the $\mathrm{CO} / \mathrm{H}_{2}$ for FT and MS, respectively.

(5) Combined reforming is considered: dry reforming is considered to convert $\mathrm{CO}_{2}$ to syngas, while steam reforming is also involved in adjusting the ratio between $\mathrm{CO}$ and $\mathrm{H}_{2}$ in the final syngas. Both reforming processes can be assumed to achieve equilibrium. ${ }^{41,42}$

(6) A reforming process is closely connected to FT or MS, thus resulting in a single subsystem.

(7) The heating utility can be replaced with low-carbon electricity for a flexible design for utility supply.

\section{Optimization framework}

The scope of the optimization framework is designed around the entire industrial park, containing of four sub-systems, i.e. [NGCC + MEA], [NGCC + PSA], [Reforming + FT] and [Reforming + MS]. To determine an optimal configuration, models of sub-systems are necessary. The current industrial practice involves the application of tailored simulators for specific systems (e.g. Dymola for dynamic process modelling, Aspen for reactors and separation units). We anticipated that it might be insightful to search a global decision space 
by simultaneously optimizing all sub-systems, ideally from a level of a higher interactive platform. To achieve this goal, as well as improve the computational efficiency of the complex optimization task, we digitalized the sub-systems using surrogates and proposed a three-level framework shown in Figure 3. This work mainly considers Artificial Neural Networks (ANNs) as surrogates, because ANNs are claimed to be universal approximators. ${ }^{43}$

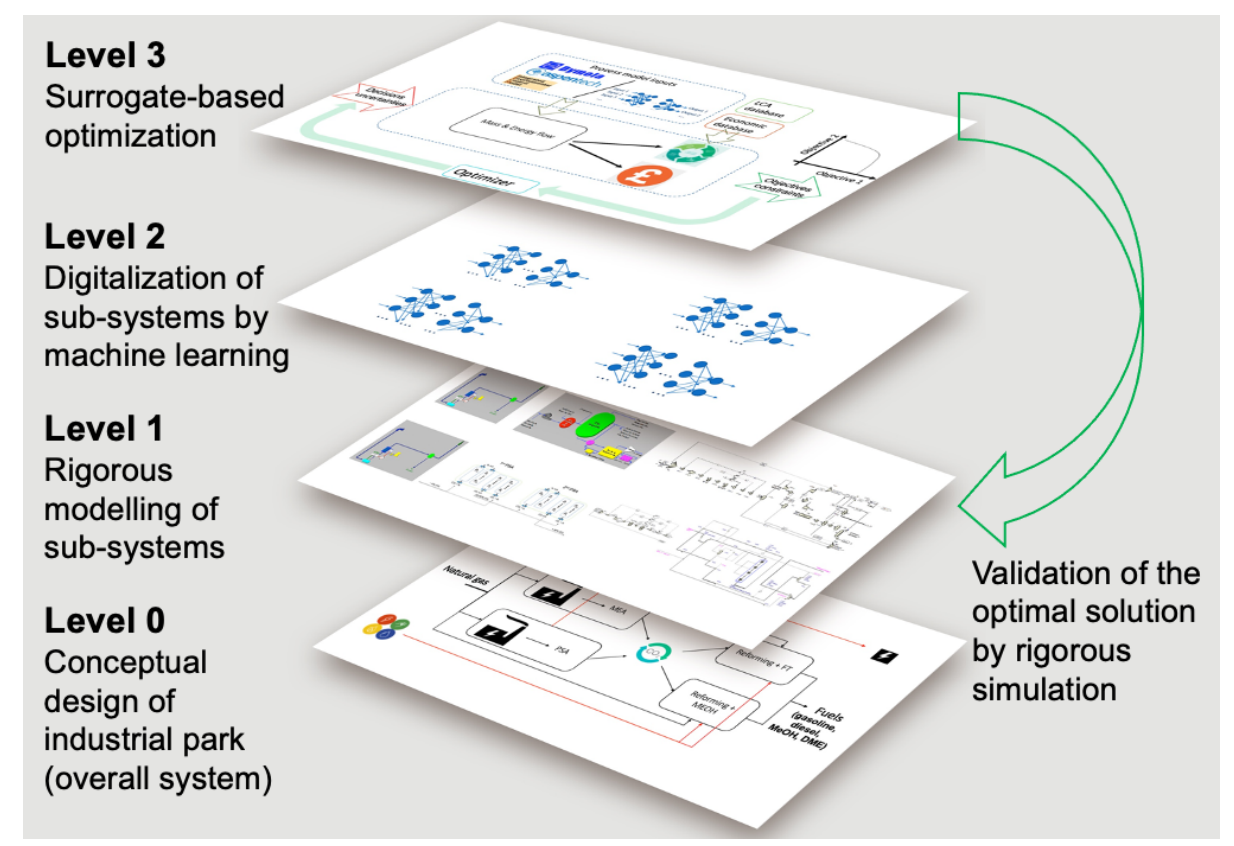

Figure 3. Three-level approach for the optimization of complex processes, illustrated by the case-study of decarbonization of an integrated industrial park.

In Level 1, the sub-systems are modelled in different dedicated simulators. The two NGCC power plants are represented in Integrated Environmental Control Model (IECM). ${ }^{44}$ MEA absorption is also modelled in IECM. The PSA is modelled in Dymola, which is a mature and broadly deployed tool for modelling dynamic processes. ${ }^{45}$ Reforming section integrated with FT/MS is modelled in Aspen Plus. The detailed information for modelling of the individual sub-systems and technical flowsheets are given in Section 1 of Supplementary Information (SI, $\mathrm{S} 1)$.

In Level 2, ANN-based surrogates are established to replace the rigorous simulations for subsystems for the overall optimization goal. Each sub-system can have one or two surrogates. For example, [Reforming + FT] sub-system contains only one surrogate, while the [NGCC + PSA] sub-system contains two surrogates for the two PSA in series. The detailed methodology for surrogate construction can be referred to our prior work, where we present how to build surrogates for the PSA and [reforming + FT]. ${ }^{46}$ The paramount step to generate surrogates is identifying the essential input/output variables, which is closely related to the optimization of 
the whole CCU system. To identify input/output variables for individual surrogates, we use a top-down systems thinking approach: (1) the decision variables and optimization objectives are the key input/output variables of the whole CCU system; the input should also include uncertainties, e.g., concertation of methane in NG or carbon price; (2) the input/output variables of whole CCU system determines those for sub-systems, which can be referred to Section S2 in SI; (3) the input/outputs variables of a sub-system determines those for surrogates (SI, Section S3). Table 1 summarized the decision variables considered. Design space of the decision variables is randomly sampled to generate sufficient input values, which are sent to the simulators in Level 1 for the corresponding output via rigorous simulations. Eventually, the obtained input/output data points can be used to train ANN-based surrogates.

In Level 3, surrogate-based optimization is performed, as illustrated in Figure 4. We deploy a simulation-based optimization approach, where simulation is executed within the optimizer. Level 1 and Level 2 offer process model inputs to one simulation platform, where decision variables and process uncertainties are used to run the overall flowsheet simulation. Subsequently, lifecycle GHG emission factors (SI, Table S3) and economic factors (SI, Table S4) are considered within the mass and energy balances calculated in the overall flowsheet simulation, thus resulting in the objective values. The optimizer varies the values of decision variables and improves the objectives iteratively. After the surrogate-based optimization is completed, we use the obtained values for the decision variables to perform rigorous simulations for individual sub-systems, as to validate the optimal solution. 


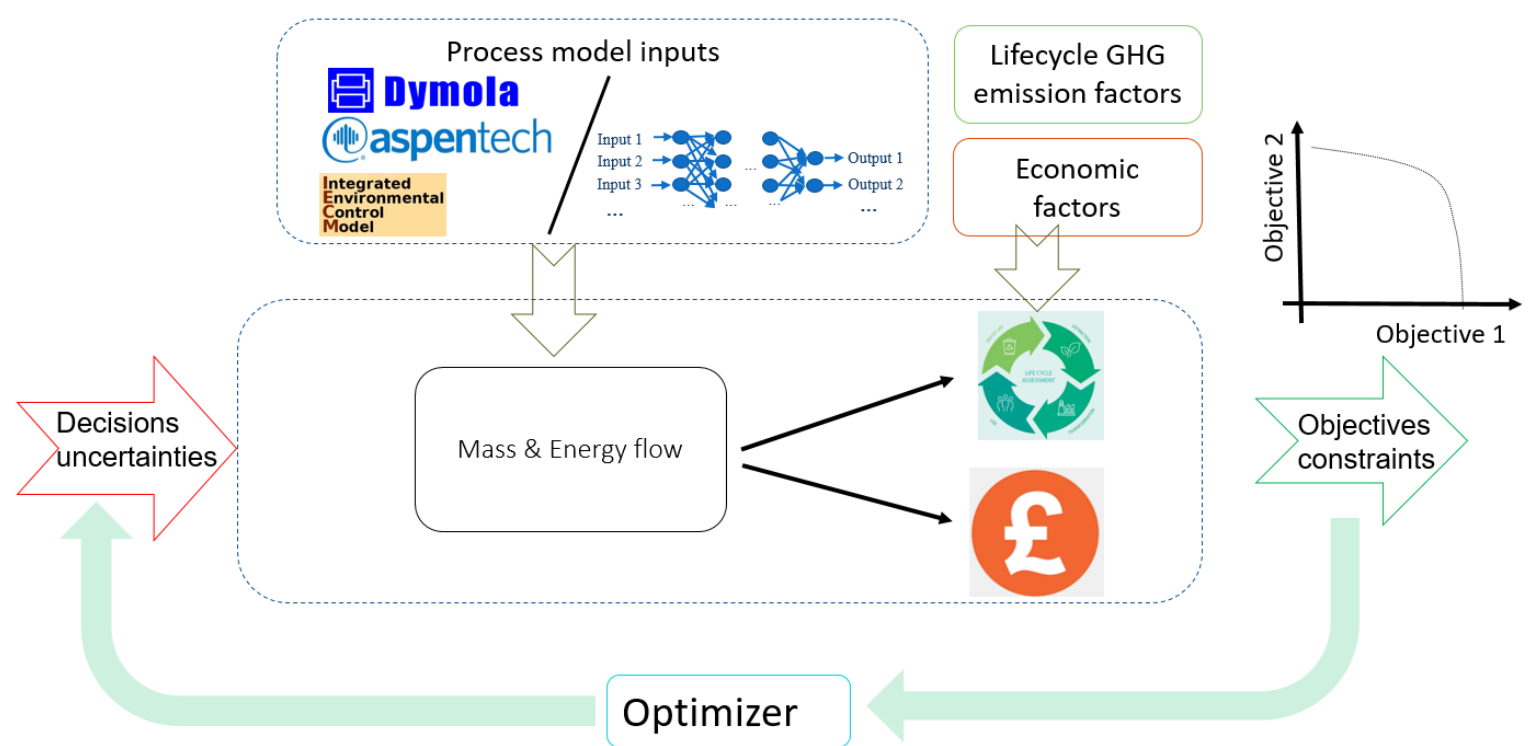

Figure 4. Detailed steps of the optimization deployed on Level 3: mass and energy flows, in conjunction with the input of environmental metrics (lifecycle GHG emissions) and economic factors are being used to evaluate the objectives and constraints. 
Table 1. Design variables for the model of the industrial park and their lower (LB) and upper bounds (UB) considered during optimization.

\begin{tabular}{|c|c|c|c|c|}
\hline & Design variables & Unit & {$[\mathrm{LB}, \mathrm{UB}]$} & Definition \\
\hline MEA & $\mathrm{r}_{\mathrm{CO}_{2}}$ & - & {$[0.60,0.95]^{47}$} & Recovery rate of $\mathrm{CO}_{2}$ \\
\hline \multirow{6}{*}{ 1st PSA } & $\mathrm{P}_{\mathrm{L} 1}$ & bar & {$[0.005,0.05]^{20}$} & Low-pressure setpoint \\
\hline & $\mathrm{P}_{\mathrm{I} 1}$ & bar & {$[0.07,0.5]^{20}$} & Intermediate-pressure setpoint \\
\hline & $v_{\text {feed } 1}$ & $\mathrm{~m} \mathrm{~s}^{-1}$ & {$[0.1,2]^{20}$} & Velocity of inlet flow \\
\hline & $t_{\text {ads1 }}$ & $\mathrm{s}$ & {$[20,100]^{20}$} & Duration of adsorption \\
\hline & $t_{b d 1}$ & $\mathrm{~s}$ & {$[30,200]^{20}$} & Duration of blowdown \\
\hline & $t_{\text {evac1 }}$ & $\mathrm{s}$ & {$[30,200]^{20}$} & Duration of evacuation \\
\hline \multirow{6}{*}{ 2nd PSA } & $\mathrm{P}_{\mathrm{L} 2}$ & bar & {$[0.005,0.05]^{20}$} & Low-pressure setpoint \\
\hline & $\mathrm{P}_{\mathrm{I} 2}$ & bar & {$[0.07,0.5]^{20}$} & Intermediate-pressure setpoint \\
\hline & $v_{\text {feed2 }}$ & $\mathrm{m} \mathrm{s}^{-1}$ & {$[0.1,2]^{20}$} & Velocity of inlet flow \\
\hline & $t_{\text {ads2 }}$ & $\mathrm{s}$ & {$[20,100]^{20}$} & Duration of adsorption \\
\hline & $t_{b d 2}$ & $\mathrm{~s}$ & {$[30,200]^{20}$} & Duration of blowdown \\
\hline & $t_{\text {evac2 }}$ & $\mathrm{s}$ & {$[30,200]^{20}$} & Duration of evacuation \\
\hline $\mathrm{CO}_{2}$ to $\mathrm{FT}$ & $\mathrm{z}_{\mathrm{FT}}$ & - & {$[0.025,0.975]$} & Splitting between FT and MS \\
\hline \multirow{7}{*}{ FT } & $\mathrm{T}_{\mathrm{FT}}$ & ${ }^{\circ} \mathrm{C}$ & {$[215,265]^{26}$} & Reaction temperature for FT \\
\hline & $\mathrm{P}_{\mathrm{FT}}$ & bar & {$[15,50]^{48,49}$} & Reaction pressure for FT \\
\hline & $\operatorname{tray}_{\mathrm{FT}}$ & - & {$[45,65]$} & Tray no. of distillation column \\
\hline & $\mathrm{T}_{\text {ref1 }}$ & ${ }^{\circ} \mathrm{C}$ & {$[750,1000]^{50}$} & Reformer temperature \\
\hline & $P_{\text {ref1 }}$ & bar & {$[3,7]^{50}$} & Reformer pressure \\
\hline & $S_{\text {purge }}$ & - & {$[0.001,0.2]$} & Fraction for purge (recycle) \\
\hline & $\operatorname{Re}_{\mathrm{FT}}$ & - & {$[0.01,0.99]$} & Fraction for FT (reformer) \\
\hline \multirow{6}{*}{$\mathrm{MEOH}$} & $\mathrm{F}_{\mathrm{NG}} / \mathrm{F}_{\mathrm{CO}}$ & - & {$[2,3.7]$} & Ratio of $\mathrm{NG}$ over $\mathrm{CO}_{2}$ \\
\hline & $\mathrm{T}_{\mathrm{MS}}$ & ${ }^{\circ} \mathrm{C}$ & {$[180,220]^{51}$} & Reaction temperature for MS \\
\hline & $\mathrm{P}_{\mathrm{MS}}$ & bar & {$[50,80]^{51}$} & Reaction pressure for MS \\
\hline & Tray $_{\text {мs }}$ & - & {$[45,65]^{52}$} & Tray No. of distillation column \\
\hline & $\mathrm{T}_{\mathrm{ref} 2}$ & ${ }^{\circ} \mathrm{C}$ & {$[800,1000]^{50}$} & Reformer temperature \\
\hline & $\mathrm{P}_{\mathrm{ref} 2}$ & bar & {$[3,7]^{50}$} & Reformer pressure \\
\hline \multirow{2}{*}{$\begin{array}{l}\text { Heating } \\
\text { utility }\end{array}$} & Frac $_{\text {fuel }}$ ele-CCS & - & {$[0,1]$} & $\begin{array}{l}\text { Fraction of fuel heating } \\
\text { substituted by CCS electricity }\end{array}$ \\
\hline & Frac $_{\text {steam }}$ ele-CCS & - & {$[0,1]$} & $\begin{array}{l}\text { Fraction of steam heating } \\
\text { substituted by CCS electricity }\end{array}$ \\
\hline
\end{tabular}

\section{Single-objective optimization regarding lifecycle GHG emissions reduction}

The optimization framework described above was applied to assess the potential of CCU to solely reduce GHG emissions (i.e., in the absence of renewable sources of energy). Here we only consider the GHG emission reduction as the objective of the optimization.

The GHG emissions are evaluated based on the life cycle assessment (LCA) with a cradle-togate boundary. We seek to compare the overall emissions from the reference process (described in Section 2: Problem statement) to emissions of the system with CCU. For a meaningful 
comparison (Fig. 4), we evaluate multiple process configurations where both the reference process and the CCU system yield exactly the same amount of electricity and fuels (defined as the system expansion strategy ${ }^{53}$ ). A more detailed information for the system boundary and the system expansion strategy can be referred to Section S4.1 - S4.2 (SI).

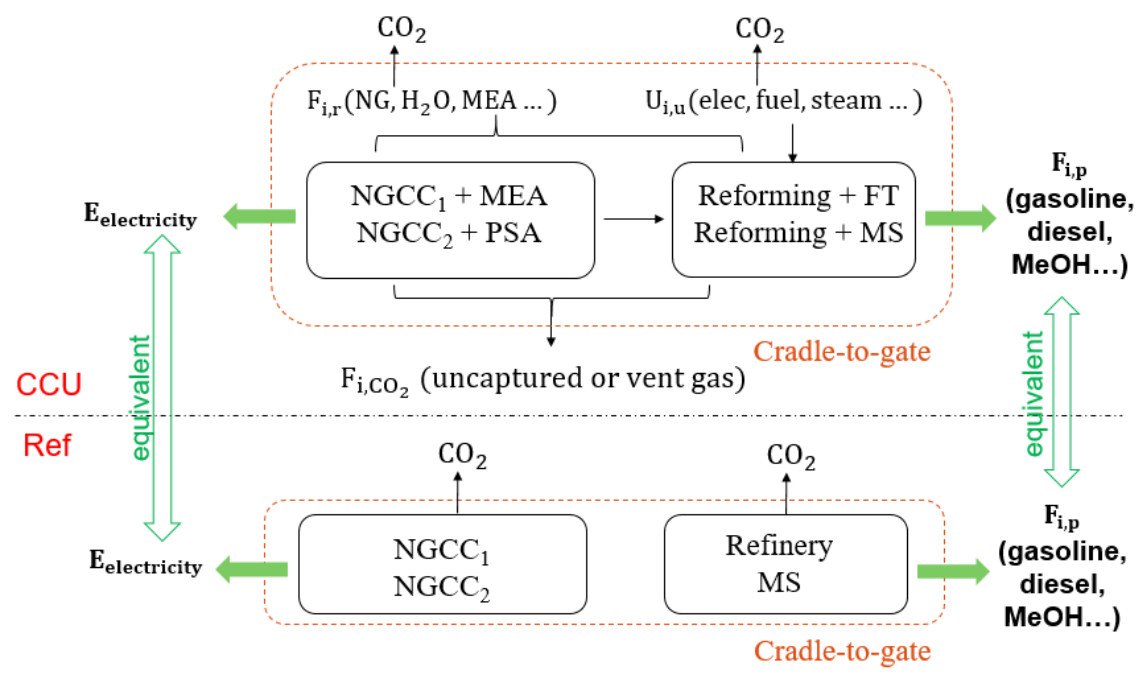

Figure 5. Comparison between CCU vs. Reference (Ref) system by the system expansion strategy: different process configurations considered within the optimization are designed to yield equivalent amount of electricity and fuels for both CCU and Reference systems.

Based on the mass and energy balances derived from process models and lifecycle GHG emission factors (SI, Table S3), the GHG reduction is calculated in Eq 1-Eq 3 (further details are given in Section S4 in SI).

$$
\begin{aligned}
& \mathrm{GHG}_{\mathrm{CCU}}=\sum_{\mathrm{i}} \sum_{\mathrm{r}} \alpha_{\mathrm{r}} \cdot \mathrm{F}_{\mathrm{i}, \mathrm{r}}+\sum_{\mathrm{i}} \sum_{\mathrm{u}} \alpha_{\mathrm{u}} \cdot \mathrm{U}_{\mathrm{i}, \mathrm{u}}+\sum_{\mathrm{i}} \mathrm{F}_{\mathrm{i}, \mathrm{CO} 2} \\
& \mathrm{GHG}_{\text {ref }}=\alpha_{N G C C} \cdot \mathrm{E}_{\text {electricity }}+\sum_{\mathrm{i}} \sum_{\mathrm{p}} \alpha_{\mathrm{p}} \cdot \mathrm{F}_{\mathrm{i}, \mathrm{p}} \\
& \mathrm{GHG}_{\text {reduction }}=1-\frac{\mathrm{GHG}_{\mathrm{CCU}}}{\mathrm{GHG}_{\mathrm{ref}}}
\end{aligned}
$$

where

$\begin{array}{ll}\mathrm{GHG}_{\mathrm{CCU}} & \mathrm{GHG} \text { emissions of the whole CCU system (the industrial park) } \\ \mathrm{GHG}_{\mathrm{ref}} & \text { GHG emissions of the reference system (no capture, refinery, MS) } \\ \mathrm{F} & \text { Mass flow, ton } / \mathrm{h} \\ \alpha_{\mathrm{r}} & \text { Lifecycle } \mathrm{GHG} \text { emission factor per raw material } \mathrm{r} \text { generation: } \operatorname{ton}_{\mathrm{CO}_{2} \text { eq }} / \mathrm{ton}_{\mathrm{r}} \\ \mathrm{U} & \text { Consumption of utility, GJ/h } \\ \alpha_{\mathrm{u}} & \text { Lifecycle } \mathrm{GHG} \text { emission factor per utility u generation: } \operatorname{ton}_{\mathrm{CO}_{2} \text { eq }} / \mathrm{GJ}\end{array}$




$\begin{array}{ll}\mathrm{F}_{\mathrm{i}, \mathrm{CO}_{2}} & \text { Uncaptured } \mathrm{CO}_{2} \text { or } \mathrm{CO}_{2} \text { in the vent gas in sub-system i, ton } \mathrm{CO}_{2} \text { eq } \\ \alpha_{\mathrm{NGCC}} & \text { Lifecycle } \mathrm{hHG} \text { emission factor per NGCC power generation: } \text { ton }_{\mathrm{CO}_{2} \text { eq }} / \mathrm{GJ} \\ \mathrm{E}_{\mathrm{electricity}} & \text { Net output of electricity from [NGCC }+\mathrm{MEA} / \mathrm{PSA}], \mathrm{GJ} / \mathrm{h} \\ \alpha_{\mathrm{p}} & \text { Lifecycle GHG emission factor per product p generation: } \text { ton }_{\mathrm{CO}_{2} \text { eq }} / \text { ton }_{\mathrm{p}} \\ \mathrm{Subscript} & \\ \mathrm{i} & \text { Notation for sub-systems } \\ \mathrm{r} & \text { Notation for raw materials (natural gas, process water, MEA, etc.) } \\ \mathrm{u} & \text { Notation for utilities (steam, fuel gas, electricity, cooling, etc.) } \\ \mathrm{p} & \text { Notation for products (gasoline, diesel, methanol, etc.) }\end{array}$

The optimization is formulated as follows,

s.t.

$$
\max _{\boldsymbol{\theta}}\left(1-\frac{\mathrm{GHG}_{\mathrm{CCU}}}{\mathrm{GHG}_{\mathrm{ref}}}\right)
$$

Eq 5

Genetic algorithm (GA) is used as the optimizer, and the progress of the optimization towards reaching the maximum reduction of GHG emissions is illustrated in Figure 6. The mean objective value is the average objective value of populations at every iteration. In the initial generations, the mean objective value is negative, which indicates CCU can even cause more GHG emissions than the reference system. We terminate the optimizer after 50 iterations, where the mean objective value is closed to the best objective. Herein, we approximate the found values for decision variables as the optimal operating condition, as shown in Table 3. Under this condition, rigorous simulation is performed and yields a similar objective value as the simulation by surrogates.

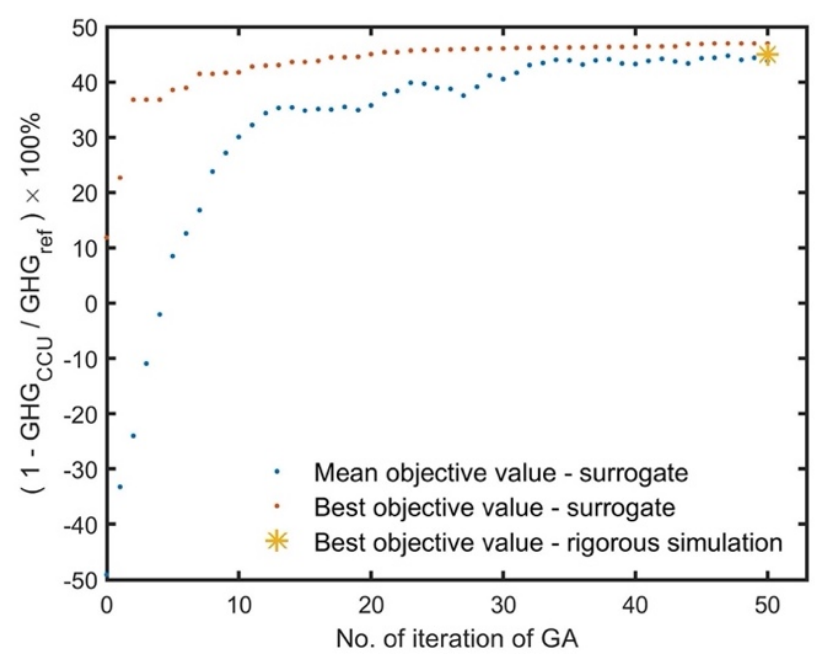

Figure 6. The optimization progress for GHG reduction in the industrial park, for singleobjective optimization (GHG reduction). 
Further, we find that surrogate simulation for GHG emissions of sub-systems is very close to rigorous simulation results under both initial (random guess) and optimal operating conditions (SI, Figure S10), what confirms the capability of the surrogate model to accurately evaluate mass and energy flows at a reduced computational cost.

The GHG emissions of sub-systems are presented in Figure 7. Under a random (initial) system configuration, CCU deployment results in more life cycle GHG emissions than the reference system, used to generate the same amount of electricity and products. This is because, within the initially evaluated process configuration, $\mathrm{CO}_{2}$-based reforming requires extensive energy input, which can lead to more emissions if no proper operating conditions are set. For example, emissions from [Reforming + FT] is almost triple of that from the refinery in the reference system (Figure 7a). Under the optimal operating condition, GA selects to produce more methanol instead of gasoline (thus, emissions from [Reforming + FT] become negligible). This is probably because $\mathrm{CO}_{2}$ cannot be converted in the FT path, ${ }^{39,40}$ while $\mathrm{CO}_{2}$ can be well utilized in MS. ${ }^{8,37,38}$
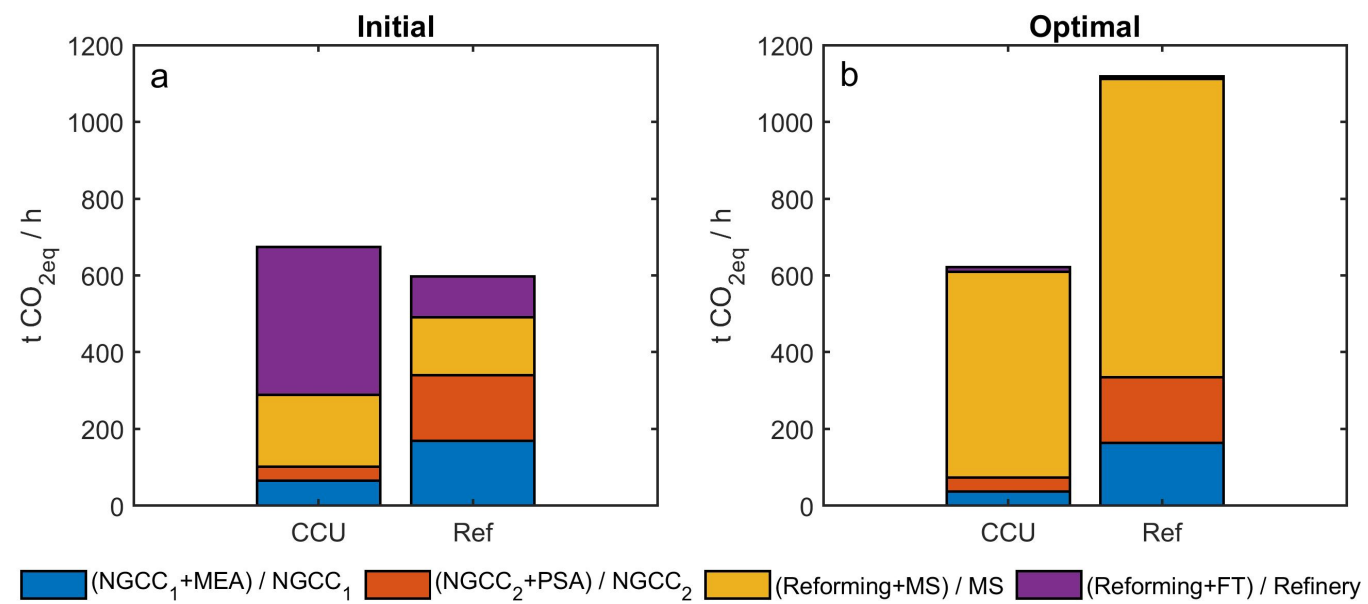

Figure 7. GHG emissions of sub-systems of the industrial park for the system with CCU deployment and the reference case (no $\mathrm{CCU}$ ). Both systems are designed to deliver equivalent output of products (electricity, methanol, fuels). a) Emissions for the initial configuration. b) emissions for the configuration determined as optimal, where methanol production is favored. Clarification for the legends : left of '/' for the CCU system, right of '/' for the reference system.

Furthermore, the optimization algorithm is capable of distinguishing between the choice of MEA from PSA unit operations, even though this is not evident from the system-level data. The use of carbon capture leads to two effects on the 500 MW NGCC plants: lowering the 
emissions but shrinking the net electricity output. As shown in Table 2, PSA has fewer emissions than MEA; $20 \%$ electricity loss is seen for the deployment of MEA, while $16 \%$ electricity loss for PSA. Hence, PSA has an advantage over MEA regarding GHG emissions reduction and energy saving. However, this advantage is negligible when referring to GHG emissions in the whole CCU system because more emissions are caused by the utilization paths than the capture paths (Figure $7 b$ ).

Table 2. Performance of carbon capture for 500 MW NGCC under the optimal operating condition determined for single-objective optimization (Figure $7 \mathrm{~b}$ ).

\begin{tabular}{llll}
\hline & & Emissions $\left[\right.$ ton $\left.\mathrm{CO}_{2} / \mathrm{h}\right]$ & Net electricity output $[\mathrm{MW}]$ \\
\hline \multirow{2}{*}{$\mathrm{CCU}$} & {$\left[\mathrm{NGCC}_{1}+\mathrm{MEA}\right]$} & 37.17 & 400 \\
& {$\left[\mathrm{NGCC}_{2}+\mathrm{PSA}\right]$} & 36.66 & 418 \\
\hline \multirow{2}{*}{ Reference } & {$\left[\mathrm{NGCC}_{1}\right]$} & 163.50 & 400 \\
& {$\left[\mathrm{NGCC}_{2}\right]$} & 170.80 & 418 \\
\hline
\end{tabular}

The optimal operating conditions are listed in Table 3. To maximize the GHG reduction, the requirements for sub-systems are as follows:

(1) MEA: high recovery rate is preferred.

(2) PSA: in $1^{\text {st }}$ PSA, the $P_{L 1}$ should be low enough to enhance capture capacity, while this requirement is not strict for $2^{\text {nd }}$ PSA. Long evacuation is preferred for two PSA columns, and thus sufficient time is allocated to recover the captured $\mathrm{CO}_{2}$.

(3) MS is favoured over FT.

(4) Heating tends to be fully substituted by low-carbon electricity.

(5) In the reforming process, the ratio of $\mathrm{NG} / \mathrm{CO}_{2}$ is suggested to approach the upper bound, meaning sufficient $\mathrm{NG}$ is required to substantially convert $\mathrm{CO}_{2}$ to $\mathrm{CO}$ in the reforming section. 
Table 3. Initial guess and optimal values (by GA) for decision variables for single objective optimization.

\begin{tabular}{|c|c|c|c|c|c|}
\hline & $\begin{array}{l}\text { Decision } \\
\text { variables } \theta\end{array}$ & Unit & $\begin{array}{l}\text { Initial } \\
\text { (base case) }\end{array}$ & Optimal & $\begin{array}{l}\text { Decision } \\
\text { index }\end{array}$ \\
\hline MEA & $\mathrm{r}_{\mathrm{CO}_{2}}$ & - & 0.775 & 0.933 & $(1)$ \\
\hline \multirow{6}{*}{ 1st PSA } & $\mathrm{P}_{\mathrm{L} 1}$ & bar & 0.0075 & 0.007 & (2) \\
\hline & $\mathrm{P}_{\mathrm{I} 1}$ & bar & 0.285 & 0.406 & (3) \\
\hline & $v_{\text {feed } 1}$ & $\mathrm{~m} \mathrm{~s}^{-1}$ & 1.05 & 0.614 & (4) \\
\hline & $\mathrm{t}_{\mathrm{ads} 1}$ & $\mathrm{~S}$ & 60 & 68.789 & (5) \\
\hline & $t_{b d 1}$ & $\mathrm{~s}$ & 115 & 32.515 & (6) \\
\hline & $t_{\text {evac1 }}$ & $\mathrm{S}$ & 115 & 183.637 & (7) \\
\hline \multirow{6}{*}{ 2nd PSA } & $\mathrm{P}_{\mathrm{L} 2}$ & bar & 0.0275 & 0.014 & (8) \\
\hline & $\mathrm{P}_{\mathrm{I} 2}$ & bar & 0.285 & 0.170 & (9) \\
\hline & $v_{\text {feed2 }}$ & $\mathrm{m} \mathrm{s}^{-1}$ & 1.05 & 0.534 & (10) \\
\hline & $\mathrm{t}_{\mathrm{ads} 2}$ & $\mathrm{~s}$ & 60 & 59.411 & (11) \\
\hline & $t_{b d 2}$ & $\mathrm{~s}$ & 115 & 44.544 & (12) \\
\hline & $t_{\text {evac2 }}$ & $\mathrm{s}$ & 115 & 178.820 & (13) \\
\hline $\mathrm{CO}_{2}$ to $\mathrm{FT}$ & $\mathrm{Z}_{\mathrm{FT}}$ & - & 0.75 & 0.027 & (14) \\
\hline \multirow{7}{*}{ FT } & $\mathrm{T}_{\mathrm{FT}}$ & ${ }^{\circ} \mathrm{C}$ & 240 & 248 & (15) \\
\hline & $\mathrm{P}_{\mathrm{FT}}$ & bar & 32.5 & 25.904 & (16) \\
\hline & $\operatorname{tray}_{\mathrm{FT}}$ & - & 55 & 62 & (17) \\
\hline & $\mathrm{T}_{\text {ref1 }}$ & ${ }^{\circ} \mathrm{C}$ & 875 & 876 & (18) \\
\hline & $\mathrm{P}_{\text {ref1 }}$ & bar & 5 & 5.073 & (19) \\
\hline & $S_{\text {purge }}$ & - & 0.1005 & 0.045 & (20) \\
\hline & $\mathrm{Re}_{\mathrm{FT}}$ & - & 0.5 & 0.573 & $(21)$ \\
\hline \multirow{6}{*}{ MS } & $\mathrm{F}_{\mathrm{NG}} / \mathrm{F}_{\mathrm{CO}_{2}}$ & - & 2.85 & 3.498 & (22) \\
\hline & $\mathrm{T}_{\mathrm{MS}}$ & ${ }^{\circ} \mathrm{C}$ & 200 & 204 & (23) \\
\hline & $\mathrm{P}_{\mathrm{MS}}$ & bar & 65 & 69.542 & (24) \\
\hline & Tray $_{\text {MS }}$ & - & 55 & 46 & $(25)$ \\
\hline & $\mathrm{T}_{\text {ref2 }}$ & ${ }^{\circ} \mathrm{C}$ & 900 & 933 & (26) \\
\hline & $\mathrm{P}_{\mathrm{ref} 2}$ & bar & 5 & 6.224 & $(27)$ \\
\hline \multirow{2}{*}{$\begin{array}{l}\text { Heating } \\
\text { utility }\end{array}$} & Frac $_{\text {fuel ele-CCS }}$ & - & 0.2 & 0.997 & (28) \\
\hline & Frac $_{\text {steam }}$ ele-CCS & - & 0.2 & 0.956 & (29) \\
\hline
\end{tabular}

While determining the optimal conditions, GA tends to replace fossil fuel-based heating with low-carbon electricity generated from sources deploying carbon capture and storage. However, we anticipate that there might exist several techno-economic limitations towards a complete substitution of heating by decarbonized electricity sources. Hence, we performed a set of scenario analyses for the heating substitution regarding the upper bound for substituting heating utility is set as $0,25 \%, 50 \%, 100 \%$. The optimization is performed respectively for them (optimization progresses can be referred to Figure S11 and optimal operating condition in Table S5). After optimization, the GHG emissions can be reduced, ranging from $13 \%$ to $47 \%$, while 
all the substitution percentages to low-carbon electricity tend to approach the upper bounds (Table 4).

Table 4. Scenario analysis for the optimization result of the industrial park, with $0-100 \%$ heating utility is substituted by low-carbon electricity (CCS-electricity).

\begin{tabular}{lllll}
\hline Max substitution [\%] & 0 & 25 & 50 & 100 \\
\hline GHG reduction [\%] & 13.0 & 19.8 & 30.5 & 47.0 \\
Fuel sub [\%] & 0 & 24.9 & 49.8 & 99.7 \\
Steam sub [\%] & 0 & 22.3 & 49.6 & 95.6 \\
\hline
\end{tabular}

Figure 8 shows the breakdowns of sources for GHG emissions in the industrial park. The largest source is heating, followed by $\mathrm{NG}, \mathrm{CO}_{2}$ emissions via vent gas and electricity, etc. When increasing the heating substitution from $0 \%$ to $100 \%$, the GHG emissions can be reduced by $40 \%$. By contrast, GHG emissions are negligible for the cooling, process water and MEA. Yet, even for $100 \%$ heating substitution by CCS-electricity, we can spot that heating still holds the most considerable contribution to GHG emissions.

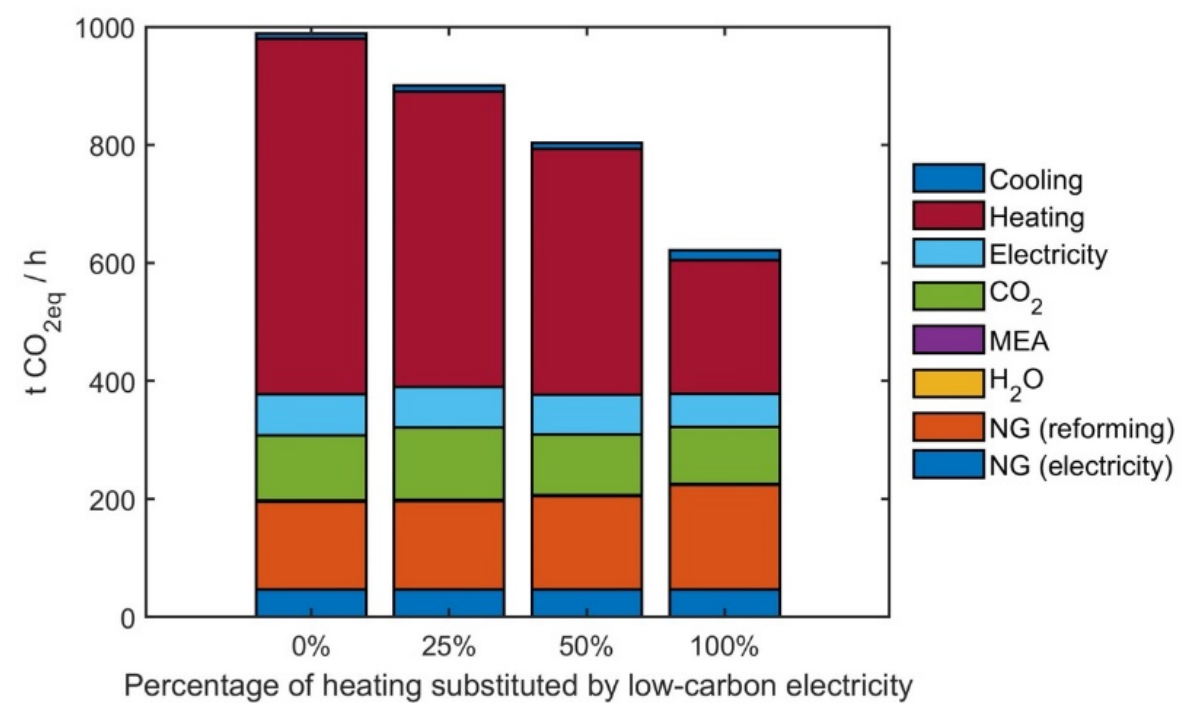

Figure 8. Sources of GHG emissions in the industrial park. Results correspond to the optimization result of the industrial park, regarding $10 \%, 25 \%, 50 \%$ and $100 \%$ heating utility are substituted by low-carbon electricity. 


\section{Multi-objective optimization regarding lifecycle GHG emissions and economic gain}

Upon exploring the capability of CCU to decarbonize the NG-based power plants and fuels production, we sought to include the economic into the optimization framework. The economic evaluation is under the following assumptions:

(1) The cost calculation considers the operational cost only, since the technology readiness level of CCU is relatively low and its capital cost cannot be quantified accurately. ${ }^{5}$

(2) This industrial park is operated in the EU. Economic assessment is based on the prices data for materials/utilities in the first half of 2021. No carbon tax is assumed at this stage of analysis.

Based on the mass \& energy flow from process models and lifecycle GHG emission factors (SI, Table S3), the profit of the CCU system is calculated following Eq. 6.

$$
\begin{gathered}
\text { Profit }=-\sum_{\mathrm{i}} \sum_{\mathrm{r}} \beta_{\mathrm{r}} \cdot \mathrm{F}_{\mathrm{i}, \mathrm{r}}-\sum_{\mathrm{i}} \sum_{\mathrm{u}} \beta_{\mathrm{u}} \cdot \mathrm{U}_{\mathrm{i}, \mathrm{u}}-\sum_{\mathrm{i}} \mathrm{F}_{\mathrm{i}, \mathrm{CO} 2} \cdot \gamma_{\mathrm{CO}_{2}} \\
+\beta_{\mathrm{CCS}} \cdot \mathrm{E}_{\text {electricity }}+\sum_{\mathrm{i}} \sum_{\mathrm{p}} \beta_{\mathrm{p}} \cdot \mathrm{F}_{\mathrm{i}, \mathrm{p}}
\end{gathered}
$$

where

$$
\begin{array}{ll}
\mathrm{F}_{\mathrm{i}, \mathrm{r}} & \text { Mass flow of raw material } \mathrm{r} \text { in sub-system i, ton } / \mathrm{h} \\
\beta_{\mathrm{r}} & \text { Cost of raw material } \mathrm{r}, \$ / \mathrm{ton}_{\mathrm{r}} \\
\mathrm{U}_{\mathrm{i}, \mathrm{u}} & \text { Consumption of utility u in sub-system i, GJ/h } \\
\beta_{\mathrm{u}} & \text { Cost of utility } \mathrm{u}, \$ / \mathrm{GJ} \\
\mathrm{F}_{\mathrm{i}, \mathrm{CO}_{2}} & \mathrm{CO}_{2} \text { emissions in the vent gas in sub-system i, ton } \mathrm{CO}_{2} \text { eq } / \mathrm{h} \\
\beta_{\mathrm{CCS}} & \text { Price of CCS electricity, } \$ / \mathrm{GJ} \\
\mathrm{E}_{\mathrm{electricity}} & \text { Net output of electricity from [NGCC }+\mathrm{MEA} / \mathrm{PSA}], \mathrm{GJ} / \mathrm{h} \\
\beta_{\mathrm{p}} & \text { Price of product } \mathrm{p}, \$ / \text { ton } \\
\mathrm{p}
\end{array}
$$


The formulation of relevant equations and economic data can be referred in Section S5 in SI (SI, S5). The optimization is formulated as follows,

$$
\max _{\boldsymbol{\theta}}\left[\left(1-\frac{\mathrm{GHG}_{\mathrm{CCU}}}{\mathrm{GHG}_{\mathrm{ref}}}\right), \text { profit }\right]
$$

s.t. $\quad \mathrm{LB} \leq \theta \leq \mathrm{UB}$

Eq 8

To solve it, we use the non-dominated sorting genetic algorithm-II (NSGA-II), a stochastic optimization algorithm that approximates the Pareto front. Pareto front offers a set of trade-off solutions, where one objective cannot be improved without worsening the other one.

\subsection{Pareto front}

Surrogate-based optimization yields the optimal values for decision variables (Figures S12S13). Based on these optimal decisions, rigorous simulations are performed to calculate the two objectives. As shown in Figure 9, when we set the GHG emissions reduction objective to a high value at $42 \%$, the profit is even negative; yet pursuing a high profit $(>3.8 \mathrm{e} 5 \$ / \mathrm{h}$ ) can make the CCU system release even more emissions than conventional processes.

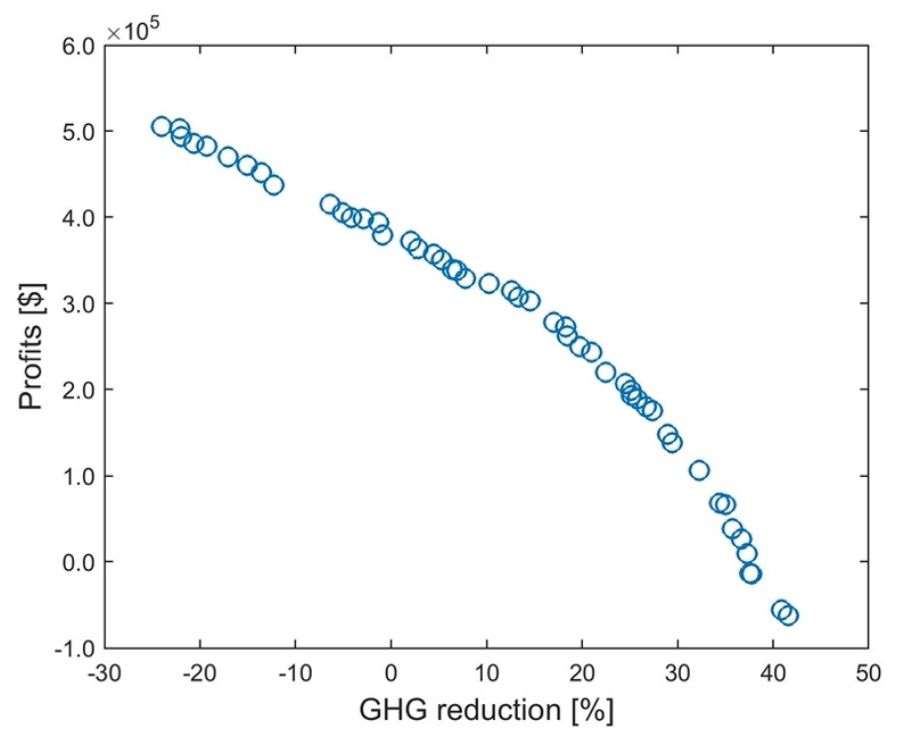

Figure 9. Multiobjective optimization of the CCU system: Pareto front between profit and GHG emissions reduction.

To better understand the trade-off between the two objectives, we refer to the economic breakdowns of several Pareto points, which are selected based on GHG emissions reduction at $-24 \%, 0 \%, 15 \%, 30 \%$ and $42 \%$. As shown in Figure 10, improving GHG emissions reduction leads to a gradual growth of utility costs and dropping revenue. Table 5 indicates that the increasing utility cost is caused by the rising percentage of heating electrification, because the 
energy price of low-carbon heating can be over four times that of fuel or steam (SI, Figure S14). Meanwhile, the shift from FT to MS can further promote the GHG emissions reduction but sacrifice the economic revenue, because the market price of methanol is much lower than FT fuels - gasoline/diesel (SI, Table S4).

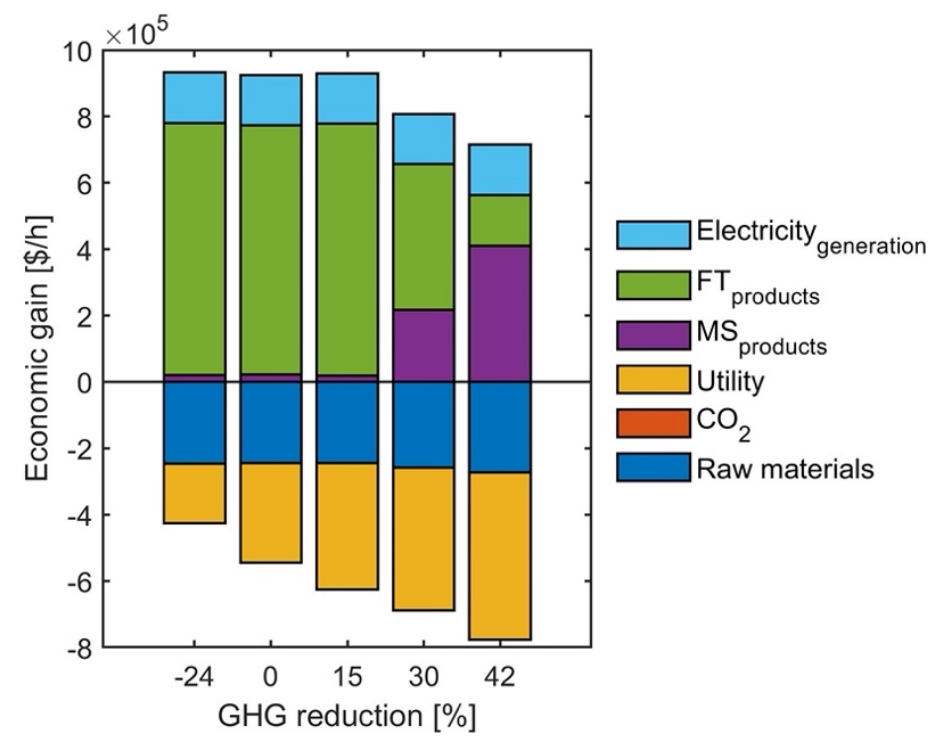

Figure 10. The breakdowns of economic gain in several Pareto front points (selected based on GHG emissions reduction at $-24 \%, 0 \%, 15 \%, 30 \%$ and $42 \%$ ).

Table 5. The trend of Pareto front points (from left to right in Figure 9).

\begin{tabular}{llllll}
\hline GHG reduction & $-24 \%$ & 0 & $15 \%$ & $30 \%$ & $42 \%$ \\
Profit $[\$ / \mathrm{h}]$ & $5.06 \mathrm{e} 5$ & $3.80 \mathrm{e} 5$ & $3.03 \mathrm{e} 5$ & $1.19 \mathrm{e} 5$ & $-6.20 \mathrm{e} 4$ \\
\hline $\mathrm{Z}_{\mathrm{FT}}$ & 0.963 & 0.958 & 0.963 & 0.565 & 0.195 \\
Frac $_{\text {fuel }}$ ele-CCS & 0.047 & 0.579 & 0.933 & 0.965 & 0.984 \\
Frac $_{\text {steam }}$ ele-CCS & 0.631 & 0.754 & 0.843 & 0.940 & 0.997
\end{tabular}

Clarification: $\mathrm{z}_{\mathrm{FT}}$ : split of $\mathrm{CO}_{2}$ to FT. $1-\mathrm{z}_{\mathrm{FT}}$ : split of $\mathrm{CO}_{2}$ to MS. Frac $\mathrm{Muel}_{\text {ele-CCS }}$ : fraction of fuel heating substituted by CCS heating. Frac steam $_{\text {ele-CCS }}$ : fraction of steam heating substituted by CCS.

5.2 Optimal values for the decision variables

When referring to the optimal values for the decision variables, multi-objective optimization can recommend the operating conditions for individual processes. As shown in Figures S12S13, each subplot refers to one decision variable, while each circle in a subplot corresponds to one solution found by NSGA-II (corresponding to a point in Pareto front in Figure 9). 
Table 6 compares the suggested operating conditions by single-objective optimization and multi-objective optimization. On the one hand, both suggest some similar operating conditions. For example, MEA is recommended to approach the upper bound in both cases. On the other hand, two types of optimization differ on some operating conditions: single-objective optimization suggests some extreme conditions (approach either lower or upper bound of decision variables). In contrast, multi-objective optimization offers more moderate operating conditions. For example, single-objective optimization selects the lowest $\mathrm{P}_{\mathrm{L}}$ (corresponding to the best recovery for $\mathrm{CO}_{2}$ but also the highest energy consumption ${ }^{20}$ ) for the PSA system; also, MS is chosen as the main $\mathrm{CO}_{2}$ utilization pathway. By contrast, multi-objective optimization determines a relatively low value for $\mathrm{P}_{\mathrm{L}}$ and recommends to mix FT with MS in the utilization pathways. This is because the multi-objective optimization delivers more practical solutions, where GHG emissions reduction should be balanced with the economic aspects. 
Table 6. Best operating conditions (decision variables) found by single-objective vs. multiobjective optimization.

\begin{tabular}{|c|c|c|c|}
\hline & \multicolumn{2}{|c|}{ Suggested operating conditions $(\theta)$ by } & \multirow{2}{*}{$\begin{array}{l}\text { Decision } \\
\text { Index }\end{array}$} \\
\hline & $\begin{array}{l}\text { Single-objective optimization } \\
\text { GA (Table 3) }\end{array}$ & $\begin{array}{l}\text { Multi-objective optimization } \\
\text { NSGA-II (Figure S12-S13) }\end{array}$ & \\
\hline MEA & High recovery rate & High recovery rate & (1) \\
\hline $1^{\text {st }}$ PSA & $\begin{array}{l}\mathrm{P}_{\mathrm{L}} \text { approaches the lowest } \\
\text { Long adsorption } \\
\text { Short desorption for } \mathrm{N}_{2} \\
\text { Long desorption for } \mathrm{CO}_{2}\end{array}$ & $\begin{array}{l}\mathrm{P}_{\mathrm{L}} \text { is relatively low } \\
\text { Long adsorption } \\
\text { Long desorption for } \mathrm{N}_{2} \\
\text { Long desorption for } \mathrm{CO}_{2}\end{array}$ & $(1-7)$ \\
\hline $2^{\text {nd }}$ PSA & $\begin{array}{l}\mathrm{P}_{\mathrm{L}} \text { approaches the lowest } \\
\text { Long desorption for } \mathrm{CO}_{2}\end{array}$ & $\begin{array}{l}\mathrm{P}_{\mathrm{L}} \text { is relatively low } \\
\text { Long desorption for } \mathrm{CO}_{2}\end{array}$ & $(8-13)$ \\
\hline $\begin{array}{l}\text { Utilization } \\
\text { pathways }\end{array}$ & MS is favored over FT. & $\begin{array}{l}\text { FT is favored over MS sometimes } \\
\text { FT and MS co-exist sometimes }\end{array}$ & (14) \\
\hline FT & $\begin{array}{l}\text { (not important, because FT is not } \\
\text { selected) } \\
\text { FT } 248{ }^{\circ} \mathrm{C}, 26 \text { bar } \\
\text { Distillation } 62 \text { trays } \\
\text { Reformer } 876^{\circ} \mathrm{C}, 5.0 \text { bar } \\
\text { Purge } \% \text { at } 4.5 \% \\
\text { More recycle to FT section }\end{array}$ & $\begin{array}{l}\text { (very important, because FT is } \\
\text { selected as a key utilization path) } \\
\text { FT } 244-246{ }^{\circ} \mathrm{C}, 28 \text { bar } \\
\text { Distillation } 55-57 \text { trays } \\
\text { Reformer } 947-950{ }^{\circ} \mathrm{C}, 4.2-4.5 \text { bar } \\
\text { Purge } \% \text { at } 4.4-7.2 \% \\
\text { More }(>80 \% \text { ) recycle to reforming }\end{array}$ & $(15-21)$ \\
\hline MS & $\begin{array}{l}\mathrm{NG} / \mathrm{CO} 2=3.5 . \\
\text { MS reactor inlet } 204{ }^{\circ} \mathrm{C} . \\
\text { MS reactor inlet } 70 \text { bar } \\
\text { Distillation } 46 \text { trays } \\
\text { Reformer } 933^{\circ} \mathrm{C}, 6.2 \mathrm{bar}\end{array}$ & $\begin{array}{l}\mathrm{NG} / \mathrm{CO}_{2}=3.6-3.7 \\
\mathrm{MS} \text { reactor inlet } 196-198{ }^{\circ} \mathrm{C} \\
\text { MS reactor inlet } 66 \mathrm{bar} \\
\text { Distillation } 55 \text { trays } \\
\text { Reformer } 863-881^{\circ} \mathrm{C}, 5.6-5.7 \mathrm{bar}\end{array}$ & $(22-27)$ \\
\hline Heating & $\begin{array}{l}\text { Fuel-gas heating is fully } \\
\text { substituted by low-carbon elec. } \\
\text { Steam-based heating is fully } \\
\text { substituted by low-carbon elec. }\end{array}$ & $\begin{array}{l}\text { Fuel-gas heating is partially } \\
\text { substituted by low-carbon elec. } \\
\text { Steam-based heating is over } 60 \% \\
\text { substituted by low-carbon elec. }\end{array}$ & $(28-29)$ \\
\hline
\end{tabular}

NSGA-II is a stochastic optimization technique, so the found solution theoretically cannot guarantee the optimality unless infinite iterations are performed. To check whether the best solutions found in our case are robust or not, we evaluate two extreme scenarios regarding the 
selection of utilization pathways - fully employing either FT or MS. As shown in Figure 11, either way does not deliver better solutions than the found solution found by NSGA-II. On the one hand, the $\mathrm{CO}_{2}$ utilization via entirely FT tends to bring in a higher profit, but the potential for GHG emissions reduction is limited to $20 \%$. On the other hand, fully MS can enhance GHG emissions reduction to $46 \%$ but dramatically lose the economic advantage compared to the original solution found by NSGA-II.
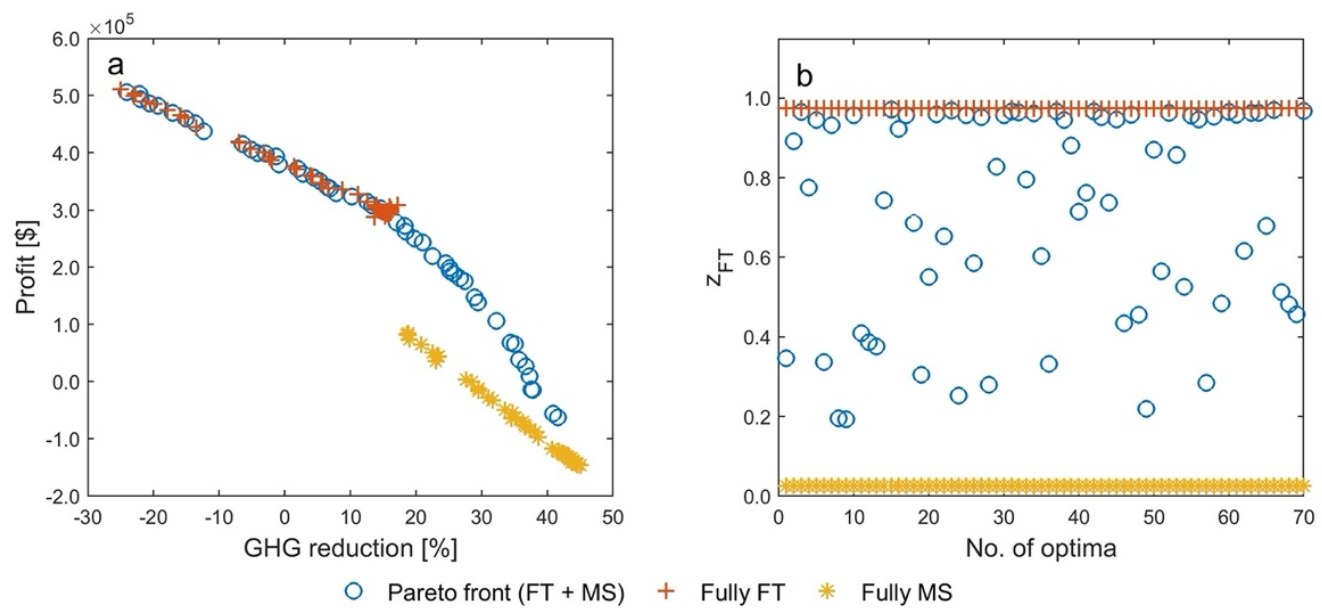

Figure 11. Influence of different utilization pathways: (a) Trade-off between profit and GHG reduction for the industrial park. (b) the fraction of $\mathrm{CO}_{2}$ utilization via FT (values of other operating conditions keep the same). 
Similarly, we evaluate another extreme scenario, where the heating is fully substituted by lowcarbon electricity. As shown in Figure 12, such a complete substitution brings in minor improvement on GHG reduction but significantly sacrifices the economic gain.

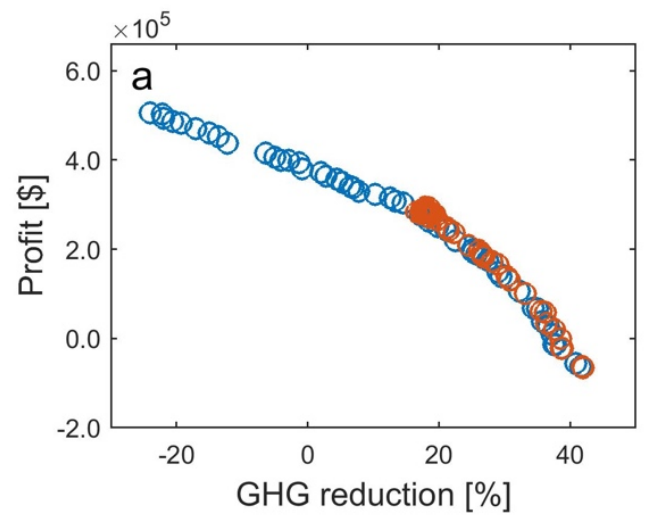

Pareto Front (heating partially substituted by low-carbon electricity)

Heating fully substituted

by low-carbon electricity
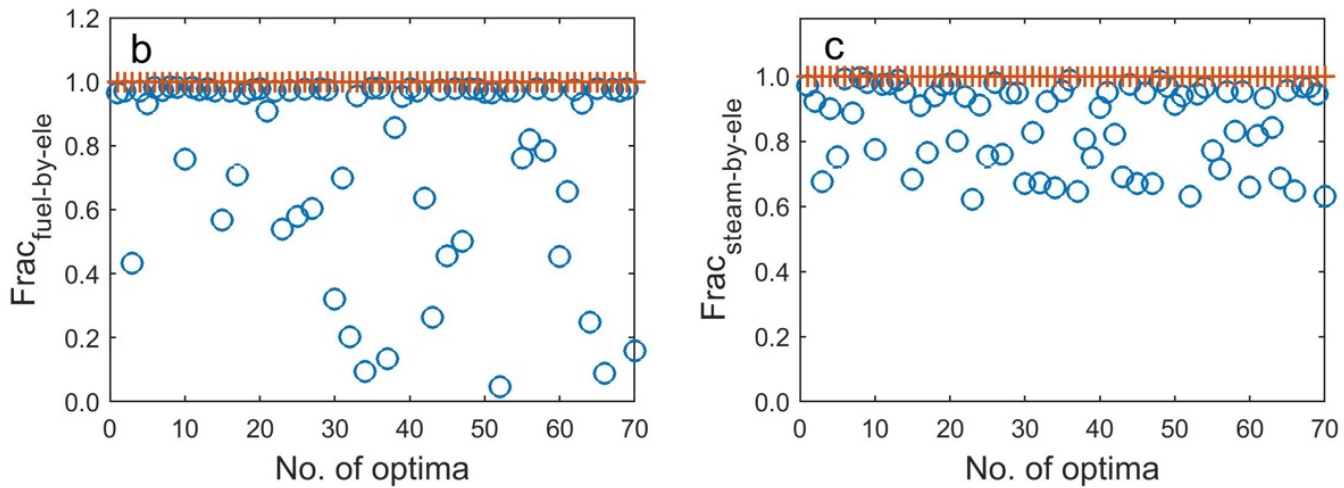

Figure 12. Influence of the heating fully substituted by low-carbon electricity: (a) trade-off between profit and GHG reduction for the industrial park; (b) the fraction of fuel-gas heating substituted by low-carbon electricity; (c) the fraction of steam heating substituted by lowcarbon electricity (values of other operating conditions keep the same).

In brief, multi-objective optimization can recommend moderate operating conditions for the industrial park. Relating the Pareto front to decision variables can offer an insight into how environmental and economic aspects are affected by operating conditions. Specifically, utilization to gasoline/diesel (FT path) can bring in more economic benefits, while utilization to methanol (MS path) and electrifying heating is more environmental-friendly. By contrast, the extreme operating conditions tend to significantly sacrifice either economic or environmental aspects.

Notably, the economic evaluation can be sensitive to the project location choice and market dynamics. Subsequently, the LCA-Economic trade-off curve may potentially change. 


\section{Influence of carbon pricing}

Lastly, we sought to examine the influence of carbon pricing on the CCU system. IEA reports that carbon price will significantly increase up to $250 \$ /$ ton- $\mathrm{CO}_{2}$ by 2050 for advanced economies. $^{2}$ As predicted by Nicholson et al., the rising carbon prices can raise the energy cost. ${ }^{54}$ as a result of an extra financial constraint for the utility emissions, which can be roughly assessed by multiplying the emission factors by the carbon price (Eq 9). We embedded different strategies for carbon tax deployment and assumed that carbon pricing is imposed both on emissions resulting from both utility usage, and also, on the life-cycle emissions from the carbon-based raw materials and products.

The economic factors contain therefore two parts: original prices and carbon tax as follows,

$$
\begin{aligned}
& \beta_{\mathrm{u}}=\beta_{\mathrm{u}, 0}+\alpha_{\mathrm{u}} \cdot \gamma_{\mathrm{CO}_{2}} \\
& \beta_{\mathrm{r}}=\beta_{\mathrm{r}, 0}+\alpha_{\mathrm{r}} \cdot \gamma_{\mathrm{CO}_{2}} \\
& \beta_{\mathrm{p}}=\beta_{\mathrm{p}, 0}+\alpha_{\mathrm{p}} \cdot \gamma_{\mathrm{CO}_{2}}
\end{aligned}
$$

where

$$
\begin{array}{ll}
\beta & \text { Economic factors, } \$ / \text { ton } \\
\alpha & \text { Lifecycle GHG emission factors, } \text { ton }_{\mathrm{CO}_{2}} / \text { ton } \\
\gamma_{\mathrm{CO}_{2}} & \text { Carbon price, } \$ / \text { ton }_{\mathrm{CO}_{2}} \\
\text { Subscript } & \\
\mathrm{i} & \text { Notation for sub-systems } \\
\mathrm{r} & \text { Notation for raw materials (natural gas, process water, MEA, etc.) } \\
\mathrm{u} & \text { Notation for utilities (steam, fuel gas, electricity, cooling, etc.) } \\
\mathrm{p} & \text { Notation for products (gasoline, diesel, methanol, etc.) } \\
0 & \text { Notation for original price (no carbon tax applies) }
\end{array}
$$

Based on the optimization results for decision variables at no carbon price, the profits are recalculated under other carbon prices (no further optimization is performed here, so it is not proper to use the term 'Pareto front'. The phrase, 'trade-off' curve, is used in this section). Figure 13 presents the change of the trade-off curves for the carbon price ranging from 0 to $250 \$ /$ ton- $\mathrm{CO}_{2}$. With the increase of carbon price, the profit shifts to different directions depending on the GHG reduction. At a low GHG reduction, the profit drops with the carbon tax increase; at a high GHG reduction, the trend is reversed. 


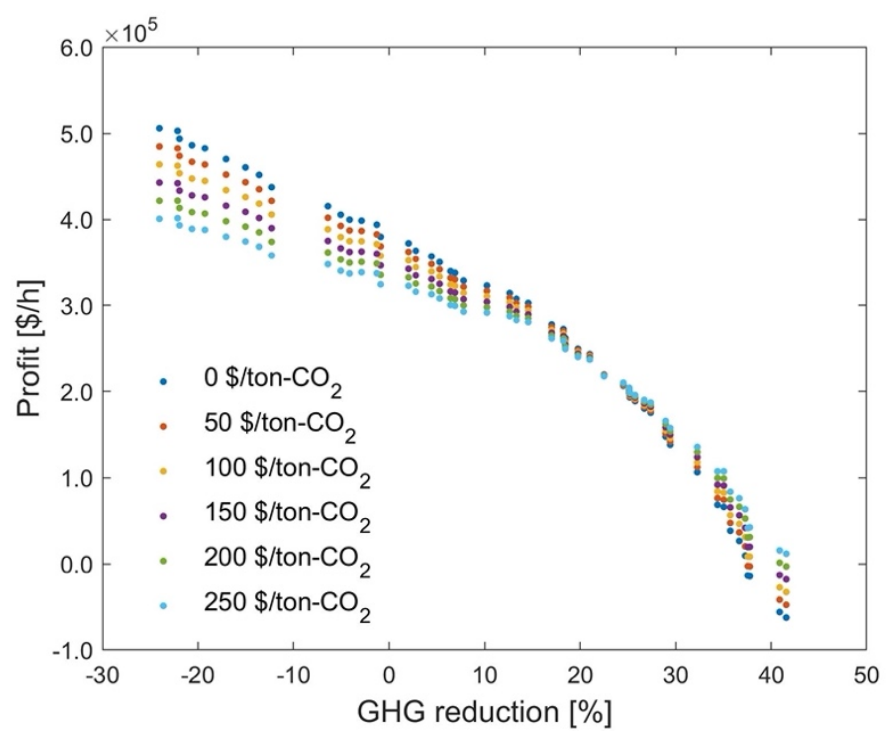

Figure 13. Influence of carbon price on the trade-off curve between profit and GHG emissions reduction.

To investigate why the trade-off curve shift to different directions, we pick the points at $-24 \%$, $23 \%$ and $42 \%$ of GHG emissions reduction, under which we investigate their economic breakdowns (Figure 14). We can find carbon tax has dual effects on this CCU system. On the one hand, the process cost increases with carbon tax. This is because the CCU plant is still associated with emissions from raw materials, utilities and unreacted $\mathrm{CO}_{2}$ emissions, so the cost of these emissions is consequently increased. On the other hand, the revenue from fuel products rises with the growth of carbon tax, as the carbon tax increases the price of fuel products, which brings in extra credits to the CCU system. MS can reduce more GHG emissions and the credit for methanol is larger than FT products. Hence, the revenue increase in methanol is much more significant than that in FT products, which reflects that raising carbon tax brings in more revenue at $42 \% \mathrm{GHG}$ reduction than that at $-24 \% \mathrm{GHG}$ emissions reduction. 


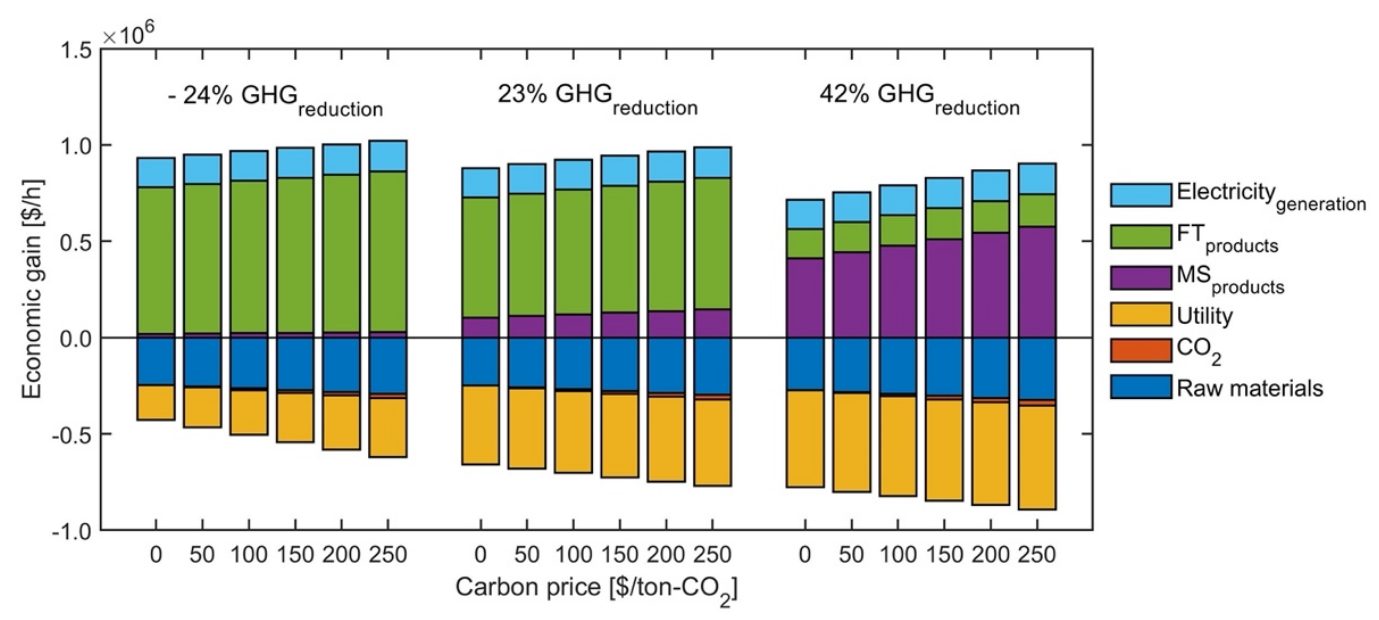

Figure 14. Influence of carbon price on the breakdowns of net profit.

Additionally, carbon price imposes a higher penalty to the utilities with higher emissions. As shown in Figure 15, the cost of utilities with direct emissions increases faster than the lowcarbon utilities. This explains why the utility cost at $-24 \%$ GHG emissions reduction, when the percentage of heating electrification is very low (Table 5), grows significantly with the increase of carbon tax (Figure 14). By contrast, heating is almost fully substituted by low-carbon electricity at $42 \%$ GHG reduction, so the growing carbon tax does not notably change the utility cost.

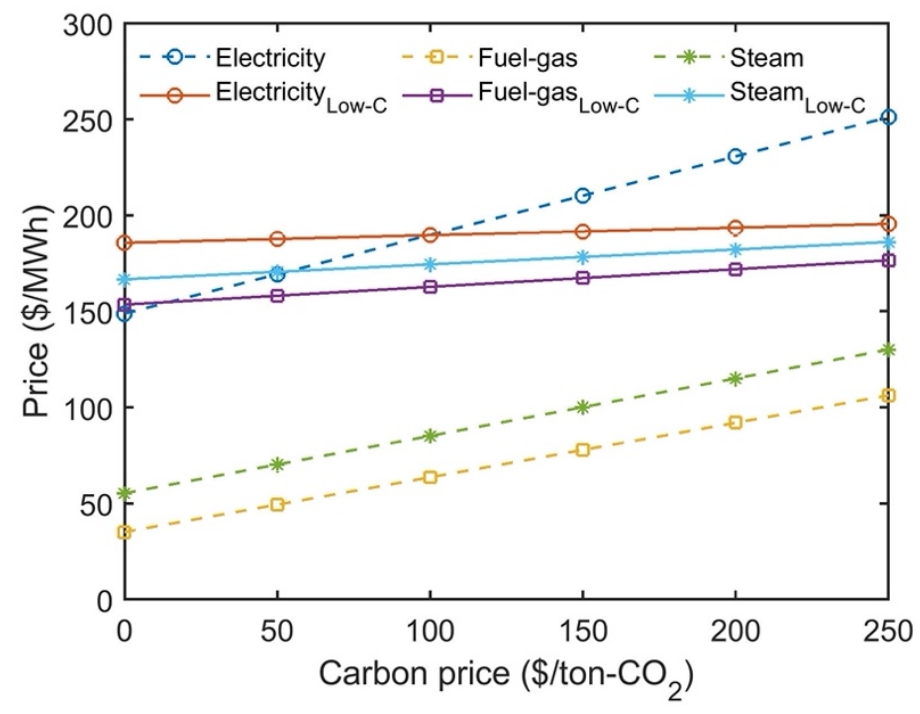

Figure 15. Influence of carbon price on the costs of utilities.

Overall, at a higher GHG emissions reduction, the carbon tax promotes a higher growth rate for credit gain and a lower growth rate for the penalty. By contrast, a lower GHG emissions reduction has an inverse trend. As such, increasing carbon tax brings the trade-off curves in an intersection at $23 \%$ GHG reduction, where the growth rate of cost is equivalent to that of 
product revenue. Notably, we analyzed here only the net profit from the CCU system, without considering how its economic performance would compare to a direct-emission system, which will become significantly less economic under the increasing carbon pricing scenario.

\section{Conclusions}

The optimization framework presented in this paper allows for optimization of complex problems with conflicting objectives, as illustrated with the case of CCU system (the proposed industrial park). To determine its best performance regarding environmental and economic aspects, we developed an optimization framework, where the industrial park is fully digitalized by ANN-based surrogates and simultaneously optimized in a cost-efficient manner. As such, the nonlinearity of sub-systems and the interaction between sub-systems are well considered during the optimization iterations. By scrutinizing the interactions between different unit operations proposed for carbon capture and utilization sections, optimization enables to determine a process configuration allowing for substantial reduction of $\mathrm{CO}_{2}$ emissions $(-13 \%)$. Importantly, the proposed decarbonization strategy does not rely on deployment of renewable energy sources hence offers a solution which is not dependent on the growth of renewables sectors. Through comparing the emissions from sub-systems under the optimal solution, we found that the GHG emissions in utilization dominate the whole CCU system, so optimizing the utilization path can be more rewarding than the capture path. This finding benefits from optimizing the sub-systems simultaneously. The GHG emissions breakdowns indicate that heating is the most significant contributor to GHG emissions of the whole system, accounting for $60 \%$. Electrifying heating fully by CCS electricity and fully producing methanol in the utilization pathways can reduce GHG emissions by $47 \%$ compared to the conventional process. Still, such extreme conditions will significantly sacrifice the economic benefit. By contrast, multi-objective optimization suggests the production of mixed methanol/gasoline/diesel and partially heating electrification, which can achieve a better trade-off between GHG reduction and economic profit.

This work also discusses the dual effect of the carbon price on this CCU system. On the one hand, carbon pricing puts an extra cost on the raw materials and utilities. On the other hand, the carbon tax can also bring in a 'credit' effect when reducing GHG emissions in production. The effect of carbon taxes on the techno-economic performance of CCU is therefore complex to predict, and consequently the optimization approach proposed here can be a useful tool to determine the optimal solution under different scenarios of carbon prices. 
Additionally, this work suggests the heating electrification can be an alternative to renewable $\mathrm{H}_{2}$ to make the $\mathrm{CCU}$ more competitive regarding the environmental aspect, while developing the affordable low-carbon heating technologies ${ }^{10,55-57}$ can enhance the economic viability.

Proposed method demonstrates that digitalization and optimization are powerful tools to explore the potential of $\mathrm{CCU}$. We anticipate that availability of tools that can generate precise process estimates under a low computational cost can support decision-making in comparing numerous technologies. Specifically, the scope of this work is [gas + CCUS], which integrates the gas-fired power plants with CCU, as well as the heating utility partially substituted by CCS electricity. Eq 12 and random simulations can deliver a rough range of emission factor of [Gas + CCUS], see the red column in Figure 16. Single-objective optimization can reach the lower bound for the emission factor, while multi-objective optimization tends to slightly increase the emissions while improve other objectives, such as the economic aspect. Figure 16 lists the emission factors of several power generation technologies,${ }^{58}$ and specific attentions should be given to renewables with the potential to form new low-carbon pathways. In a long term, net zero needs various low-carbon pathways. While their decarbonization performances are exploited by optimization, the overall progress of net zero will be accelerated.

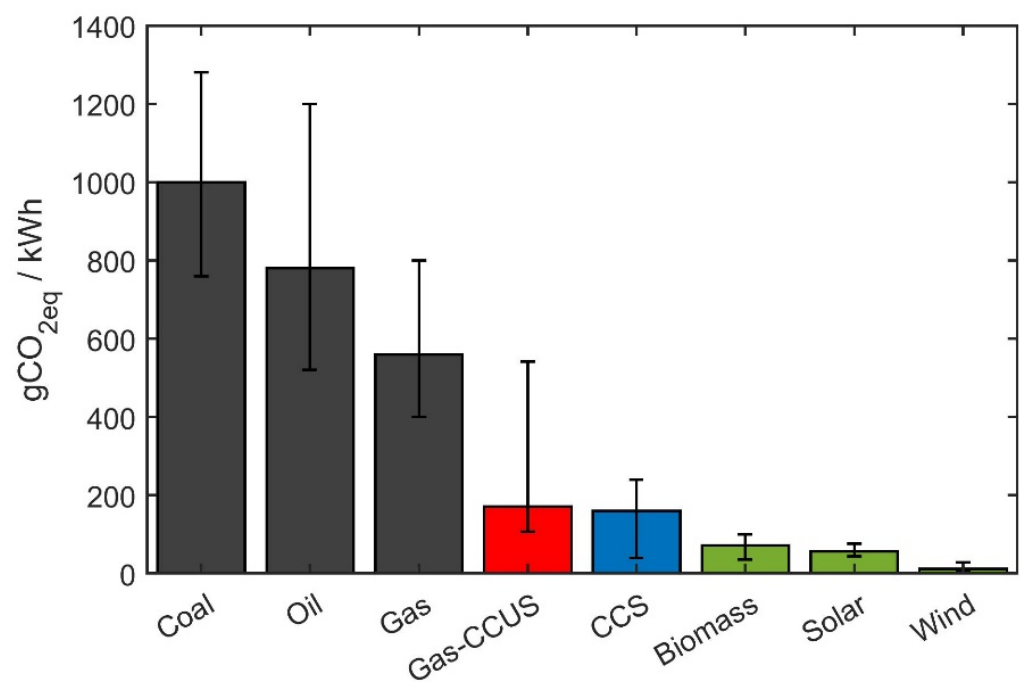

Figure 16. Lifecycle GHG emission factors of various power generation technologies. Scope of this work is [Gas-CCUS], and its emission factor is calculated as Eq 12. Other values can be found in Weisser. ${ }^{58}$

$$
\alpha_{\text {gas-CCUS }}=\frac{\mathrm{GHG}_{\mathrm{CCU}}}{\mathrm{E}_{\text {electricity }}+\sum_{\mathrm{i}} \sum_{\mathrm{p}} \mathrm{e}_{\mathrm{p}} \cdot \mathrm{F}_{\mathrm{i}, \mathrm{p}}}
$$

where 


$\begin{array}{ll}\alpha_{\text {gas-CCUS }} & \text { Lifecycle GHG emission factor of [gas-CCUS]: } \text { ton }_{\mathrm{CO}_{2} \text { eq }} / \mathrm{GJ} \\ \mathrm{GHG}_{\mathrm{CCU}} & \text { GHG emissions of the whole CCU system (the industrial park) } \\ \mathrm{F} & \text { Mass flow, ton/h } \\ \mathrm{e} & \text { Energy density: GJ/ton } \\ \mathrm{E}_{\text {electricity }} & \text { Net output of electricity from }[\mathrm{NGCC}+\mathrm{MEA} / \mathrm{PSA}], \mathrm{GJ} / \mathrm{h} \\ \mathrm{Subscript} & \\ \mathrm{i} & \text { Notation for sub-systems } \\ \mathrm{p} & \text { Notation for products (gasoline, diesel, methanol, etc.) }\end{array}$

\section{Acknowledgments}

Authors declare no competing financial interest. $\mathrm{ZH}$ thanks the fruitful discussions with Dr. Roh Kosan (Chungnam National University) regarding the LCA analysis on CCU, with Prof. Johan Grievink (TU Delft) regarding the steady-state approximation for CCU. ZH acknowledges financial support from Cambridge Trust and Chinese Scholarship Council. ZH's final-year $\mathrm{PhD}$ was partially funded by Sustainable Reaction Engineering research group of Prof. Lapkin. AAL and MHB acknowledge funding from National Research Foundation (NRF), Prime Minister's Office, Singapore under its Campus for Research Excellence and Technological Enterprise (CREATE) program as a part of the Cambridge Centre for Advanced Research and Education in Singapore Ltd (CARES, C4T project).

\section{References}

1. United Nations, The Global Coalition for Net-zero Emissions is Growing, https://www.un.org/en/climatechange/net-zero-coalition), accessed: 2021-12-10.

2. International Energy Agency, Net Zero by 2050: A Roadmap for the Global Energy Sector, 2021.

3. M. Bui, C. S. Adjiman, A. Bardow, E. J. Anthony, A. Boston, S. Brown, P. S. Fennell, S. Fuss, A. Galindo, L. A. Hackett, J. P. Hallett, H. J. Herzog, G. Jackson, J. Kemper, S. Krevor, G. C. Maitland, M. Matuszewski, I. S. Metcalfe, C. Petit, G. Puxty, J. Reimer, D. M. Reiner, E. S. Rubin, S. A. Scott, N. Shah, B. Smit, J. P. M. Trusler, P. Webley, J. Wilcox and N. Mac Dowell, Energy Environ Sci., 2018, 11, 1062-1176.

4. J. Burre, D. Bongartz, S. Deutz, C. Mebrahtu, O. Osterthun, R. Sun, S. Völker, A. Bardow, J. Klankermayer, R. Palkovits and A. Mitsos, Energy Environ Sci., 2021, 14, 3686-3699.

5. K. Roh, A. S. Al-Hunaidy, H. Imran and J. H. Lee, AIChE J., 2019, 65, e16580.

6. K. Roh, R. Frauzem, T. B. H. Nguyen, R. Gani and J. H. Lee, Comput Chem Eng., 2016, 91, 407-421.

7. B. Rego de Vasconcelos and J. M. Lavoie, Front Chem., 2019, 7, 392.

8. V. Dieterich, A. Buttler, A. Hanel, H. Spliethoff and S. Fendt, Energy Environ Sci., 2020, 13, 3207-3252.

9. M. H. Barecka, J. W. Ager and A. A. Lapkin, Energy Environ Sci., 2021, 14, 1530-1543.

10. A. Sternberg and A. Bardow, Energy Environ Sci., 2015, 8, 389-400.

11. C. Chen and A. Yang, Energ Convers Manage, 2021, 228, 113673.

12. Siemens-Energy, Power-to-X: the Crucial Business on the Way to a Carbon-free World, https://www.siemens-energy.com/global/en/offerings/technical-papers/download-power-tox.html, accessed: 2021-11-10.

13. VoltaChem, Power-to-Fuels, https://www.voltachem.com/applications/power-to-fuels, accessed: 2021-11-10. 
14. N. M. Haegel, R. Margolis, T. Buonassisi, D. Feldman, A. Froitzheim, R. Garabedian, M. Green, S. Glunz, H.-M. Henning, B. Holder, I. Kaizuka, B. Kroposki, K. Matsubara, S. Niki, K. Sakurai, R. A. Schindler, W. Tumas, E. R. Weber, G. Wilson, M. Woodhouse and S. Kurtz, Science, 2017, 356, 141-143.

15. A. González-Garay, M. S. Frei, A. Al-Qahtani, C. Mondelli, G. Guillén-Gosálbez and J. PérezRamírez, Energy Environ Sci., 2019, 12, 3425-3436.

16. J. Deutch, Joule, 2020, 4, 2237-2240.

17. T. Bruhn, H. Naims and B. Olfe-Kräutlein, Environ Sci Policy, 2016, 60, 38-43.

18. A. Zapantis, A. Townsend and D. Rassool, Thought Leadership Report. Global CCS Institute (GCCSI), 2019.

19. H. A. Balogun, D. Bahamon, S. AlMenhali, L. F. Vega and A. Alhajaj, Energy Environ Sci, 2021, 14, 6360-5380.

20. R. Haghpanah, A. Majumder, R. Nilam, A. Rajendran, S. Farooq, I. A. Karimi and M. Amanullah, Ind Eng Chem Res., 2013, 52, 4249-4265.

21. Z. Hao, A. Caspari, A. M. Schweidtmann, Y. Vaupel, A. A. Lapkin and A. Mhamdi, Chem Eng $J ., 2021,423,130248$.

22. S. G. Subraveti, Z. K. Li, V. Prasad and A. Rajendran, Ind Eng Chem Res., 2019, 58, $20412-$ 20422.

23. M. M. F. Hasan, R. C. Baliban, J. A. Elia and C. A. Floudas, Ind Eng Chem Res., 2012, 51, 15642-15664.

24. W. Chung and J. H. Lee, Ind Eng Chem Res., 2020, 59, 18951-18964.

25. A. Gonzalez-Garay and G. Guillen-Gosalbez, Chem Eng Res Des., 2018, 137, 246-264.

26. Y. H. Kim, K.-W. Jun, H. Joo, C. Han and I. K. Song, Chem Eng J., 2009, 155, 427-432.

27. C. Zhang, K.-W. Jun, K.-S. Ha, Y.-J. Lee and S. C. Kang, Environ Sci Technol., 2014, 48, 8251-8257.

28. L. T. Biegler and I. E. Grossmann, Comput Chem Eng., 2004, 28, 1169-1192.

29. C. A. Henao and C. T. Maravelias, AIChE J., 2011, 57, 1216-1232.

30. K. McBride and K. Sundmacher, Chem Ing Tech., 2019, 91, 228-239.

31. D. C. Miller, D. Agarwal, D. Bhattacharyya, J. Boverhof, Y.-W. Cheah, Y. Chen, J. Eslick, J. Leek, J. Ma, P. Mahapatra, B. Ng, N. V. Sahinidis, C. Tong and S. E. Zitney, in Computer Aided Chemical Engineering, eds. Z. Kravanja and M. Bogataj, Elsevier, 2016, vol. 38, pp. 2391-2396.

32. A. Agarwal, L. T. Biegler and S. E. Zitney, Ind Eng Chem Res, 2009, 48, 2327-2343.

33. K. T. Leperi, D. Yancy-Caballero, R. Q. Snurr and F. You, Ind Eng Chem Res., 2019, 58, 18241-18252.

34. Global CCS Institute, Accelerating the Uptake of CCS: Industrial Use of Captured Carbon Dioxide, 2011.

35. C. A. Grande, Int Sch Res Notices, 2012, Article ID 982934.

36. C. C. S. Reddy, in Chemical Process Retrofitting and Revamping, 2016, pp. 19-56.

37. G. H. Graaf, E. J. Stamhuis and A. A. C. M. Beenackers, Chem Eng Sci., 1988, 43, 3185-3195.

38. K. M. V. Bussche and G. F. Froment, J Catal., 1996, 161, 1-10.

39. P. Kaiser, R. B. Unde, C. Kern and A. Jess, Chem Ing Tech., 2013, 85, 489-499.

40. C. G. Visconti, L. Lietti, E. Tronconi, P. Forzatti, R. Zennaro and E. Finocchio, Appl Catal A: Gen., 2009, 355, 61-68.

41. J. Baltrusaitis and W. L. Luyben, ACS Sustain Chem Eng., 2015, 3, 2100-2111.

42. Y. Lim, C. J. Lee, Y. S. Jeong, I. H. Song, C. J. Lee and C. Han, Ind Eng Chem Res., 2012, 51, 4982-4989.

43. K. Hornik, M. Stinchcombe and H. White, Neural Netw., 1989, 2, 359-366.

44. IECM, Integrated Environmental Control Model (IECM) Version 11.4 (Carnegie Mellon University), https://www.cmu.edu/epp/iecm/index.html, accessed: 2020-08-01.

45. Dymola. This software is currently maintained and distributed by Dassault Systems. https://www.3ds.com/products-services/catia/products/dymola/.

46. Z. Hao, C. Zhang and A. Lapkin, Efficient Surrogates Construction of Chemical Processes: Case studies on Pressure Swing Adsorption and Gas-to-Liquids. ChemRxiv, 2021.

47. P. Brandl, M. Bui, J. P. Hallett and N. Mac Dowell, Int J Greenh Gas Con., 2021, 105, 103239. 
48. B. Bao, M. M. El-Halwagi and N. O. Elbashir, Fuel Process Technol., 2010, 91, 703-713.

49. S. A. Al-Sobhi, A. Elkamel, F. S. Erenay and M. A. Shaik, Energies, 2018, 11, 362.

50. K.-S. Ha, J. W. Bae, K.-J. Woo and K.-W. Jun, Environ Sci Technol., 2010, 44, 1412-1417.

51. A. A. Kiss, J. J. Pragt, H. J. Vos, G. Bargeman and M. T. de Groot, Chem Eng J., 2016, 284, 260-269.

52. AspenTech, Aspen Plus Methanol Synthesis Model, 2018. The methanol synthesis model can be downloaded from esupport.aspentech.com. Alternatively, for Aspen Plus V11 and higher version, the model file can be accessed in C: $\backslash$ Program Files $\backslash$ AspenTech $\backslash$ Aspen Plus Vxx.x\GUI\Examples\Bulk Chemical\Methanol.

53. A. Zimmermann, L. Müller, Y. Wang, T. Langhorst, J. Wunderlich, A. Marxen, K. Armstrong, G. Buchner, A. Kätelhön and M. Bachmann, Techno-Economic Assessment \& Life Cycle Assessment Guidelines for CO2 Utilization (Version 1.1), 2020.

54. M. Nicholson, T. Biegler and B. W. Brook, Energy, 2011, 36, 305-313.

55. E. J. Sheu, E. M. A. Mokheimer and A. F. Ghoniem, Int J Hydrog Energy., 2015, 40, 1292912955.

56. Y. Sun, T. Ritchie, S. S. Hla, S. McEvoy, W. Stein and J. H. Edwards, J Nat Gas Chem., 2011, 20, 568-576.

57. H. Von Storch, S. Becker-Hardt and C. Sattler, Energies, 2018, 11, 2537.

58. D. Weisser, Energy, 2007, 32, 1543-1559. 


\title{
Supplementary Information
}

Optimization Boosts Decarbonization: Accelerating Net Zero from the perspective of Optimizing a Carbon Capture and Utilization System

\author{
Zhimian Hao, ${ }^{1}$ Magda H. Barecka, ${ }^{2}$ Alexei A. Lapkin ${ }^{1,2 *}$ \\ ${ }^{1}$ Department of Chemical Engineering and Biotechnology, University of Cambridge, \\ Cambridge CB3 OAS, UK \\ ${ }^{2}$ Cambridge Centre for Advanced Research and Education in Singapore Ltd, 1 Create Way, \\ CREATE Tower \#05-05, 138602, Singapore
}

Table of Contents

S1. Rigorous process models for sub-systems.......................................................................2

S1.1. NG-based Power plant (NGCC) .........................................................................................2

S1.2. MEA absorption process .....................................................................................................3

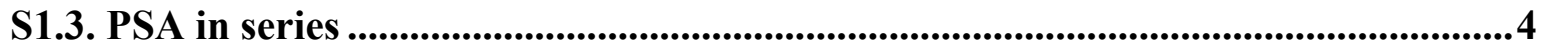

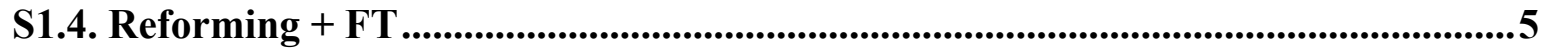

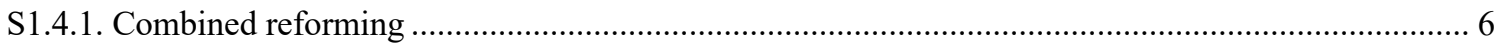

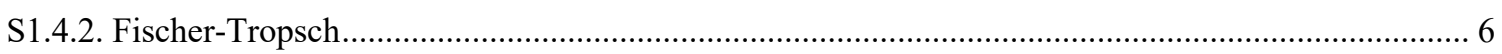

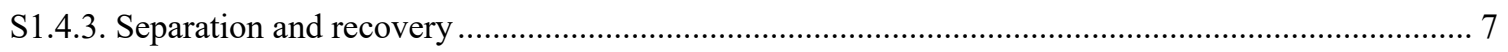

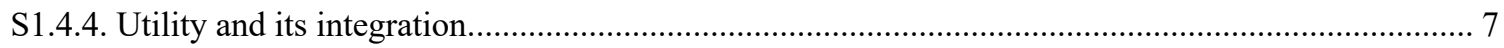

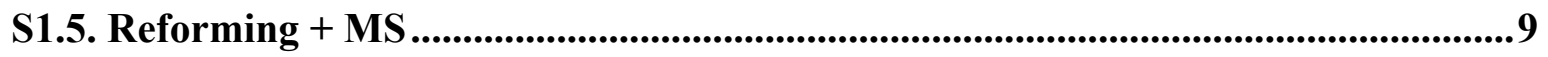

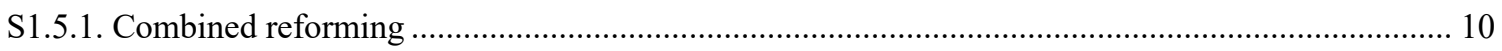

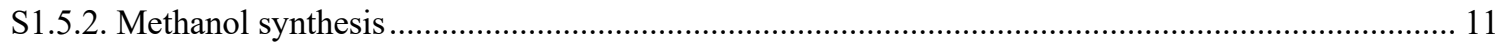

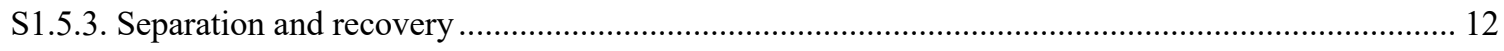

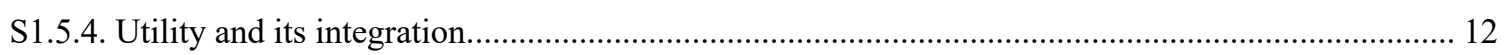

S2. Overview of essential input/output of sub-systems ...................................................13

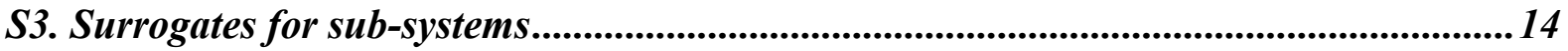

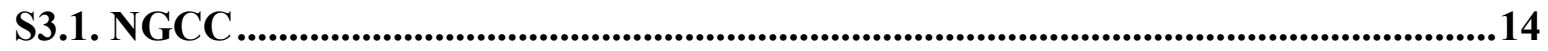

S3.2. [NGCC + MEA] .....................................................................................................

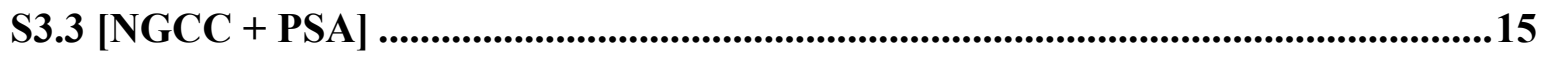


S3.4. Reforming + FT .16

S3.5. Reforming + MS .16

S4. Evaluation of GHG emissions for the industrial park 17

S4.1. System boundary in this work: cradle-to-gate .17

S4.2. System expansion strategy to compare CCU with a reference process. .18

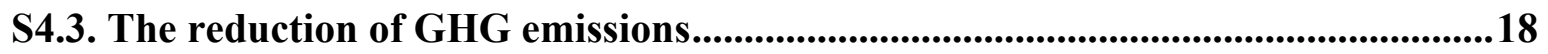

S4.4. Calculation of emission factors for low-carbon electricity .....................................19

S4.5. Calculation of GHG emission factor for low-carbon heating ..............................20

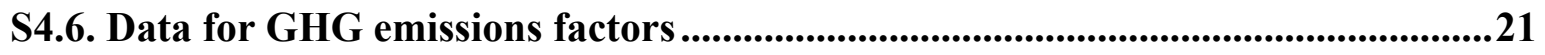

S5. Evaluation of economic aspect for the industrial park ....................................................22

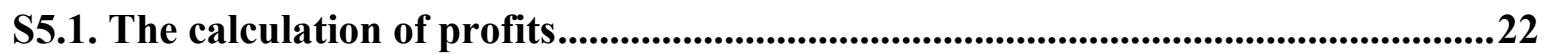

S5.2. Calculation of economic factors for low-carbon electricity ..................................23

S5.3. Calculation of economic factors for low-carbon heating...................................24

S5.4. Calculation of economic factors involving with carbon tax. ...............................24

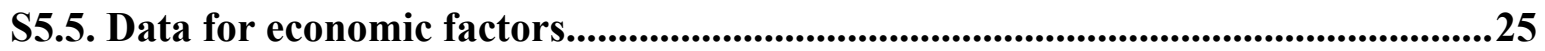

S6. Single-optimization (LCA) of the industrial park........................................................26

S7. Multi-objective (LCA-Economic) optimization of the industrial park ...........................29

S7.1. Optimal values for decision carbon @ Carbon price $=0$....................................29

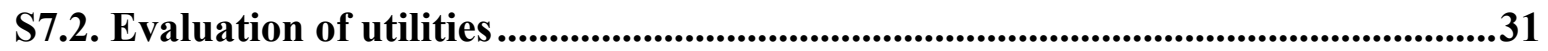

Reference

\section{S1. Rigorous process models for sub-systems}

This section describes the how sub-systems are simulated in a rigorous way.

\section{S1.1. NG-based Power plant (NGCC)}

The natural gas combined cycle power plant (NGCC) is simulated in the Integrated Environmental Control Model (IECM) platform. ${ }^{1}$ Wet cooling water is selected as the cooling 
system. Based on the simulation, we can obtain the consumptions of raw materials (NG, water) and emissions per unit of electricity generated.

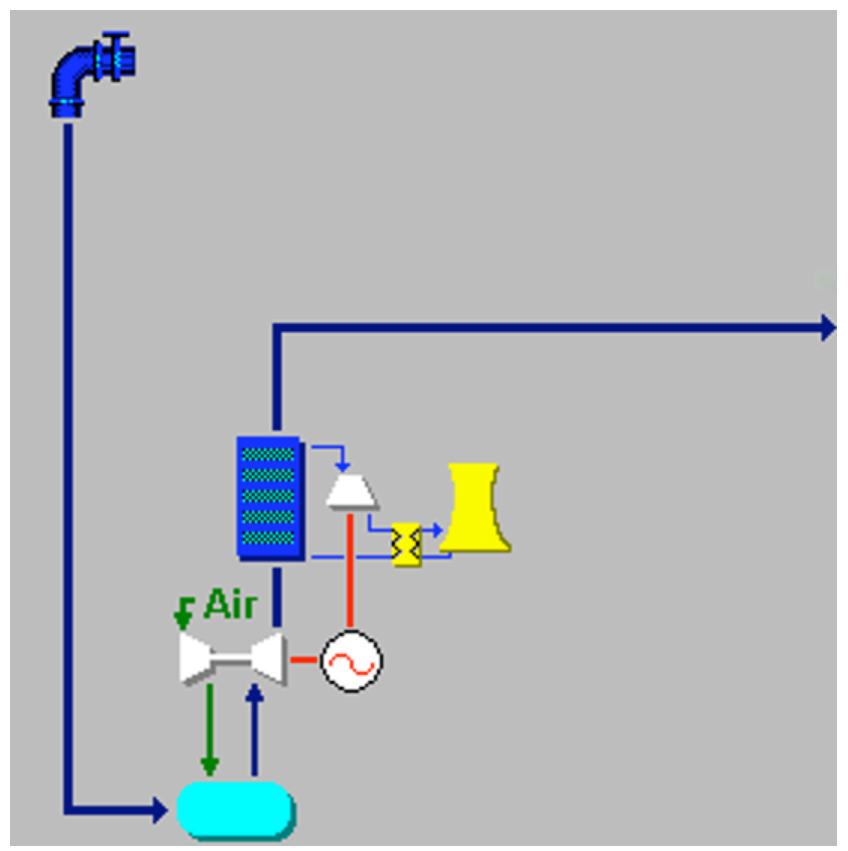

Figure S1. NGCC power plant.

\section{S1.2. MEA absorption process}

A MEA absorption process is set up in the Integrated Environmental Control Model (IECM) platform. In IECM, a power plant equipped with carbon capture (NGCC-MEA) can be simulated. Based on the simulation, we can obtain the consumptions of raw materials (NG, water, MEA) and emissions per net electricity generated.

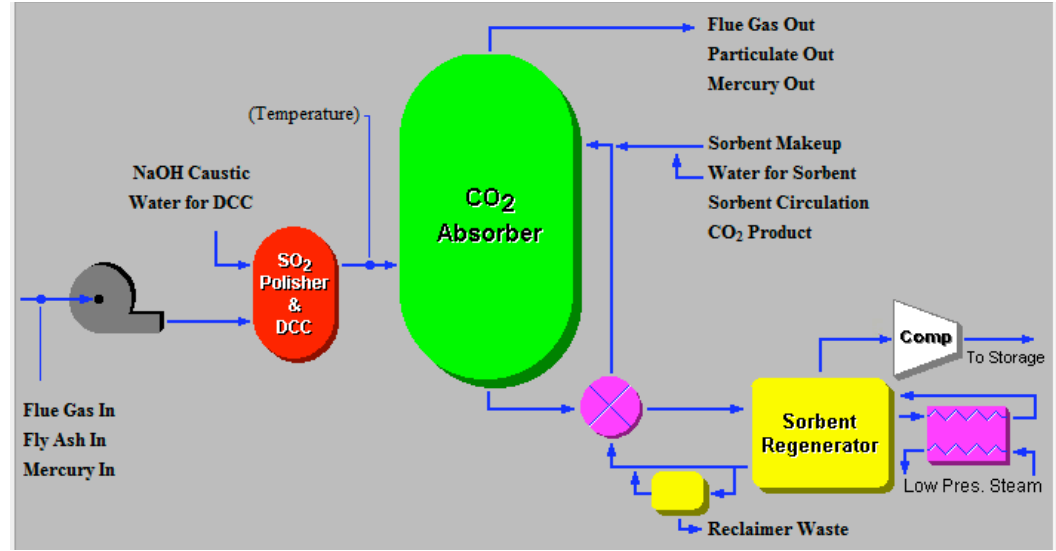

Figure S2. MEA absorption process. 


\section{S1.3. PSA in series}

A more detailed description on PSA process (balance equations, boundary conditions, cyclic steady state) can be referred to our prior work. ${ }^{2}$ After our initial trail, one PSA unit cannot guarantee the required purity ( $90 \%$ for carbon capture), due to the low $\mathrm{CO}_{2}$ concentration in the flue gas $(\sim 4 \%)$. Herein, we propose to use two PSA in series to gradually improve the purity of $\mathrm{CO}_{2}$. A trade-off relationship is reported between recovery and purity. ${ }^{3,4}$ To maintain a relatively high recovery, the first PSA aims to increase the $\mathrm{CO}_{2}$ purity to $20 \% \sim 50 \%$ (ranging from $25 \%$ to $75 \%$ among the $\mathrm{CO}_{2}$ purity distribution), while the second one PSA further improve the $\mathrm{CO}_{2}$ purity over $90 \%$.

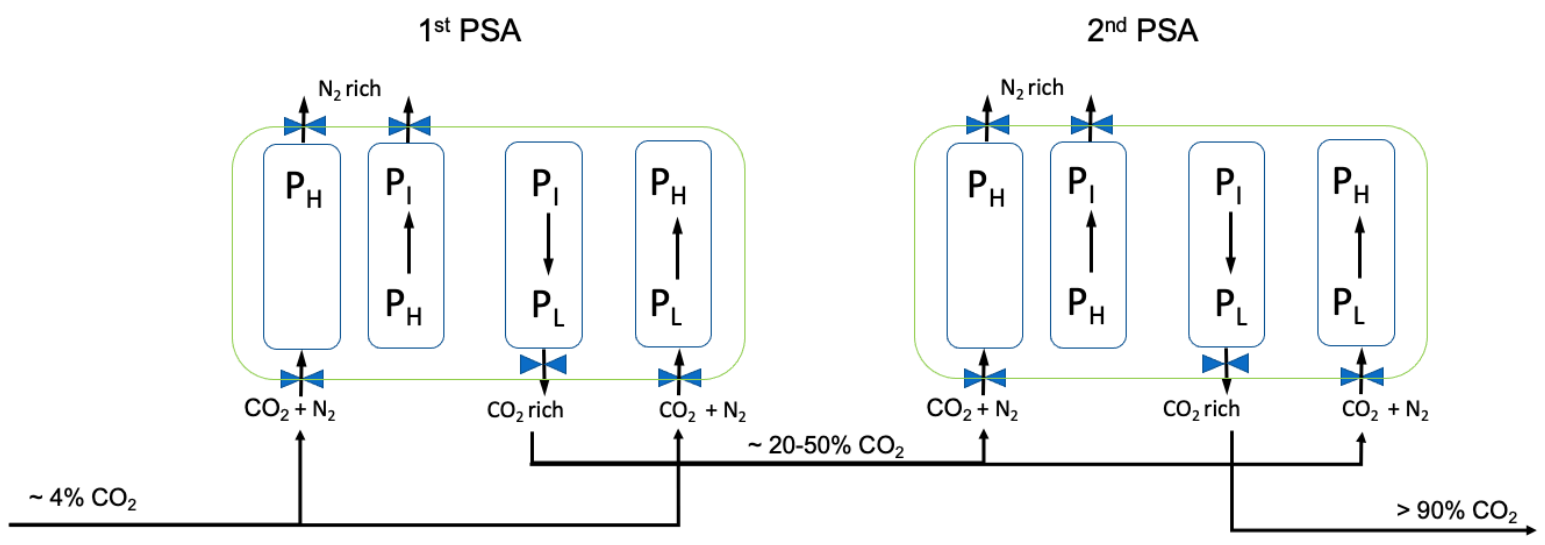

Figure S3 Two PSA in series. 


\section{S1.4. Reforming + FT}

A more detailed description on [Reforming + FT] sub-system can be referred to the process modelling for GTL in our prior work. ${ }^{2}$ This section only mentions some essential information related to this work. As shown in Figure S4, the [Reforming + FT] sub-system is modelled in Aspen Plus, including combined reforming, FT synthesis, and product upgrading section. This process starts with the combined reforming $\left(\mathrm{CO}_{2}+\mathrm{H}_{2} \mathrm{O}\right)$ of natural gas to syngas, followed by FT synthesis for fuels. Since the upgrading section has little influence on the overall performance, ${ }^{5}$ we use a distillation column to simplify it. To deal with a petrochemical process, Peng-Robinson is selected as the thermodynamic method.

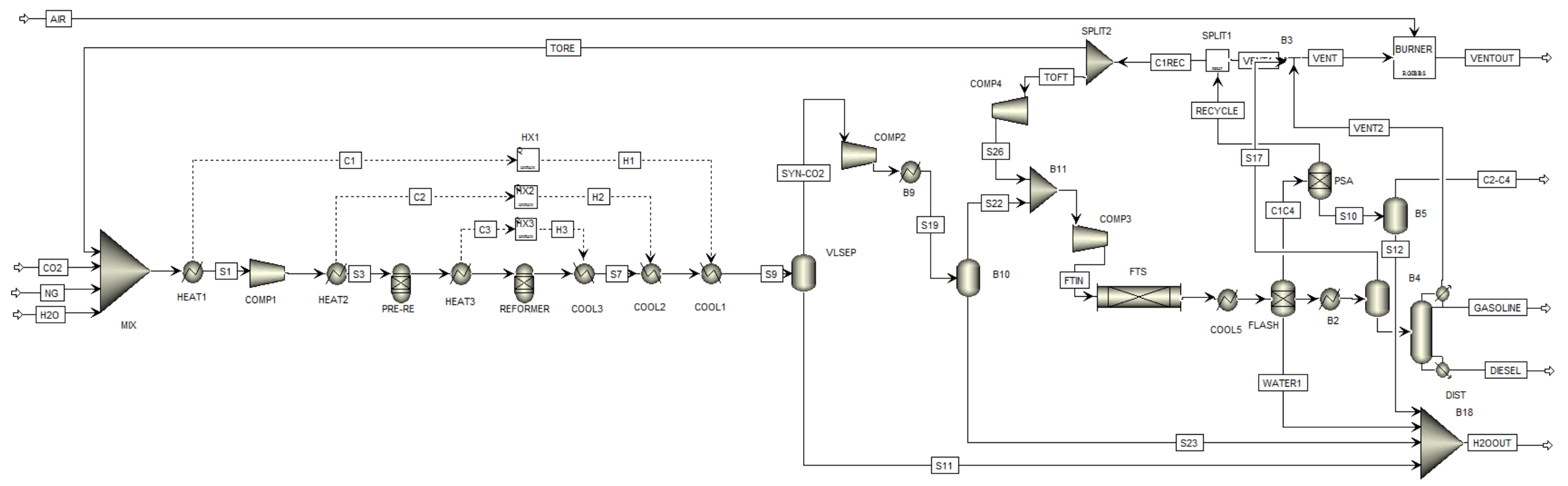

Figure S4. Flowsheet for GTL built in Aspen Plus. 


\section{S1.4.1. Combined reforming}

In the reforming section, GTL starts with $\mathrm{NG}$, water and $\mathrm{CO}_{2}$. In the pre-reformer, all the carbon components are converted to $\mathrm{CO}$ and $\mathrm{CH}_{4}$. In Aspen Plus, the reformer is modelled by an RGibbs reactor, where the total Gibbs energy is minimized to the reach the equilibrium ('Restricted Chemical Equilibrium' is set for the combined reforming reactions). A flowsheet option is set to vary the flowrate of $\mathrm{H}_{2} \mathrm{O}$ and $\mathrm{NG}$ to guarantee the ratio of $\mathrm{CO}: \mathrm{H}_{2}$ falls in a range of $2.0-2.2$ in the reformer outlet.

Combined reforming

$$
\mathrm{CH}_{4}+\mathrm{H}_{2} \mathrm{O} \rightarrow 3 \mathrm{H}_{2}+\mathrm{CO}
$$

$$
\mathrm{CH}_{4}+\mathrm{CO}_{2} \rightarrow 2 \mathrm{H}_{2}+2 \mathrm{CO}
$$

\section{S1.4.2. Fischer-Tropsch}

Fischer-Tropsch (FT) has a long industrial history of producing high-quality fuels. ${ }^{6,7}$ Lowtemperature FT (LTFT) is considered in this work. This is because FT reaction is highly exothermic, and a lower temperature can improve the final conversion regarding the thermodynamic equilibrium. For LTFT, the desired syngas ratio falls in the range of $2-2.2$ for $\mathrm{H}_{2}: \mathrm{CO},{ }^{5-7}$ and the reaction temperature is reported to range from 200 to $270{ }^{\circ} \mathrm{C}^{6,8,9}$ as well as pressure in $15-50$ bar. $^{8-10}$

$$
(2 \mathrm{n}+1) \mathrm{H}_{2}+\mathrm{nCO} \rightarrow \mathrm{C}_{\mathrm{n}} \mathrm{H}_{2 \mathrm{n}+2}+\mathrm{nH}_{2} \mathrm{O}
$$

For FT kinetics, Yates et al. developed a simple but reliable expression 30 years ago for the consumption rate of $\mathrm{CO}$ as Equation S.1.11

$$
\mathrm{r}_{\mathrm{CO}}=\frac{\mathrm{F} \cdot \mathrm{a} \cdot \mathrm{P}_{\mathrm{CO}} \cdot \mathrm{P}_{\mathrm{H}_{2}}}{\left(1+\mathrm{b} \cdot \mathrm{P}_{\mathrm{CO}}\right)^{2}}
$$

where, F: catalyst improvement factor since Yates' kinetics proposed in 1991;

$P_{i}:$ partial pressure of component $i$

a: reaction rate coefficient;

b: adsorption coefficient.

In the FT section, the syngas is pressurized before entering the FT reactor. RPlug is chose to simulate the multi-tubular fixed-bed reactor for FT in Aspen Plus. Yates' kinetics is used for the overall consuming rate of $\mathrm{CO}\left(r_{C O}\right),{ }^{11}$ while the Anderson-Schulz-Flory mechanism can be 
used to estimate the distribution of FT products. ${ }^{7}$ Since the properties of hydrocarbons (HCs) are similar, .we employ four reactions $(\mathrm{R} 1 \sim \mathrm{R} 4)$ to represent the whole range of HCs for simplification during the simulation as the Table $\mathrm{S} 1 . \mathrm{CO}_{2}$ is reported not to react on the Cobaltbased catalyst and can be regarded as an inert gas in the FT reaction. ${ }^{12,}{ }^{13}$ Based on the information mentioned above, we used the kinetic information in Rplug model.

Table S1. Components and reactions used in the simulation.

\begin{tabular}{lllll}
\hline C range & Molar fraction & Representations & Representative reactions & $\mathrm{R}_{\mathrm{CO}}$ \\
\hline $\mathrm{C}_{1}$ & 0.07 & $\mathrm{CH}_{4}$ & $\mathrm{R} 1: 3 \mathrm{H}_{2}+\mathrm{CO} \rightarrow \mathrm{CH}_{4}+\mathrm{H}_{2} \mathrm{O}$ & $0.007 \mathrm{r}_{\mathrm{CO}}$ \\
$\mathrm{C}_{2} \sim \mathrm{C}_{4}$ & 0.18 & $\mathrm{C}_{3} \mathrm{H}_{8}$ & $\mathrm{R} 2: 7 \mathrm{H}_{2}+3 \mathrm{CO} \rightarrow \mathrm{C}_{3} \mathrm{H}_{8}+3 \mathrm{H}_{2} \mathrm{O}$ & $0.053 \mathrm{r}_{\mathrm{CO}}$ \\
$\mathrm{C}_{5} \sim \mathrm{C}_{12}$ & 0.30 & $\mathrm{C}_{8} \mathrm{H}_{18}$ (gasoline) & $\mathrm{R} 3: 17 \mathrm{H}_{2}+8 \mathrm{CO} \rightarrow \mathrm{C}_{8} \mathrm{H}_{18}+8 \mathrm{H}_{2} \mathrm{O}$ & $0.234 \mathrm{r}_{\mathrm{CO}}$ \\
$\mathrm{C}_{13+}$ & 0.45 & $\mathrm{C}_{16} \mathrm{H}_{34}$ (diesel) & $\mathrm{R} 4: 33 \mathrm{H}_{2}+16 \mathrm{CO} \rightarrow \mathrm{C}_{16} \mathrm{H}_{34}+16 \mathrm{H}_{2} \mathrm{O}$ & $0.706 \mathrm{r}_{\mathrm{CO}}$ \\
\hline Total & 1.00 & & & $\mathrm{r}_{\mathrm{CO}}$ \\
\hline
\end{tabular}

\section{S1.4.3. Separation and recovery}

Following the FT reactor, a three-phase flash is used to split the mixed stream into gas, liquid HCs and wastewater. As a simplification to the upgrading system, we use a distillation column (RadFrac) to separate gasoline from diesel. For the gas mixture in the simulation, we use an ideal separator (in the real world, PSA can be an option) to recycle all the $\mathrm{C} 1$ components. The GTL system contains inert gas $\left(\mathrm{N}_{2}\right)$, which must be purged (otherwise, it will gradually accumulate in the recycle stream, making the convergence impossible to achieve). Here, the recycle stream is split to vent (to purge) and CIREC, which will be followed by splitting into reforming section and FT sections, respectively.

\section{S1.4.4. Utility and its integration}

The heating utility is supplied by steam at $300{ }^{\circ} \mathrm{C}$ and fuel gas over $1000^{\circ} \mathrm{C}$. The cooling utility is provided by air and cooling water at room temperature. Pump and compressor are powered by electricity.

A high temperature is required for the reforming reaction. Thus, the reformer outflow has an extremely high temperature and needs to be cooled before the FT process. We built three heat exchangers to gradually cool down the reformer outflow, while the recycled heat is used to pre- 
heat the mixed stream to the gas form $\left(>100{ }^{\circ} \mathrm{C}\right)$, an intermediate temperature for pre-reformer $\left(\sim 500^{\circ} \mathrm{C}\right)$ and a high temperature for reformer $\left(700 \sim 1000^{\circ} \mathrm{C}\right)$.

Additionally, the purge stream contains $\mathrm{CO}$ and $\mathrm{CH}_{4}$, which will bring in considerable greenhouse emissions if the direct emissions apply. With the assistance of air, a burner is used to deal with these $\mathrm{C} 1$ components. An RGibbs reactor @ $600{ }^{\circ} \mathrm{C}$ is used to simulate the burner. Due to the exothermic reactions, the burner will release heat, while the waste heat recovery technology ${ }^{14,15}$ can be used to recover the part of burner heating (utilization efficiency is assumed at $\eta_{\text {burner }}=60 \%$ ) to reduce the heating utility of steam or fuel gas. 
S1.5. Reforming + MS

The [Reforming + MS] sub-system contains two sections: (1) combined reforming, which generates the syngas with the composition ratio as $\frac{2 \mathrm{CO}+3 \mathrm{CO}_{2}}{\mathrm{H}_{2}}=1$ (Figure S5); (2) methanol synthesis (MS) converted the syngas to methanol (Figure S6). The MS process model was reported in the Aspen Plus model library. ${ }^{16}$

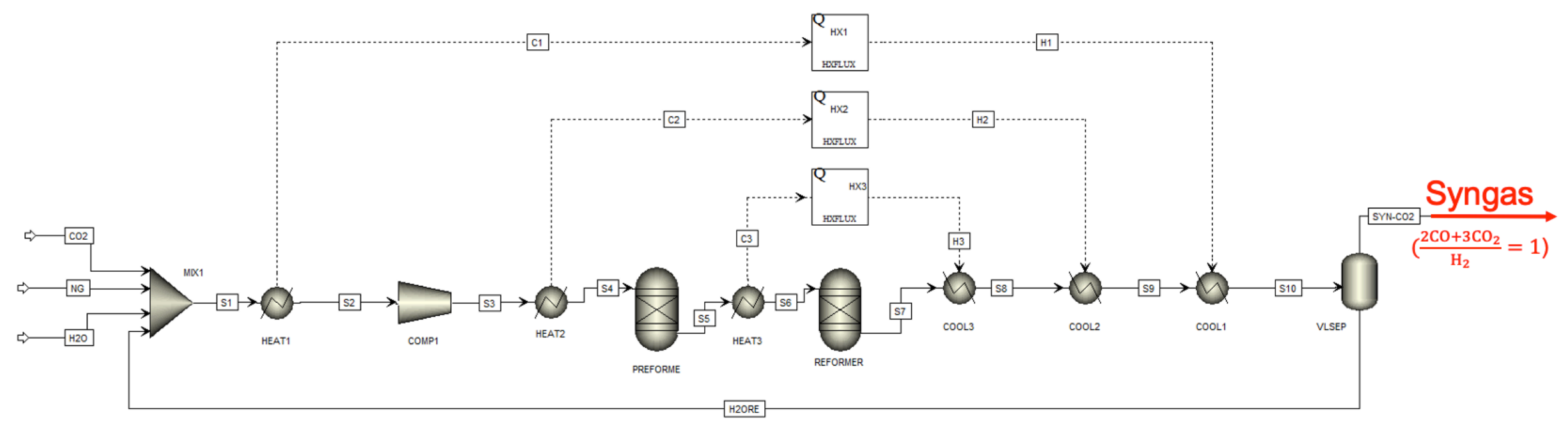

Figure S5. Reforming section for [Reforming + MS]. 


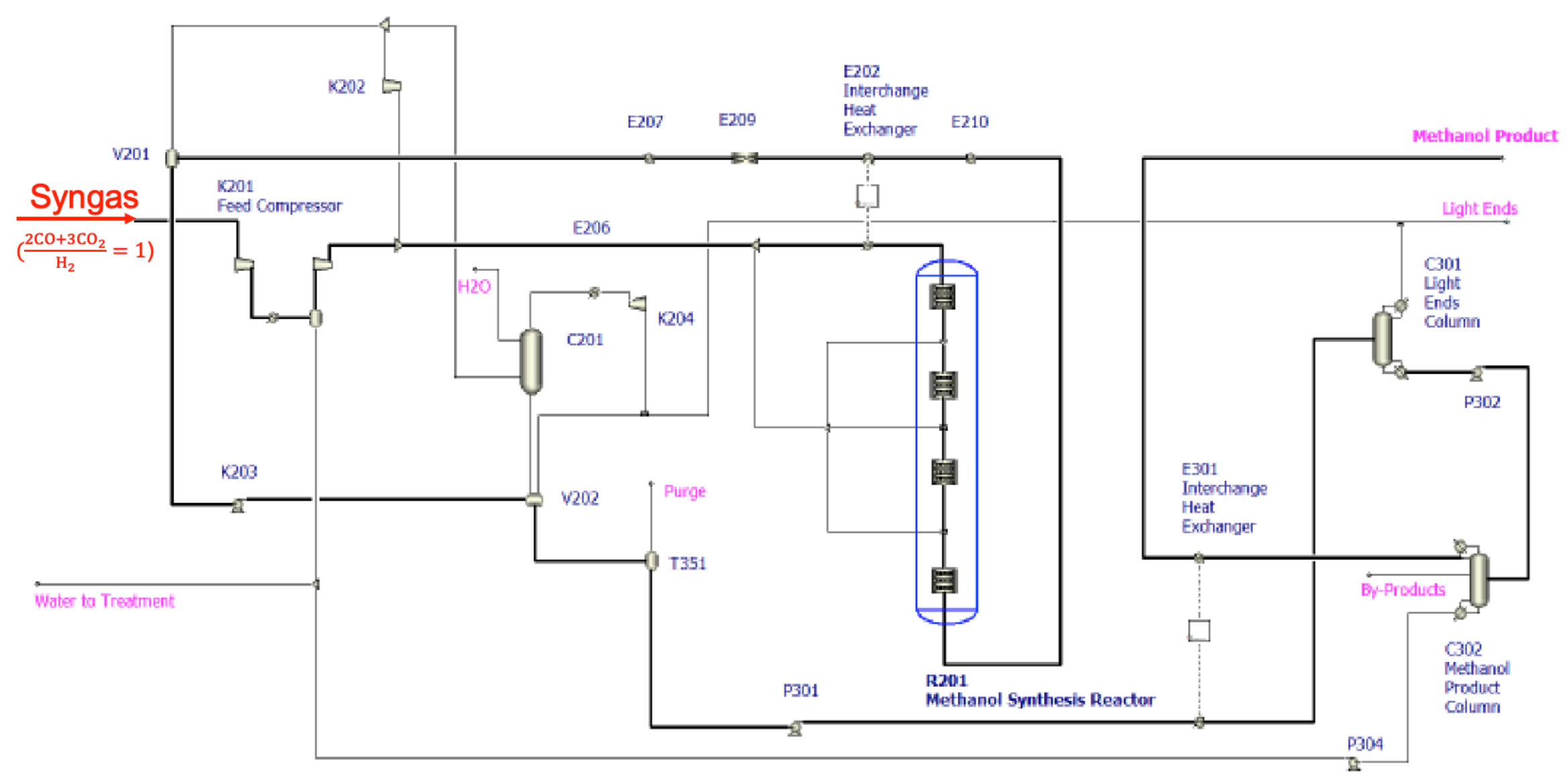

Figure S6. MS process model, taken from Aspen Tech model library. ${ }^{16}$

\section{S1.5.1. Combined reforming}

Combined reforming section is similar to S1.4.1. Combined reforming; flowsheet options are set to manipulate the flowrates of NG and inlet water, in order to the guarantee the optimal syngas ratio as $\frac{2 \mathrm{CO}+3 \mathrm{CO}_{2}}{\mathrm{H}_{2}}=1$ for MS reaction (Figure S5). 


\section{S1.5.2. Methanol synthesis}

For the MS section, Aspen Tech Model library offers an industrial-scale process model (Figure S6), where the thermodynamics, reaction kinetics and mass balance are validated. The process model is reported to be capable to simulate the most common industrial methanol process - ICI Synetix low pressure methanol process (LPM). A four-stage quench reactor is used to perform the heat integration between the inlet stream and exothermic MS reactions. More detailed information about the process models can be referred to the Aspen Tech documents. ${ }^{16}$

$$
\begin{gathered}
\mathrm{CO}_{2}+3 \mathrm{H}_{2} \leftrightarrow \mathrm{CH}_{3} \mathrm{OH}+\mathrm{H}_{2} \mathrm{O} \\
\mathrm{CO}_{2}+\mathrm{H}_{2} \leftrightarrow \mathrm{CO}+\mathrm{H}_{2} \mathrm{O} \text { (RWGS) }
\end{gathered}
$$

Vanden Bussche and Froment kinetics ${ }^{17}$ are used for MS.

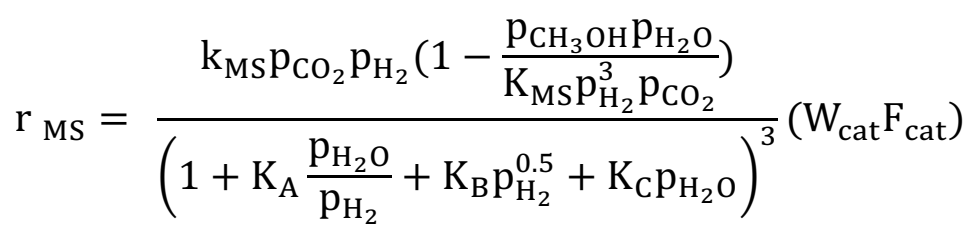

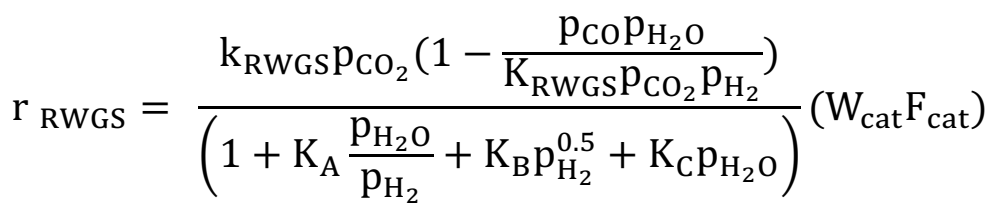

where the rate constants can be expressed as follows,

$$
\begin{aligned}
& \mathrm{k}_{\mathrm{MS}}=\mathrm{k}_{\mathrm{MS}, \mathrm{ref}} \exp \left(-\frac{\mathrm{E}_{\mathrm{MS}}}{\mathrm{R}}\left(\frac{1}{\mathrm{~T}}-\frac{1}{\mathrm{~T}_{\mathrm{ref}}}\right)\right) \\
& \mathrm{k}_{\mathrm{RWGS}}=\mathrm{k}_{\mathrm{RWGS,ref}} \exp \left(-\frac{\mathrm{E}_{\mathrm{RWGS}}}{\mathrm{R}}\left(\frac{1}{\mathrm{~T}}-\frac{1}{\mathrm{~T}_{\text {ref }}}\right)\right)
\end{aligned}
$$

where, $\mathrm{r}_{\mathrm{MS}}$ : rate of methanol synthesis, $\mathrm{kmol} / \mathrm{s}$;

$\mathrm{p}_{\mathrm{i}}$ : partial pressure of component $\mathrm{i}$, bar $\left(\mathrm{i}=\mathrm{H}_{2}, \mathrm{H}_{2} \mathrm{O}, \mathrm{CH}_{3} \mathrm{OH}, \mathrm{CO}, \mathrm{CO}_{2}\right)$;

$\mathrm{k}_{\mathrm{j}}$ : rate constant of reaction $\mathrm{j}, \mathrm{kmol} / \mathrm{kg}-\mathrm{cat} / \mathrm{s}(\mathrm{j}=\mathrm{MS}, \mathrm{RWGS})$

$\mathrm{T}_{\text {ref }}$ : reference temperature, $501.57 \mathrm{~K}$

$\mathrm{k}_{\mathrm{j}, \mathrm{ref}}$ : rate constant of reaction $\mathrm{j} @ \mathrm{~T}_{\text {ref }}, \mathrm{kmol} / \mathrm{kg}$-cat $/ \mathrm{s}(\mathrm{j}=\mathrm{MS}, \mathrm{RWGS})$

$E_{j}$ : activation energy of reaction $j, \mathrm{kmol} / \mathrm{kg}$-cat/s ( $\left.\mathrm{j}=\mathrm{MS}, \mathrm{RWGS}\right)$ 
$K_{j}$ : equilibrium constant of reaction $j(j=M S, R W G S)$, expressed as $\ln K_{j}=A_{j}+\frac{B_{j}}{T}$

$\mathrm{W}_{\text {cat }}:$ rate constant of reaction $\mathrm{j}, \mathrm{kmol} / \mathrm{kg}$-cat $/ \mathrm{s}(\mathrm{j}=\mathrm{MS}, \mathrm{RWGS})$

$\mathrm{F}_{\text {cat }}:$ catalyst activity factor, $\mathrm{F}_{\text {cat }}=1 @$ fresh catalyst.

\section{S1.5.3. Separation and recovery}

We do not modify the separation part of the original process model. More detailed information about the process models can be referred to the Aspen Tech documents. ${ }^{16}$

\section{S1.5.4. Utility and its integration}

This section is the same as the Section S1.4.4. Utility and its integration. 


\section{S2. Overview of essential input/output of sub-systems}

The carbon capture and utilization (CCU) system can be divided into four sub-systems: [NGCC + MEA], [NGCC + PSA], [Reforming + FT] and [Reforming + MS]. Table S2 lists the input and output for sub-systems. The input of a sub-system contains the decision variables and relevant variables from other sub-system. The output of a sub-system contains its mass and energy balance. After the decision variables $\theta=\left[\theta_{\mathrm{MEA}}, \theta_{\mathrm{PSA} 1}, \theta_{\mathrm{PSA} 2}, \mathrm{z}_{\mathrm{FT}}, \theta_{\mathrm{FT}}, \theta_{\mathrm{MS}}, \epsilon, \varepsilon\right]$ are given a set of values, the mass and energy balance of the whole CCU system can be assembled from the sub-systems.

Table S2. Inputs and outputs for sub-systems.

\begin{tabular}{|l|l|l|}
\hline Sub-systems (i) & Input & Output \\
\hline NGCC + MEA & $\theta_{\mathrm{MEA}}$ & $\mathrm{F}_{\mathrm{MEA}, \mathrm{CO}_{2} \mathrm{cap}}, \mathrm{F}_{\mathrm{MEA}, \mathrm{CO}_{2} \mathrm{e}}, \mathrm{E}_{\mathrm{NGCC}-\mathrm{MEA}}$ \\
\hline $\mathrm{NGCC}+\mathrm{PSA}$ & {$\left[\theta_{\mathrm{PSA} 1}, \theta_{\mathrm{PSA} 2}\right]$} & $\mathrm{F}_{\mathrm{PSA}, \mathrm{CO}_{2} \mathrm{cap}}, \mathrm{F}_{\mathrm{PSA}, \mathrm{CO}_{2} \mathrm{e}}, \mathrm{E}_{\mathrm{NGCC}-\mathrm{PSA}}$ \\
\hline Reforming + FT & {$\left[\theta_{\mathrm{FT}}, \mathrm{F}_{\mathrm{MEA}, \mathrm{CO}_{2} \mathrm{cap}}, \mathrm{F}_{\mathrm{PSA}, \mathrm{CO}_{2} \mathrm{cap}}, \mathrm{z}_{\mathrm{FT}}\right]$} & $\mathrm{F}_{\mathrm{FT}, \mathrm{r}}, \mathrm{F}_{\mathrm{FT}, \mathrm{p}}, \mathrm{F}_{\mathrm{FT}, \mathrm{CO}_{2 \mathrm{e}}}, \mathrm{U}_{\mathrm{FT}, \mathrm{u}}$ \\
\hline Reforming + MS & {$\left[\theta_{\mathrm{MS}}, \mathrm{F}_{\mathrm{MEA}, \mathrm{CO}_{2} \mathrm{ca}}, \mathrm{F}_{\mathrm{PSA}, \mathrm{CO}_{2} \mathrm{cap}}, 1-\mathrm{z}_{\mathrm{FT}}\right]$} & $\mathrm{F}_{\mathrm{MS}, \mathrm{r}}, \mathrm{F}_{\mathrm{MS}, \mathrm{p}}, \mathrm{F}_{\mathrm{MS}, \mathrm{CO}_{2 \mathrm{e}}}, \mathrm{U}_{\mathrm{MS}, \mathrm{u}}$ \\
\hline
\end{tabular}

where,

$\theta_{\mathrm{MEA}}:$ decision variables for MEA absorption process.

$\theta_{\mathrm{PSA} 1}$ : decision variables for $1^{\text {st }}$ PSA process.

$\theta_{\mathrm{PSA} 2}:$ decision variables for $2^{\text {nd }}$ PSA process.

$\theta_{\mathrm{FT}}:$ decision variables for [reforming $\left.+\mathrm{FT}\right]$.

$\theta_{\mathrm{MS}}:$ decision variables for [reforming $+\mathrm{MS}$ ] sub-system.

$\mathrm{Z}_{\mathrm{FT}}$ : distribution of captured $\mathrm{CO}_{2}$ to $\mathrm{FT}$ process.

$\mathrm{F}_{\mathrm{MEA}, \mathrm{CO}_{2} \text { cap }}$ : mass flow of captured $\mathrm{CO}_{2}$ by MEA absorption process, $\operatorname{ton}_{\mathrm{CO}_{2}} / \mathrm{h}$.

$\mathrm{F}_{\mathrm{MEA}, \mathrm{CO}_{2} \mathrm{e}}$ : mass flow of uncaptured $\mathrm{CO}_{2}$ by MEA absorption process, $\operatorname{ton}_{\mathrm{CO}_{2}} / \mathrm{h}$.

$\mathrm{F}_{\mathrm{PSA}, \mathrm{CO}_{2} \text { cap }}$ : mass flow of captured $\mathrm{CO}_{2}$ by the two PSA in series, $\operatorname{ton}_{\mathrm{CO}_{2}} / \mathrm{h}$.

$\mathrm{F}_{\mathrm{PSA}, \mathrm{CO}_{2} \mathrm{e}}$ : mass flow of uncaptured $\mathrm{CO}_{2}$ by the two PSA in series, $\operatorname{ton}_{\mathrm{CO}_{2}} / \mathrm{h}$. 
$\mathrm{E}_{\mathrm{NGCC}-\mathrm{MEA}}$ : net electricity output for [NGCC + MEA] sub-system, netMW.

$\mathrm{E}_{\mathrm{NGCC}-\mathrm{PSA}}$ : net electricity output for [NGCC + PSA] sub-system, netMW.

$\mathrm{F}_{\mathrm{ii}, \mathrm{r}}$ : mass flow for required raw materials, $\mathrm{ii}=[\mathrm{FT}, \mathrm{MS}], \mathrm{r}=\left[\mathrm{NG}, \mathrm{H}_{2} \mathrm{O}\right]$, ton/h.

$\mathrm{F}_{\mathrm{ii}, \mathrm{p}}$ : mass flow for products, $\mathrm{ii}=[\mathrm{FT}, \mathrm{MS}], \mathrm{p}=$ [gasoline, diesel, $\left.\mathrm{MEOH}\right]$, ton $/ \mathrm{h}$.

$\mathrm{F}_{\mathrm{ii}, \mathrm{CO}_{2 \mathrm{e}}}$ : mass flow for $\mathrm{CO}_{2}$ emissions via the vent gas, $\mathrm{ii}=[\mathrm{FT}, \mathrm{MS}]$, ton $/ \mathrm{h}$.

$\mathrm{U}_{\mathrm{ii}, \mathrm{u}}$ : utility consumption, $\mathrm{ii}=[\mathrm{FT}, \mathrm{MS}], \mathrm{u}=$ [fuel gas, steam, electricity, cooling], GJ/h.

\section{S3. Surrogates for sub-systems}

\section{S3.1. NGCC}

There is no surrogate here. For NGCC, the IECM software can yield

$\mathrm{GHG}_{\mathrm{MWh}}$ : emissions per unit of electricity generation, ton/MWh;

$\mathrm{NG}_{\mathrm{MWh}}$ : $\mathrm{NG}$ consumption per unit of electricity generation, ton/MWh;

$\mathrm{H}_{2} \mathrm{O}_{\mathrm{MWh}}$ : water consumption per unit of electricity generation, ton/MWh.

\section{S3.2. [NGCC + MEA]}

The $[\mathrm{NGCC}+\mathrm{MEA}]$ sub-system aims to build the relationship between $\theta_{\mathrm{MEA}}$ and $\left[\mathrm{F}_{\mathrm{MEA}, \mathrm{CO}_{2} \mathrm{Cap}}, \mathrm{F}_{\mathrm{MEA}, \mathrm{CO}_{2} \mathrm{e}}, \mathrm{E}_{\mathrm{NGCC}-\mathrm{MEA}}\right]$.

$\theta_{\mathrm{MEA}}$ only contains one decision variable as the recovery rate of $\mathrm{CO}_{2}$ in MEA process $\left(\operatorname{Re}_{\mathrm{CO}_{2}, \mathrm{MEA}}\right)$. When assigning a set of values to $\mathrm{Re}_{\mathrm{MEA}}$, the IECM software can yield the corresponding simulation outputs. With the inputs/outputs, we train a linear regression model as follows:

$$
\left[\operatorname{Re}_{\mathrm{MEA}}, \eta_{\mathrm{MEA}}, \mathrm{H}_{2} \mathrm{O}_{\text {netMWh }}, \mathrm{MEA}_{\text {netMWh }}\right]=\text { surrogate }_{\mathrm{NGCC}-\mathrm{MEA}}\left(\theta_{\mathrm{MEA}}\right)
$$

where, $\mathrm{Re}_{\mathrm{MEA}}$ : recovery rate of $\mathrm{CO}_{2}$ in MEA process.

$\eta_{\mathrm{MEA}}$ : net power out per NGCC power generation (partial loss in MEA), netMW/MW After coupled with a MEA absorption process, a $500 \mathrm{MW}$ NGCC power station generate net power $\left(\mathrm{E}_{\mathrm{NGCC}-\mathrm{MEA}}\right.$, netMW) and captured $\mathrm{CO}_{2}\left(\mathrm{~F}_{\mathrm{MEA}, \mathrm{CO}_{2} \mathrm{cap}}\right.$, ton $\left.\mathrm{CO}_{2} / \mathrm{h}\right)$ as follows,

$$
\mathrm{E}_{\mathrm{NGCC}-\mathrm{MEA}}=\eta_{\mathrm{MEA}} \cdot 500
$$




$$
\begin{aligned}
& \mathrm{F}_{\mathrm{MEA}, \mathrm{CO}_{2} \mathrm{cap}}=500 \cdot \mathrm{GHG}_{\mathrm{MWh}} \cdot \mathrm{Re}_{\mathrm{MEA}} \\
& \mathrm{F}_{\mathrm{MEA}, \mathrm{CO}_{2} \mathrm{e}}=500 \cdot \mathrm{GHG}_{\mathrm{MWh}} \cdot\left(1-\mathrm{Re}_{\mathrm{MEA}}\right)
\end{aligned}
$$

\section{S3.3 [NGCC + PSA]}

The $[\mathrm{NGCC}+$ MEA] sub-system aims to build the relationship between $\left[\theta_{\mathrm{PSA} 1}, \theta_{\mathrm{PSA} 2}\right]$ and $\left[\mathrm{F}_{\mathrm{PSA}, \mathrm{CO}_{2} \mathrm{cap}}, \mathrm{F}_{\mathrm{PSA}, \mathrm{CO}_{2} \mathrm{e}}, \mathrm{E}_{\mathrm{NGCC}-\mathrm{PSA}}\right]$.

Two surrogates are built for two PSA processes, respectively. The obtained $\mathrm{CO}_{2}$ purity from $1^{\text {st }}$ PSA is the inlet $\mathrm{CO}_{2}$ concentration for the $2^{\text {nd }}$ PSA. Their input variables are as follows,

$$
\begin{gathered}
\theta_{\mathrm{PSA} 1}=\left[\mathrm{P}_{\mathrm{L} 1}, \mathrm{P}_{\mathrm{I} 1}, \mathrm{v}_{\mathrm{feed} 1}, \mathrm{t}_{\mathrm{ads} 1}, \mathrm{t}_{\mathrm{bd} 1}, \mathrm{t}_{\mathrm{evac} 1}\right] \\
{\left[\mathrm{Pu}_{\mathrm{PSA} 1}, \theta_{\mathrm{PSA} 2}\right]=\left[\mathrm{Pu}_{\mathrm{PSA} 1}, \mathrm{P}_{\mathrm{L} 2}, \mathrm{P}_{\mathrm{I} 2}, \mathrm{v}_{\mathrm{feed} 2}, \mathrm{t}_{\mathrm{ads} 2}, \mathrm{t}_{\mathrm{bd} 2}, \mathrm{t}_{\mathrm{evac} 2}\right]}
\end{gathered}
$$

A well-distributed values for input can generated by employing Latin hypercube sampling (LHS) for the design space of input variables. Based on these input values, the rigorous PSA simulation on Dymola can yield outputs (purity, recovery and energy consumption). With the inputs/outputs, we train two ANN models as follows,

$$
\begin{array}{ll}
{\left[\mathrm{Pu}_{\mathrm{PSA} 1}, \mathrm{Re}_{\mathrm{PSA} 1}, \text { Energy }_{\mathrm{PSA} 1}\right]=\text { Surrogate }_{\mathrm{PSA} 1}\left(\theta_{\mathrm{PSA} 1}\right)} & \mathrm{S} .10 \\
{\left[\mathrm{Pu}_{\mathrm{PSA} 2}, \mathrm{Re}_{\mathrm{PSA} 2}, \text { Energy }_{\mathrm{PSA} 2}\right]=\text { Surrogate }_{\mathrm{PSA} 2}\left(\left[\mathrm{Pu}_{\mathrm{PSA} 1}, \theta_{\mathrm{PSA} 1}\right]\right)} & \mathrm{S} .11
\end{array}
$$

where, $\mathrm{Re}_{\mathrm{PSA} 1}$ : recovery rate of $\mathrm{CO}_{2}$ in $1^{\text {st }}$ PSA process

$\mathrm{Re}_{\mathrm{PSA} 1}$ : recovery rate of $\mathrm{CO}_{2}$ in $2^{\text {nd }}$ PSA process

Energy ${ }_{\mathrm{PSA} 1}$ : energy consumption per $\mathrm{CO}_{2}$ captured in $1^{\text {st }} \mathrm{PSA}, \mathrm{MWh} / \mathrm{ton}_{\mathrm{CO}_{2}}$

Energy $\mathrm{PSA}_{2}$ : energy consumption per $\mathrm{CO}_{2}$ captured in $2^{\text {nd }} \mathrm{PSA}, \mathrm{MWh} / \mathrm{ton}_{\mathrm{CO}_{2}}$.

The overall performance for [NGCC + PSA] sub-system can be obtained in the following equations:

$$
\begin{aligned}
& \mathrm{Pu}_{\mathrm{PSA}}=\mathrm{Pu}_{\mathrm{PSA} 2} \\
& \operatorname{Re}_{\mathrm{PSA}}=\operatorname{Re}_{\mathrm{PSA} 1} \cdot \operatorname{Re}_{\mathrm{PSA} 2} \\
& \eta_{\mathrm{PSA}}=1-\mathrm{GHG}_{\mathrm{MWh}} \cdot\left(\text { Energy }_{\mathrm{PSA} 1} \cdot \operatorname{Re}_{\mathrm{PSA} 1}+\text { Energy }_{\mathrm{PSA} 2} \cdot \operatorname{Re}_{\mathrm{PSA}}\right)
\end{aligned}
$$

where $\mathrm{Pu}_{\mathrm{PSA}}$ : purity of $\mathrm{CO}_{2}$ from the two PSA

$\mathrm{Re}_{\mathrm{PSA}}$ : recovery rate of $\mathrm{CO}_{2}$ from the two PSA 
$\eta_{\mathrm{PSA}}$ : net power out per NGCC power generation (partial loss in PSA), netMW/MW

After coupled with two PSA in series, a 500 MW NGCC power station generate net power $\left(\mathrm{E}_{\mathrm{NGCC}-\mathrm{PSA}}\right.$, netMW) and captured $\mathrm{CO}_{2}\left(\mathrm{~F}_{\mathrm{PSA}, \mathrm{CO}_{2} \text { cap }}\right.$, ton $\left._{\mathrm{CO}_{2}} / \mathrm{h}\right)$ as follows,

$$
\begin{aligned}
& \mathrm{E}_{\mathrm{NGCC}-\mathrm{MEA}}=\eta_{\mathrm{PSA}} \cdot 500 \\
& \mathrm{~F}_{\mathrm{PSA}, \mathrm{CO}_{2} \mathrm{cap}}=500 \cdot \mathrm{GHG}_{\mathrm{MWh}} \cdot \mathrm{Re}_{\mathrm{PSA}} \\
& \mathrm{F}_{\mathrm{PSA}, \mathrm{CO}_{2} \mathrm{e}}=500 \cdot \mathrm{GHG}_{\mathrm{MWh}} \cdot\left(1-\mathrm{Re}_{\mathrm{PSA}}\right)
\end{aligned}
$$

\section{S3.4. Reforming + FT}

The [Reforming + FT] sub-system aims to build the relationship between $\left[\theta_{\mathrm{FT}}, \mathrm{F}_{\mathrm{MEA}, \mathrm{CO}_{2} \mathrm{cap}}, \mathrm{F}_{\mathrm{PSA}, \mathrm{CO}_{2} \mathrm{cap}}, \mathrm{z}_{\mathrm{FT}}, \epsilon, \varepsilon\right]$ and $\left[\mathrm{F}_{\mathrm{FT}, \mathrm{r}}, \mathrm{F}_{\mathrm{FT}, \mathrm{p}}, \mathrm{F}_{\mathrm{FT}, \mathrm{CO}_{2 \mathrm{e}}}, \mathrm{U}_{\mathrm{FT}, \mathrm{u}}\right]$.

The amount of $\mathrm{CO}_{2}$ flowing to [Reforming $\left.+\mathrm{FT}\right]$ can be calculated as follows,

$$
\mathrm{F}_{\mathrm{FT}, \mathrm{CO}_{2}}=\left(\mathrm{F}_{\mathrm{MEA}, \mathrm{CO}_{2} \mathrm{cap}}+\mathrm{F}_{\mathrm{PSA}, \mathrm{CO}_{2} \mathrm{cap}}\right) \cdot \mathrm{z}_{\mathrm{FT}}
$$

The input variables for [Reforming + FT] are as follows,

$$
\left[\mathrm{F}_{\mathrm{FT}, \mathrm{CO}_{2}}, \theta_{\mathrm{FT}}\right]=\left[\mathrm{F}_{\mathrm{FT}, \mathrm{CO}_{2}}, \mathrm{~T}_{\mathrm{FT}}, \mathrm{P}_{\mathrm{FT}}, \text { Tray }_{\mathrm{ref} 1}, \mathrm{~T}_{\text {ref } 1}, \mathrm{P}_{\text {ref } 1}, \mathrm{~S}_{\mathrm{purge}}, \mathrm{Re}_{\mathrm{FT}}\right]
$$

A well-distributed values for input can generated by employing Latin hypercube sampling (LHS) for the design space of input variables. Based on these input values, the rigorous simulation on Aspen Plus can yield outputs (mass flows and utilities). With the inputs/outputs, we train an ANN model for [Reforming + FT] sub-system as follows,

$$
\left[\mathrm{F}_{\mathrm{FT}, \mathrm{r}}, \mathrm{F}_{\mathrm{FT}, \mathrm{p}}, \mathrm{F}_{\mathrm{FT}, \mathrm{CO}_{2 \mathrm{e}}}, \mathrm{U}_{\mathrm{FT}, \mathrm{u}}\right]=\text { Surrogate }_{\text {reforming }+\mathrm{FT}}\left(\left[\mathrm{F}_{\mathrm{FT}, \mathrm{CO}_{2}}, \theta_{\mathrm{FT}}\right]\right)
$$

\section{S3.5. Reforming + MS}

The [Reforming + MS] sub-system aims to build the relationship between $\left[\theta_{\mathrm{MS}}, \mathrm{F}_{\mathrm{MEA}, \mathrm{CO}_{2} \mathrm{cap}}, \mathrm{F}_{\mathrm{PSA}, \mathrm{CO}_{2} \mathrm{cap}}, 1-\mathrm{z}_{\mathrm{FT}}\right]$ and $\left[\mathrm{F}_{\mathrm{MS}, \mathrm{r}}, \mathrm{F}_{\mathrm{MS}, \mathrm{p}}, \mathrm{F}_{\mathrm{MS}, \mathrm{CO}_{2 \mathrm{e}}}, \mathrm{U}_{\mathrm{MS}, \mathrm{u}}\right]$.

The amount of $\mathrm{CO}_{2}$ flowing to [Reforming $+\mathrm{MS}$ ] can be calculated as follows,

$$
\mathrm{F}_{{\mathrm{MS}, \mathrm{CO}_{2}}_{2}}=\left(\mathrm{F}_{\mathrm{MEA}, \mathrm{CO}_{2} \mathrm{cap}}+\mathrm{F}_{\mathrm{PSA}_{,} \mathrm{CO}_{2} \mathrm{cap}}\right) \cdot\left(1-\mathrm{z}_{\mathrm{FT}}\right)
$$

The input variables for [Reforming $+\mathrm{MS}$ ] are as follows,

$$
\left[\mathrm{F}_{\mathrm{MS}, \mathrm{CO}_{2}}, \theta_{\mathrm{MS}}\right]=\left[\mathrm{F}_{\mathrm{MS}, \mathrm{CO}_{2}}, \mathrm{~T}_{\mathrm{FT}}, \mathrm{P}_{\mathrm{FT}}, \mathrm{Tray}_{\mathrm{ref} 1}, \mathrm{~T}_{\mathrm{ref} 1}, \mathrm{P}_{\mathrm{ref} 1}, \mathrm{~S}_{\mathrm{purge}}, \mathrm{Re}_{\mathrm{FT}}\right]
$$


A well-distributed values for input can generated by employing Latin hypercube sampling (LHS) for the design space of input variables. Based on these input values, the rigorous simulation on Aspen Plus can yield outputs (mass flows and utilities). With the inputs/outputs, we train an ANN model for [Reforming + MS] sub-system as follows,

$$
\left[\mathrm{F}_{\mathrm{MS}, \mathrm{r}}, \mathrm{F}_{\mathrm{MS}, \mathrm{p}}, \mathrm{F}_{\mathrm{MS}, \mathrm{CO}_{2 \mathrm{e}}}, \mathrm{U}_{\mathrm{MS}, \mathrm{u}}\right]=\text { Surrogate }_{\text {reforming }+\mathrm{MS}}\left(\left[\mathrm{F}_{\mathrm{MS}, \mathrm{CO}_{2}}, \theta_{\mathrm{MS}}\right]\right)
$$

\section{S4. Evaluation of GHG emissions for the industrial park}

\section{S4.1. System boundary in this work: cradle-to-gate}

This section explains the 'cradle-to-gate' boundary adopted for the analysis. The GHG emissions for the whole CCU system are evaluated based on the life cycle assessment (LCA). The system boundary determines the life cycle stages required for the evaluation. A strict LCA can cover the evaluation of emissions throughout entire 'cradle-to-grave' life cycle stages ranging from raw material, manufacturing, distributing, use, to recycling/disposal. However, the evaluation of the entire life cycle of a product requires excessive workloads. Further, LCA is mainly used in comparative assessments. The cradle-to-gate (from raw materials to manufacturing) is sufficient to compare the emissions for different technology, while the downstream emissions are identical. ${ }^{18}$ As shown in Figure S7, the cradle-to-gate approach for the $\mathrm{CCU}$ system will quantify the GHG emissions of raw materials and utility as well as $\mathrm{CO}_{2}$ emissions in the process (e.g. uncaptured $\mathrm{CO}_{2}$ and $\mathrm{CO}_{2}$ emissions via vent gas).

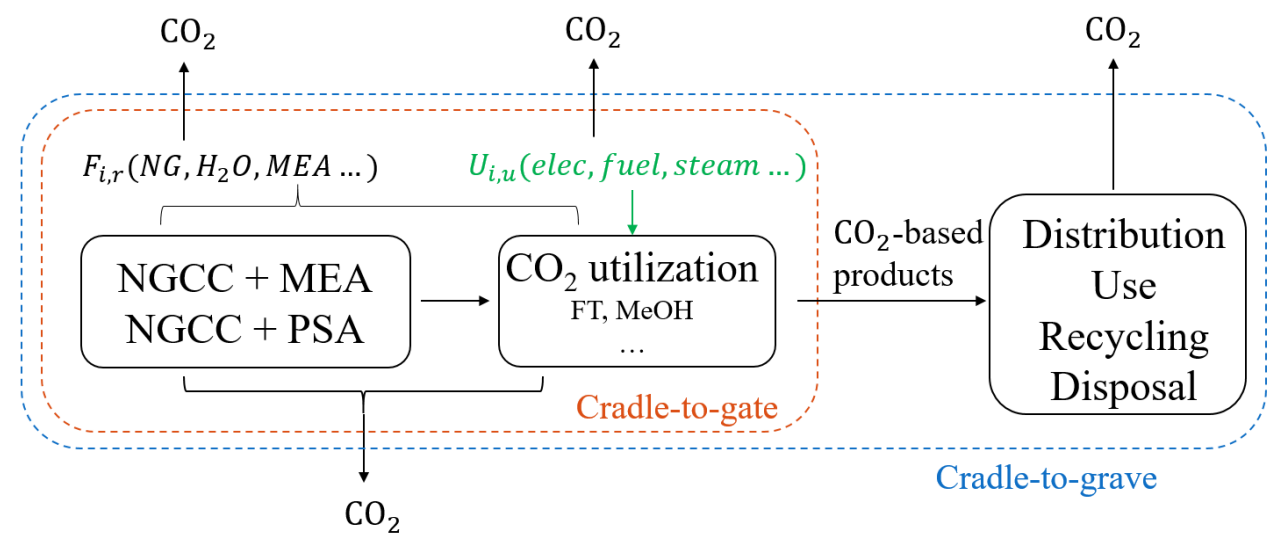

Figure S7. System boundaries of cradle-to-gate vs. cradle-to-grave approach for the emissions of a CCU system. 


\section{S4.2. System expansion strategy to compare CCU with a reference process.}

The 'system expansion' strategy is particularly useful for LCA of a system with multiple functions. ${ }^{18}$ The CCU system achieves multiple functions, i.e. the co-productions of several fuels and the generation of low-carbon electricity. For a proper comparison, the 'system expansion' strategy expands a reference process to include all the functions as the original process. As shown in Figure S8, the reference system can generate the electricity (no capture technology) and fuels by conventional process. Meanwhile, the amount of electricity generation and the production of fuels are equivalent in the two systems for a fair comparison.

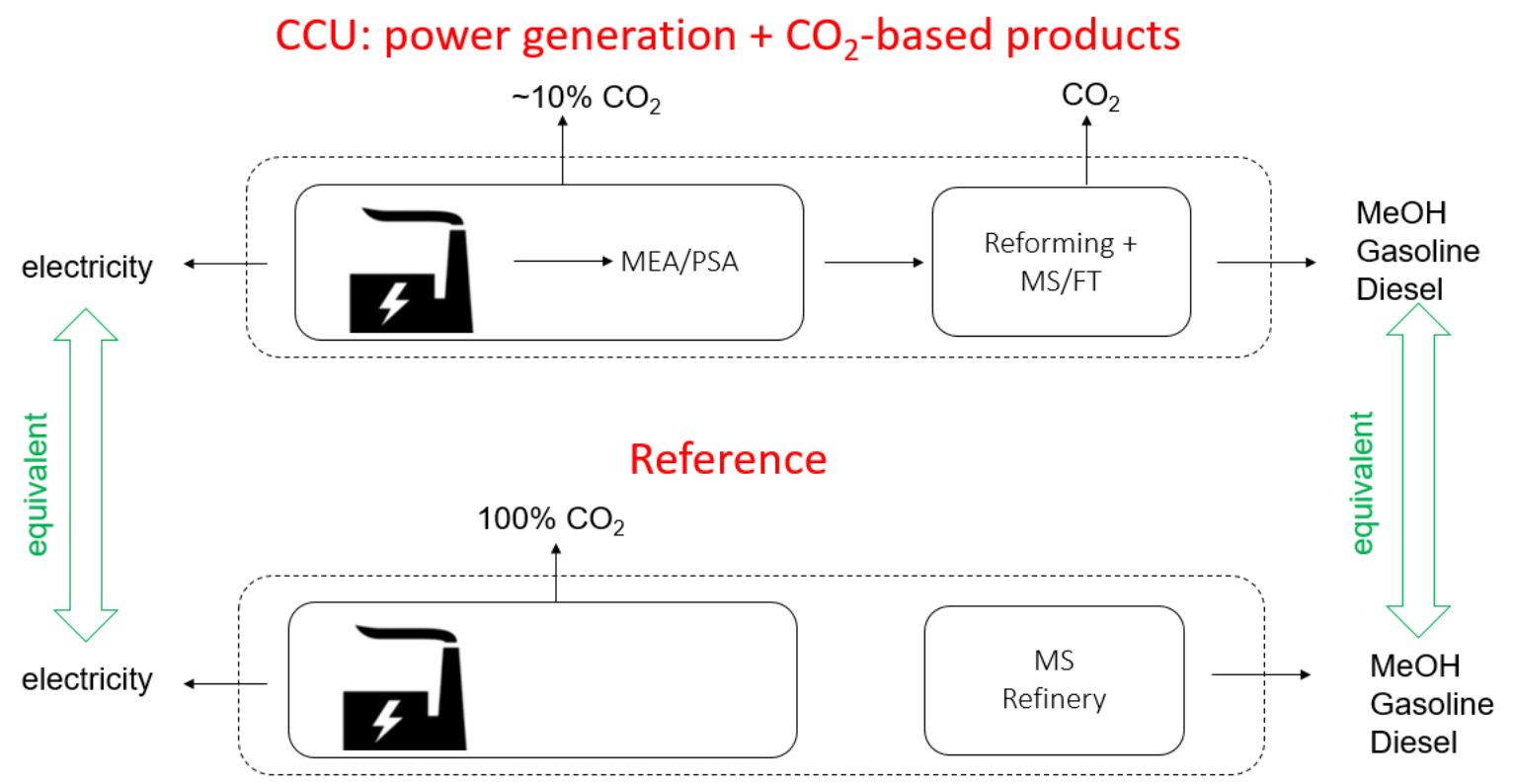

Figure S8. Expansion strategy for a fair comparison between CCU system and a conventional system.

\section{S4.3. The reduction of $\mathrm{GHG}$ emissions}

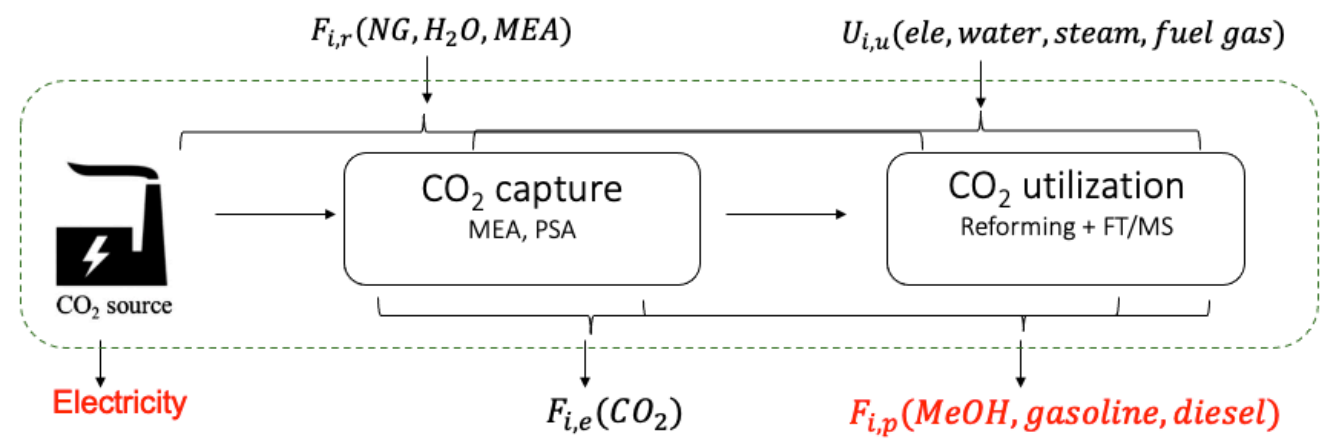

Figure S9. Sources of GHG emissions in the cradle-to-gate system boundary. 


$$
\begin{aligned}
& \mathrm{GHG}_{\mathrm{CCU}}=\sum_{\mathrm{i}} \sum_{\mathrm{r}} \alpha_{\mathrm{r}} \cdot \mathrm{F}_{\mathrm{i}, \mathrm{r}}+\sum_{\mathrm{i}} \sum_{\mathrm{u}} \alpha_{\mathrm{u}} \cdot \mathrm{U}_{\mathrm{i}, \mathrm{u}}+\sum_{\mathrm{i}} \mathrm{F}_{\mathrm{i}, \mathrm{CO} 2} \\
& \mathrm{GHG}_{\text {ref }}=\alpha_{N G C C} \cdot \mathrm{E}_{\text {electricity }}+\sum_{\mathrm{i}} \sum_{\mathrm{p}} \alpha_{\mathrm{p}} \cdot \mathrm{F}_{\mathrm{i}, \mathrm{p}} \\
& \mathrm{GHG}_{\text {reduction }}=1-\frac{\mathrm{GHG}_{\mathrm{CCU}}}{\mathrm{GHG}_{\mathrm{ref}}}
\end{aligned}
$$

where

F: mass flow, ton/hour

U: utility, GJ/hour

$\alpha_{\mathrm{r}}$ : emission factor per raw material $\mathrm{r}$ generation: $\operatorname{ton}_{\mathrm{CO}_{2} \mathrm{eq}} / \operatorname{ton}_{\mathrm{r}}$

$\alpha_{\mathrm{u}}$ : emission factor per utility $\mathrm{u}$ generation: $\operatorname{ton}_{\mathrm{CO}_{2} \mathrm{eq}} / \mathrm{GJ}$

$\alpha_{\mathrm{p}}$ : emission factor per product $\mathrm{p}$ generation: $\operatorname{ton}_{\mathrm{CO}_{2} \mathrm{eq}} / \operatorname{ton}_{\mathrm{p}}$

Subscript

i: notation for sub-systems

r: notation for raw materials (natural gas, process water, MEA)

$\mathrm{u}$ : notation for utilities (steam, fuel gas, electricity, cooling water)

p: notation for products

\section{S4.4. Calculation of emission factors for low-carbon electricity}

In this work, the emission factor is defined as the GHG emission in generating a material (per ton) or a utility (per GJ). In the proposed industrial park, two $500 \mathrm{MW}$ power stations generate electricity by natural gas combined cycle (NGCC) technology. When no carbon capture is applied, as shown in Equation S.25, the emission factor per unit of electricity generation is calculated by the sum of emissions in generating raw materials (NG, water) together with the direct emissions. As such, the emission factor of NGCC electricity is calculated as 0.41 $\mathrm{kg}_{\mathrm{CO}_{2} \mathrm{eq}} / \mathrm{kWh}$, which falls in the range reported by Weisser. ${ }^{19}$

$$
\alpha_{\mathrm{NGCC}}=\frac{\sum_{\mathrm{r}} \alpha_{\mathrm{r}} \cdot \mathrm{F}_{\mathrm{NGCC}, \mathrm{r}}+\mathrm{F}_{\mathrm{NGCC}, \mathrm{CO}_{2} \mathrm{e}}}{\mathrm{E}_{\mathrm{NGCC}}}
$$


In our work, the low-carbon electricity specifically refers to CCS electricity (NGCC integrated with CCS). MEA decarbonizes one NGCC, while PSA decarbonizes the other one. The emission factors of low-carbon electricity is approximated by the average value between [NGCC-PSA-storage] and [NGCC-MEA-storage]. Equation S.26-S.28 shows how the emission factor for low-carbon electricity. As such, the cost of low-carbon electricity is estimated at $0.098 \mathrm{~kg}_{\mathrm{CO}_{2}} / \mathrm{kwh}$ (value may slightly change subject to the amount of $\mathrm{CO}_{2}$ captured), which is in agreement with the literature value. ${ }^{19}$

$$
\begin{gathered}
\alpha_{\mathrm{CCS}}=\left(\alpha_{\mathrm{PSA}}+\alpha_{\mathrm{MEA}}\right) / 2 \\
\alpha_{\mathrm{PSA}}=\frac{\sum_{\mathrm{r}} \alpha_{\mathrm{r}} \cdot \mathrm{F}_{\mathrm{NGCC}, \mathrm{r}}+\mathrm{F}_{\mathrm{PSA}, \mathrm{CO}_{2} \mathrm{e}}}{\mathrm{E}_{\mathrm{NGCC}-\mathrm{PSA}}} \\
\alpha_{\mathrm{MEA}}=\frac{\sum_{\mathrm{r}} \alpha_{\mathrm{r}} \cdot \mathrm{F}_{\mathrm{NGCC}, \mathrm{r}}+\sum_{\mathrm{r}} \alpha_{\mathrm{r}} \cdot \mathrm{F}_{\mathrm{MEA}, \mathrm{r}}+\mathrm{F}_{\mathrm{MEA}, \mathrm{CO}_{2} \mathrm{e}}}{\mathrm{E}_{\mathrm{NGCC}-\mathrm{MEA}}}
\end{gathered}
$$

$\mathrm{E}_{\mathrm{NGCC}}$ : power generation of NGCC, GJ/h

$\mathrm{E}_{\mathrm{NGCC}-\mathrm{PSA}}$ : net power out for a NGCC coupled with PSA, GJ/h

$\mathrm{E}_{\mathrm{NGCC}-\mathrm{MEA}}$ : net power out for a NGCC coupled with MEA, GJ/h

$\mathrm{F}_{\mathrm{PSA}, \mathrm{CO}_{2} \mathrm{e}}$ : emissions for a NGCC coupled with PSA, ton $_{\mathrm{CO}_{2}} / \mathrm{h}$

$\mathrm{F}_{\mathrm{MEA}, \mathrm{CO}_{2} \mathrm{e}}$ : emissions for a NGCC coupled with MEA, ton $\mathrm{CO}_{2} / \mathrm{h}$

$\mathrm{F}_{\mathrm{PSA}, \mathrm{CO}_{2} \mathrm{~s}}$ : the amount of stored $\mathrm{CO}_{2}$ for a $\mathrm{NGCC}$ coupled with PSA, ton $\mathrm{CO}_{2} / \mathrm{h}$

$\mathrm{F}_{\mathrm{MEA}, \mathrm{CO}_{2} \mathrm{~s}}$ : the amount of stored $\mathrm{CO}_{2}$ for a $\mathrm{NGCC}$ coupled with MEA, $\operatorname{ton}_{\mathrm{CO}_{2}} / \mathrm{h}$

$\mathrm{F}_{\mathrm{MEA}, \mathrm{r}}$ : mass flow of raw materials $\left(\mathrm{MEA}, \mathrm{H}_{2} \mathrm{O}\right)$ in MEA absorption process, ton/hour

Subscript:

$\mathrm{CO}_{2 \mathrm{e}}, \mathrm{CO}_{2}$ emission to envrioment

$\mathrm{CO}_{2 \mathrm{~s}}, \mathrm{CO}_{2}$ storage to underground

\section{S4.5. Calculation of GHG emission factor for low-carbon heating}

In this work, heating is proposed to be partially substituted by CCS electricity. As such, lowcarbon heating is used in the CCU system. Herein, the GHG emission factor for low-carbon heating is calculated as follows, 


$$
\begin{gathered}
\alpha_{\text {fuel low }-\mathrm{C}_{\text {lo }}}=\epsilon \cdot \alpha_{\mathrm{CCS}}+(1-\epsilon) \alpha_{\text {fuel }} \\
\alpha_{\text {steam }}{ }_{\text {low }-\mathrm{C}}=\varepsilon \cdot \alpha_{\mathrm{CCS}}+(1-\varepsilon) \alpha_{\text {steam }}
\end{gathered}
$$

where,

$\alpha_{\text {fuel }_{\text {low-C }}}$ : GHG emission factor for low-carbon heating (partially by CCS electricity and partially by fuel gas), ton/GJ

$\alpha_{\text {fuel }}$ : GHG emission factor for heating by fuel gas, ton/GJ

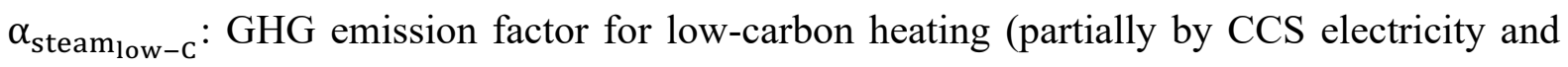
partially by steam), ton/GJ

$\alpha_{\text {steam }}:$ GHG emission factor for heating by steam, ton/GJ

\section{S4.6. Data for $G H G$ emissions factors}

$\alpha_{\mathrm{r}}$ : emission factor per raw material $\mathrm{r}$ generation: ton $_{\mathrm{CO}_{2} \mathrm{eq}} /$ ton $_{\mathrm{r}}$

$\alpha_{\mathrm{u}}$ : emission factor per utility u generation: $\operatorname{ton}_{\mathrm{CO}_{2} \text { eq }} / \mathrm{GJ}$

$\alpha_{\mathrm{p}}$ : emission factor per product $\mathrm{p}$ generation (in conventional or reference process): ton $_{\mathrm{CO}_{2} \text { eq }} /$ ton $_{\mathrm{p}}$

Table S3. GHG emissions factors for materials $\left(\alpha_{r}\right.$ or $\left.\alpha_{p}\right)$ and utilities $\left(\alpha_{u}\right)$

\begin{tabular}{|l|l|l|l|}
\hline & GHG emissions factors & Unit & source \\
\hline Natural gas & 0.354 & $\operatorname{ton}_{\mathrm{CO}_{2} \mathrm{eq}} /$ ton $_{\mathrm{NG}}$ & $1)$ \\
\hline Process water & $5.4 \mathrm{e}-4$ & ton $_{\mathrm{CO}_{2} \text { eq }} /$ ton $_{\text {water }}$ & $1)$ \\
\hline Methanol & 0.762 & ton $_{\mathrm{CO}_{2} \text { eq }} /$ ton $_{\mathrm{MEOH}}$ & $1)$ \\
\hline Gasoline & 0.802 & $\operatorname{ton}_{\mathrm{CO}_{2} \text { eq }} /$ ton $_{\text {gasoline }}$ & $1)$ \\
\hline Diesel & 0.663 & $\operatorname{ton}_{\mathrm{CO}_{2} \text { eq }} /$ ton $_{\text {diesel }}$ & $1)$ \\
\hline MEA & 3.40 & $\operatorname{ton}_{\mathrm{CO}_{2} \text { eq }} /$ ton $_{\mathrm{MEA}}$ & $2)$ \\
\hline Ethanol & 3.74 & $\operatorname{ton}_{\mathrm{CO}_{2} \text { eq }} /$ ton $_{\mathrm{EtOH}}$ & $3)$ \\
\hline C2-C4 & 1.11 & $\operatorname{ton}_{\mathrm{CO}_{2} \text { eq }} /$ ton $_{\mathrm{C} 3}$ & $4)$ \\
\hline
\end{tabular}




\begin{tabular}{|l|l|c|l|}
\hline Electricity & 0.114 & $\operatorname{ton}_{\mathrm{CO}_{2} \mathrm{eq}} / \mathrm{GJ}$ & $5)$ \\
\hline Fuel gas & 0.079 & $\operatorname{ton}_{\mathrm{CO}_{2} \mathrm{eq}} / \mathrm{GJ}$ & \\
\hline Steam & & $\operatorname{ton}_{\mathrm{CO}_{2} \mathrm{eq}} / \mathrm{GJ} \mathrm{J}_{\text {steam }}$ & $1)$ \\
\hline Cooling water & 0.083 & $\operatorname{ton}_{\mathrm{CO}_{2} \mathrm{eq}} / \mathrm{GJ}$ & $1)$ \\
\hline
\end{tabular}

1) Roh et al. ${ }^{20}$

2) Cuéllar-Franca et al. ${ }^{21}$

3) Munoz et al. ${ }^{22}$

4) Average the emission factors of propene and propane in the software Umberto (method: ReCiPe Midpoint (H) w/o LT).

5) The emission factor of electricity (from a NGCC power plant) is based on the sum of $\mathrm{NG}$, process water, $\mathrm{CO}_{2}$ emissions (refer to Equation S.25).

6) The emission factor of cooling is calculated by water emission factor times its required amount (based on $\Delta \mathrm{T}=20^{\circ} \mathrm{C}$, heat transfer efficiency $\eta=0.8$ ).

\section{S5. Evaluation of economic aspect for the industrial park}

\section{S5.1. The calculation of profits}

$$
\begin{aligned}
\text { Profit }_{\mathrm{CCU}}= & -\sum_{\mathrm{i}} \sum_{\mathrm{r}} \beta_{\mathrm{r}} \cdot \mathrm{F}_{\mathrm{i}, \mathrm{r}}-\sum_{\mathrm{i}} \sum_{\mathrm{u}} \beta_{\mathrm{u}} \cdot \mathrm{U}_{\mathrm{i}, \mathrm{u}}-\sum_{\mathrm{i}} \mathrm{F}_{\mathrm{i}, \mathrm{CO} 2} \cdot \gamma_{\mathrm{CO}_{2}} \\
& +\beta_{\mathrm{CCS}} \cdot \mathrm{E}_{\text {electricity }}+\sum_{\mathrm{i}} \sum_{\mathrm{p}} \beta_{\mathrm{p}} \cdot \mathrm{F}_{\mathrm{i}, \mathrm{p}}
\end{aligned}
$$

where

F: mass flow, ton/hour

U: utility, GJ/hour

$\beta_{\mathrm{r}}$ : cost of raw material $\mathrm{r}, \$ /$ ton

$\beta_{\mathrm{u}}$ : cost of utility $\mathrm{u}, \$ / \mathrm{GJ}$

$\gamma_{\mathrm{CO}_{2}}:$ carbon tax (carbon price), $\$ /$ ton $_{\mathrm{CO}_{2}}$

$\beta_{\mathrm{CCS}}$ : cost of low-carbon electricity (equivalent to CCS electricity), \$/GJ

$\beta_{\mathrm{p}}$ : price of product $\mathrm{p}, \$ /$ ton 


\section{Subscript}

i: notation for sub-systems

r: notation for raw materials (natural gas, process water, MEA)

$\mathrm{u}$ : notation for utilities (steam, fuel gas, electricity, cooling water)

p: notation for products

\section{S5.2. Calculation of economic factors for low-carbon electricity}

Economic factors refer to the costs of raw materials and utilities as well as the prices of products. The emission factors of low-carbon electricity is approximated by the average value between [NGCC-PSA-storage] and [NGCC-MEA-storage]. The cost of carbon storage is obtained by IECM software.

$$
\begin{aligned}
& \beta_{\mathrm{CCS}}=\left(\beta_{\mathrm{PSA}}+\beta_{\mathrm{MEA}}\right) / 2 \\
& \beta_{\mathrm{PSA}}=\frac{\beta_{\mathrm{NGCC}} \cdot \mathrm{E}_{\mathrm{NGCC}}+\gamma_{\mathrm{CO}_{2}} \cdot \mathrm{F}_{\mathrm{PSA}, \mathrm{CO}_{2} \mathrm{e}}+\delta_{\mathrm{CO}_{2}} \cdot \mathrm{F}_{\mathrm{PSA} \mathrm{CO}_{2} \mathrm{~s}}}{\mathrm{E}_{\mathrm{NGCC}-\mathrm{PSA}}} \\
& \beta_{\mathrm{MEA}}=\frac{\beta_{\mathrm{NGCC}} \cdot \mathrm{E}_{\mathrm{NGCC}}+\sum_{\mathrm{r}} \beta_{\mathrm{r}} \cdot \mathrm{F}_{\mathrm{MEA}, \mathrm{r}}+\gamma_{\mathrm{CO}_{2}} \cdot \mathrm{F}_{\mathrm{MEA}, \mathrm{CO}_{2} \mathrm{e}}+\delta_{\mathrm{CO}_{2}} \cdot \mathrm{F}_{{\mathrm{MEA}, \mathrm{CO}_{2} \mathrm{~s}}}}{\mathrm{E}_{\mathrm{NGCC}-\mathrm{MEA}}}
\end{aligned}
$$

$\beta_{\mathrm{CCS}}:$ cost of low-carbon electricity (CCS electricity), \$/GJ

$\beta_{\mathrm{PSA}}$ : cost of electricity from [NGCC-PSA-storage] (the value can change based on the carbon price and the amount of captured $\left.\mathrm{CO}_{2}\right), \$ / \mathrm{GJ}$

$\beta_{\mathrm{NGCC}}$ : cost of electricity from NGCC, \$/GJ

$\beta_{\mathrm{MEA}}$ : cost of electricity from [NGCC-MEA-storage] (the value can change based on the carbon price and the amount of captured $\left.\mathrm{CO}_{2}\right), \$ / \mathrm{GJ}$

$\delta_{\mathrm{CO}_{2}}$ : cost of the $\mathrm{CO}_{2}$ transportation and storage in underground (obtained in IECM, assuming a $50 \mathrm{~km}$ pipeline is used for transportation), $\$ / \operatorname{ton}_{\mathrm{CO}_{2} \mathrm{~s}}$

$\mathrm{F}_{\mathrm{MEA}, \mathrm{CO}_{2 \mathrm{~s}}}$ : cost of electricity from [NGCC-MEA-storage] (the value can change based on the carbon price and the amount of captured $\left.\mathrm{CO}_{2}\right), \$ / \mathrm{GJ}$ 


\section{S5.3. Calculation of economic factors for low-carbon heating}

In this work, heating is proposed to be partially substituted by CCS electricity. As such, lowcarbon heating is used in the CCU system. Herein, the economic factor for low-carbon heating is calculated as follows,

$$
\begin{gathered}
\beta_{\text {fuel low }-\mathrm{C}_{\text {lo }}}=\epsilon \cdot \beta_{\mathrm{CCS}}+(1-\epsilon) \beta_{\text {fuel }} \\
\beta_{\text {steam }_{\text {low }-\mathrm{C}}}=\varepsilon \cdot \beta_{\mathrm{CCS}}+(1-\varepsilon) \beta_{\text {steam }}
\end{gathered}
$$

where,

$\beta_{\text {fuel }_{\text {low-C }}}$ : economic factor for low-carbon heating (partially by CCS electricity and partially by fuel gas), ton/GJ

$\beta_{\text {fuel }}$ : economic factor for heating by fuel gas, ton/GJ

$\beta_{\text {steam }}{ }_{\text {low-C }}$ : economic factor for low-carbon heating (partially by CCS electricity and partially by steam), ton/GJ

$\beta_{\text {steam }}$ : economic factor for heating by steam, ton/GJ

\section{S5.4. Calculation of economic factors involving with carbon tax.}

The economic factors contain two parts: original prices and carbon tax.

$$
\begin{aligned}
& \beta_{\mathrm{r}}=\beta_{\mathrm{r}, 0}+\alpha_{\mathrm{r}} \cdot \gamma_{\mathrm{CO}_{2}} \\
& \beta_{\mathrm{u}}=\beta_{\mathrm{u}, 0}+\alpha_{\mathrm{u}} \cdot \gamma_{\mathrm{CO}_{2}} \\
& \beta_{\mathrm{p}}=\beta_{\mathrm{p}, 0}+\alpha_{\mathrm{p}} \cdot \gamma_{\mathrm{CO}_{2}}
\end{aligned}
$$

where

$\beta$

$\alpha$

$\gamma_{\mathrm{CO}_{2}}$

Subscript

i

r
Economic factors, $\$ /$ ton $_{\mathrm{r}}$

Emission factors, $\operatorname{ton}_{\mathrm{CO}_{2}} / \operatorname{ton}_{\mathrm{p}}$

Carbon price, $\$ /$ ton $_{\mathrm{CO}_{2}}$

Notation for sub-systems

Notation for raw materials (natural gas, process water, MEA, etc.) 


\section{S5.5. Data for economic factors}

For the key materials (NG, methanol, gasoline, diesel), we use the prices data in the first half of 2021. Due to the EU energy crisis in the second half of 2021, the prices for all petrol-products dramatically surge in different speeds [FT], so the very latest price data may cause bias in the economic analysis.

Table S4. Economic factors for materials $\left(\beta_{r, 0}\right.$ or $\left.\beta_{p, 0}\right)$, utilities $\left(\beta_{u, 0}\right)$ and $\mathrm{CO}_{2}$ storage $\left(\delta_{\mathrm{CO}_{2}}\right)$.

\begin{tabular}{|l|l|c|l|}
\hline & $\begin{array}{l}\text { Economic factors } \\
{[\$ / \text { ton }]}\end{array}$ & Unit & source \\
\hline Natural gas & 475.4 & $\$ /$ ton $_{\mathrm{NG}}$ & $1)$ \\
\hline Process water & 0.036 & $\$ /$ ton $_{\text {water }}$ & $2)$ \\
\hline Methanol & 475.6 & $\$ /$ ton $_{\mathrm{MEOH}}$ & $3)$ \\
\hline Gasoline & 2254.8 & $\$ /$ ton $_{\text {gasoline }}$ & $4)$ \\
\hline Diesel & 1808.6 & $\$ /$ ton $_{\text {diesel }}$ & $4)$ \\
\hline MEA & 1100.0 & $\$ /$ ton $_{\mathrm{MEA}}$ & $5)$ \\
\hline Ethanol & 705.7 & $\$ /$ ton $_{\text {EtoH }}$ & $6)$ \\
\hline C2-C4 & 1067.2 & $\$ /$ ton $_{\mathrm{C3}}$ & $6)$ \\
\hline Electricity & 41.34 & $\$ / \mathrm{GJ}_{\mathrm{NGCC}}$ & $1)$ \\
\hline Fuel gas & 9.76 & $\$ / \mathrm{G}_{\text {fuel-gas }}$ & $1)$ \\
\hline Steam & 15.35 & $\$ / \mathrm{GJ}_{\text {steam }}$ & $7)$ \\
\hline Cooling water & 0.029 & $\$ /$ ton $_{\text {water }}$ & $2)$ \\
\hline Cooling utility & 0.43 & $\$ / \mathrm{GJ}_{\text {cooling }}$ & $8)$ \\
\hline CO 2 storage & 5.56 & $\$$ ton $_{\mathrm{CO}}$ s & $9)$ \\
\hline
\end{tabular}

1) Eurostat. Choose the prices for $\mathrm{EU}$ in the first half $2021{ }^{23}$

2) Boulamanti et al. ${ }^{24}$ 
3) Methanex. Choose the prices for EU in April 2021.25

4) European Commission - Weekly Oil Bulletin. Choose the prices for EU in April $2021 .^{26}$

5) Brandl et al. ${ }^{27}$

6) ICIS $2019 \mathrm{EU}^{28}$

7) $\operatorname{TLV}^{29}$

8) The cost of cooling is calculated by cooling water emission factor times its required amount (based on $\Delta T=20^{\circ} \mathrm{C}$, heat transfer efficiency $\eta=0.8$ ).

9) $\delta_{\mathrm{CO}_{2}}$ : cost of the $\mathrm{CO}_{2}$ transportation and storage in underground is obtained in IECM (assuming a $50 \mathrm{~km}$ pipeline is used for transportation). ${ }^{1}$

\section{S6. Single-optimization (LCA) of the industrial park}
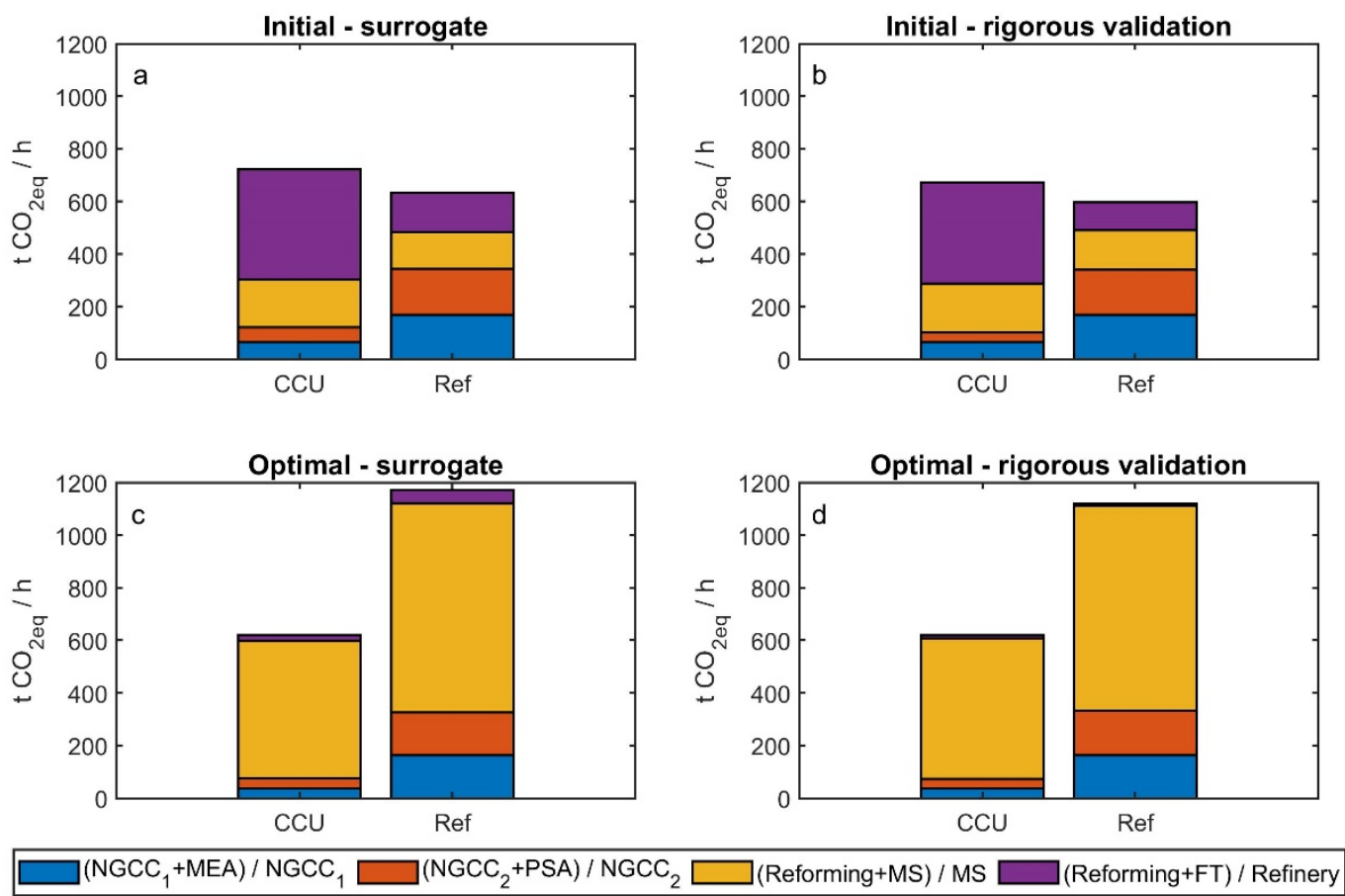

Figure S10. Validation of surrogate models by rigorous simulation for the industrial park regarding: (a) initial operating condition based on surrogates; (b) initial operating condition based on rigorous process models; (c) optimal operating condition based on surrogates; (d) optimal operating condition based on rigorous process models. For the legends: left of '/ for CCU system, right of '/ for the reference system. 

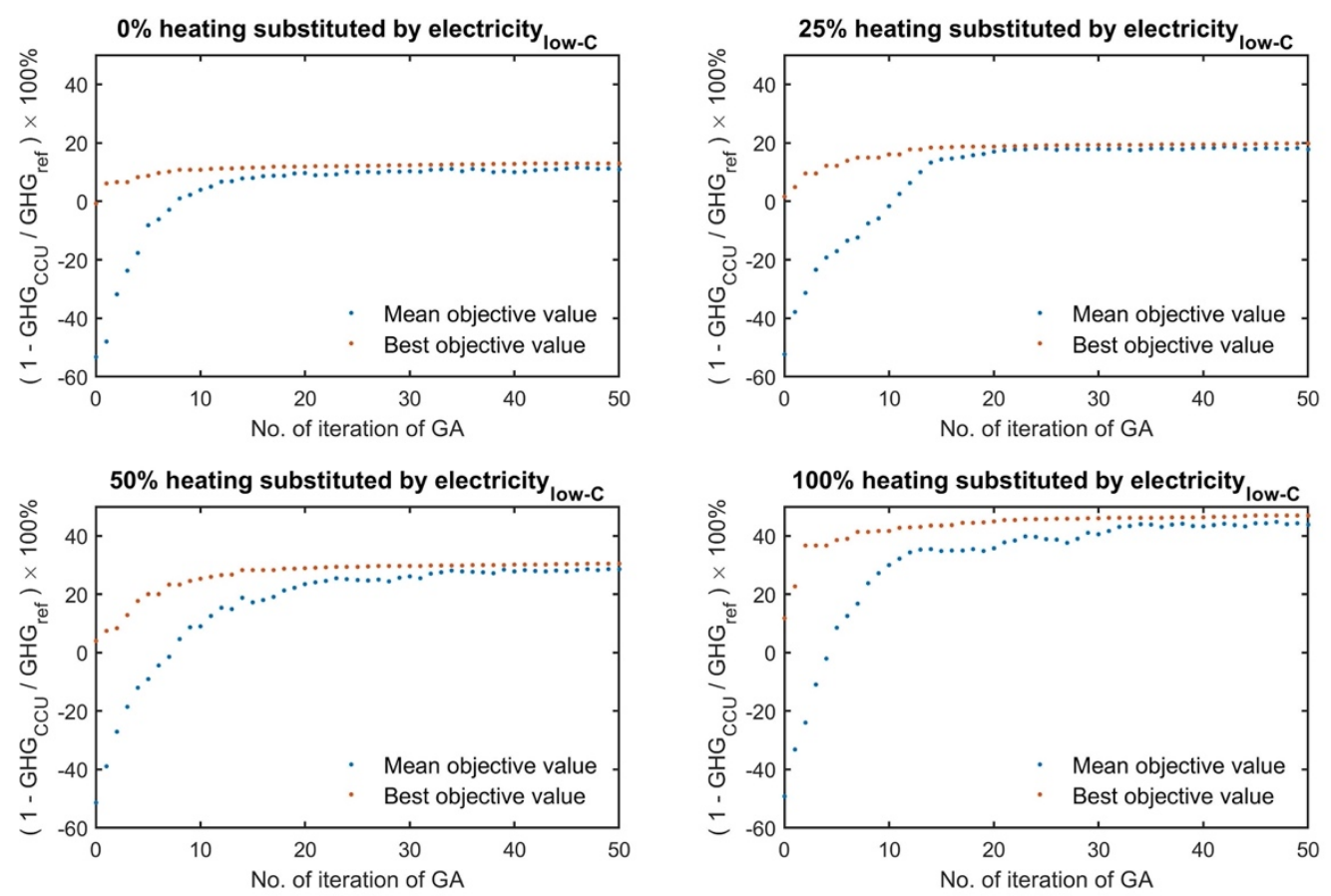

Figure S11. Scenario analysis for the optimization progress, regarding $10 \%, 25 \%, 50 \%$ and $100 \%$ heating utility is substituted by electricity. 
Table S5. Scenario analysis for optimal values of decision variables, regarding maximum $10 \%$, $25 \%, 50 \%$ and $100 \%$ heating utility is substituted by electricity.

\begin{tabular}{|c|c|c|c|c|c|c|}
\hline & \multirow[b]{2}{*}{$\begin{array}{l}\text { design } \\
\text { variables }\end{array}$} & \multirow[b]{2}{*}{ Unit } & \multicolumn{4}{|c|}{ Max heating percentage substituted by CCS-elec } \\
\hline & & & 1 & 0.5 & 0.25 & 0 \\
\hline MEA & $\mathrm{r}_{\mathrm{CO}_{2}}$ & - & 0.933 & 0.935 & 0.917 & 0.925 \\
\hline \multirow{6}{*}{ 1st PSA } & $\mathrm{P}_{\mathrm{L} 1}$ & bar & 0.007 & 0.008 & 0.006 & 0.006 \\
\hline & $\mathrm{P}_{\mathrm{I} 1}$ & bar & 0.406 & 0.375 & 0.447 & 0.203 \\
\hline & $v_{\text {feed } 1}$ & $\mathrm{~m} / \mathrm{s}$ & 0.614 & 0.614 & 1.265 & 0.857 \\
\hline & $\mathrm{t}_{\mathrm{ads} 1}$ & $\mathrm{~s}$ & 68.789 & 80.648 & 51.744 & 69.800 \\
\hline & $t_{b d 1}$ & $\mathrm{~s}$ & 32.515 & 54.996 & 50.743 & 42.274 \\
\hline & $t_{\text {evac1 }}$ & $\mathrm{s}$ & 183.637 & 179.226 & 194.448 & 190.152 \\
\hline \multirow{6}{*}{ 2nd PSA } & $\mathrm{P}_{\mathrm{L} 2}$ & bar & 0.014 & 0.011 & 0.011 & 0.019 \\
\hline & $\mathrm{P}_{\mathrm{I} 2}$ & bar & 0.170 & 0.266 & 0.432 & 0.267 \\
\hline & $v_{\text {feed2 }}$ & $\mathrm{m} / \mathrm{s}$ & 0.534 & 0.917 & 0.917 & 0.316 \\
\hline & $\mathrm{t}_{\mathrm{ads} 2}$ & $\mathrm{~s}$ & 59.411 & 46.559 & 59.411 & 60.379 \\
\hline & $t_{b d 2}$ & $s$ & 44.544 & 36.050 & 35.890 & 82.815 \\
\hline & $t_{\text {evac2 }}$ & $\mathrm{s}$ & 178.820 & 178.820 & 191.707 & 176.463 \\
\hline $\mathrm{CO}_{2}$ to $\mathrm{FT}$ & $\mathrm{z}_{\mathrm{FT}}$ & - & 0.027 & 0.027 & 0.046 & 0.027 \\
\hline \multirow{7}{*}{ FT } & $\mathrm{T}_{\mathrm{FT}}$ & ${ }^{\circ} \mathrm{C}$ & 247.886 & 263.910 & 254.435 & 257.929 \\
\hline & $\mathrm{P}_{\mathrm{FT}}$ & bar & 25.904 & 17.334 & 46.535 & 42.624 \\
\hline & $\operatorname{tray}_{\mathrm{FT}}$ & - & 62 & 52 & 52 & 52 \\
\hline & $\mathrm{T}_{\mathrm{ref} 1}$ & ${ }^{\circ} \mathrm{C}$ & 876.081 & 876.081 & 774.820 & 858.981 \\
\hline & $P_{\text {ref1 }}$ & bar & 5.073 & 5.130 & 4.730 & 3.129 \\
\hline & $S_{\text {purge }}$ & - & 0.045 & 0.069 & 0.194 & 0.102 \\
\hline & $\mathrm{Re}_{\mathrm{FT}}$ & - & 0.573 & 0.828 & 0.660 & 0.468 \\
\hline \multirow{6}{*}{$\mathrm{MEOH}$} & $\mathrm{F}_{\mathrm{NG}} / \mathrm{F}_{\mathrm{CO}}$ & - & 3.498 & 3.643 & 3.656 & 3.656 \\
\hline & $\mathrm{T}_{\mathrm{MS}}$ & ${ }^{\circ} \mathrm{C}$ & 204.318 & 198.258 & 187.149 & 189.011 \\
\hline & $\mathrm{P}_{\mathrm{MS}}$ & bar & 69.542 & 78.283 & 75.294 & 77.341 \\
\hline & Tray $_{\text {Ms }}$ & - & 46 & 61 & 60 & 64 \\
\hline & $\mathrm{T}_{\mathrm{ref} 2}$ & ${ }^{\circ} \mathrm{C}$ & 933.319 & 864.478 & 913.001 & 876.951 \\
\hline & $\mathrm{P}_{\mathrm{ref} 2}$ & bar & 6.224 & 4.615 & 5.474 & 5.176 \\
\hline \multirow{2}{*}{$\begin{array}{l}\text { Heating } \\
\text { utility }\end{array}$} & Frac $_{\text {fuel }}$ ele-cCS & - & 0.997 & 0.498 & 0.250 & 0.000 \\
\hline & Frac $_{\text {steam ele-CCS }}$ & - & 0.956 & 0.496 & 0.223 & 0.000 \\
\hline
\end{tabular}


S7. Multi-objective (LCA-Economic) optimization of the industrial park

S7.1. Optimal values for decision carbon @ Carbon price=0
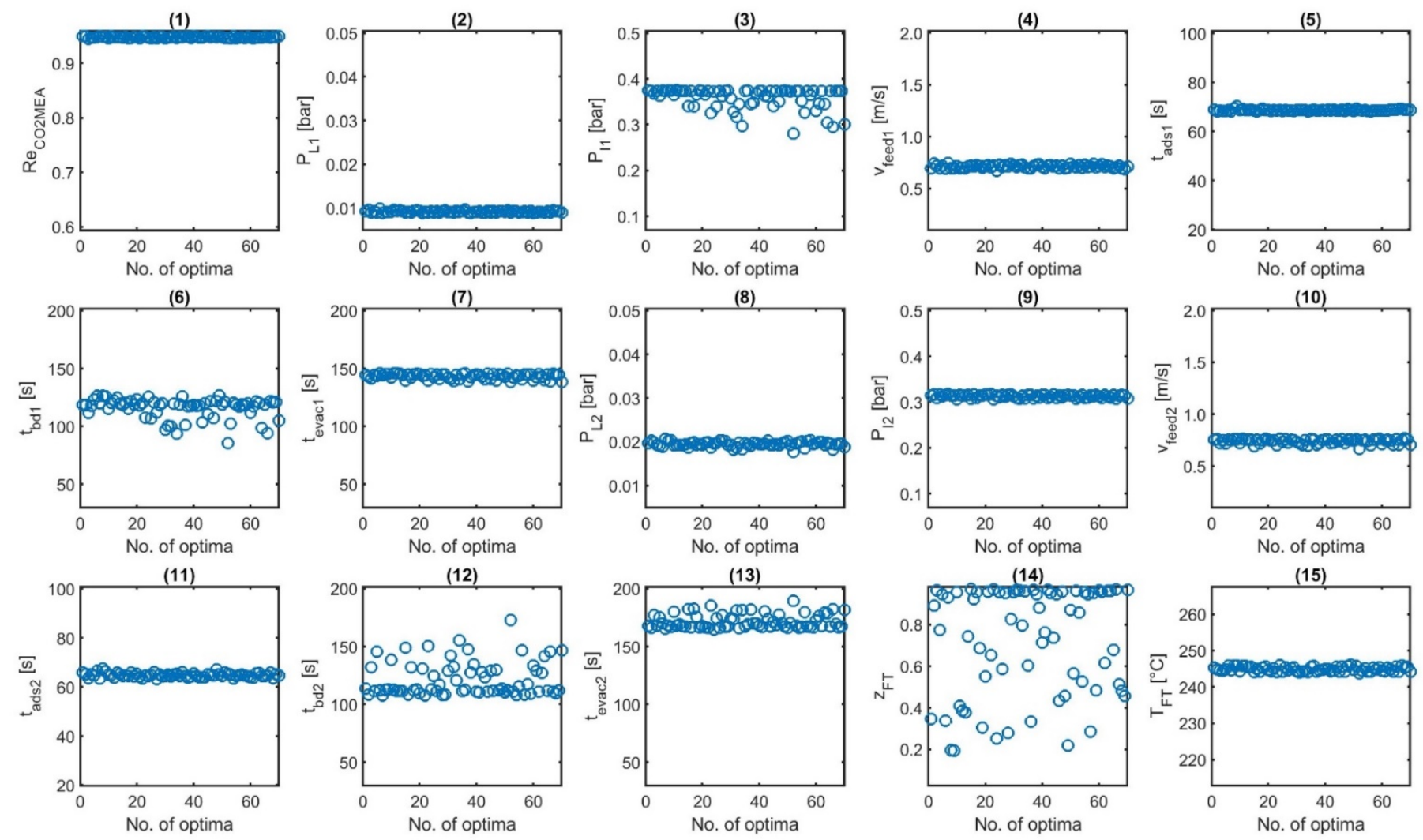

Figure S12. Optimal values of decision variables $x_{1} \sim x_{15}$ after multi-objective optimization $@ C_{\text {tax }}=0 \$$ /ton- $\mathrm{CO}_{2}$ (corresponding to the Pareto front in Figure 8). 

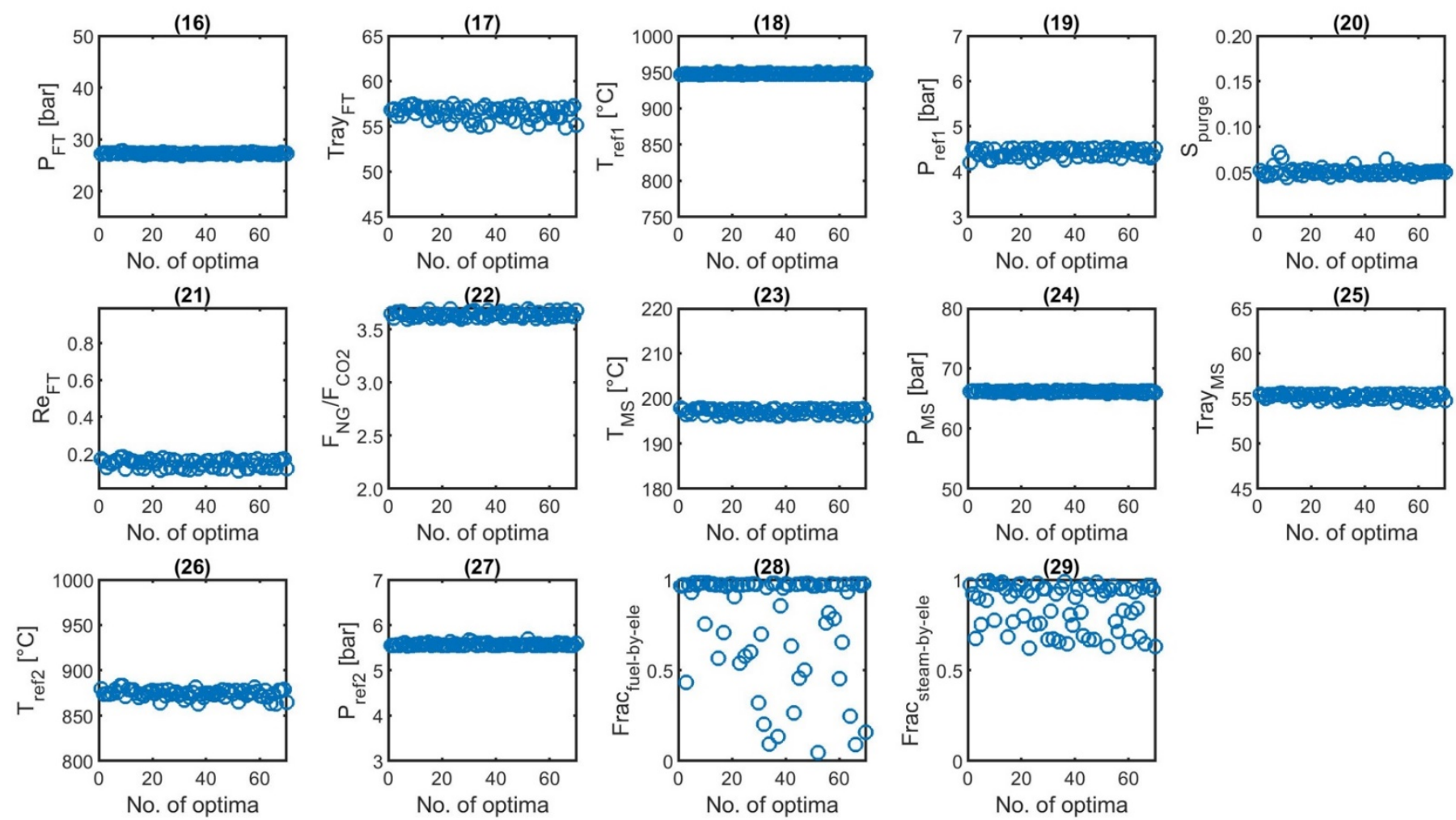

Figure S13. Optimal values of decision variables $x_{16} \sim x_{29}$ after multi-objective optimization $@ C_{\text {tax }}=0 \$ /$ ton- $\mathrm{CO}_{2}$ (corresponding to the Pareto front in Figure 8). 


\section{S7.2. Evaluation of utilities}

As indicated by the single-objective optimization, the heating utility is accounted for the biggest role in the GHG emissions. Herein, we once again check the influence of optimized utility on both economic aspects and GHG emissions. NSGA-II promotes low-carbon heating. On the one hand, switching to the low-carbon electricity increases the energy cost, by $25 \%$ for electricity and by average $337 \%$ for fuel-gas heating as well as $201 \%$ for steam heating. On the other hand, switching to the low-carbon electricity dramatically reduces the GHG emissions, by $76 \%$ for electricity and by $52 \%$ for fuel-gas heating as well as average $57 \%$ for steam heating.
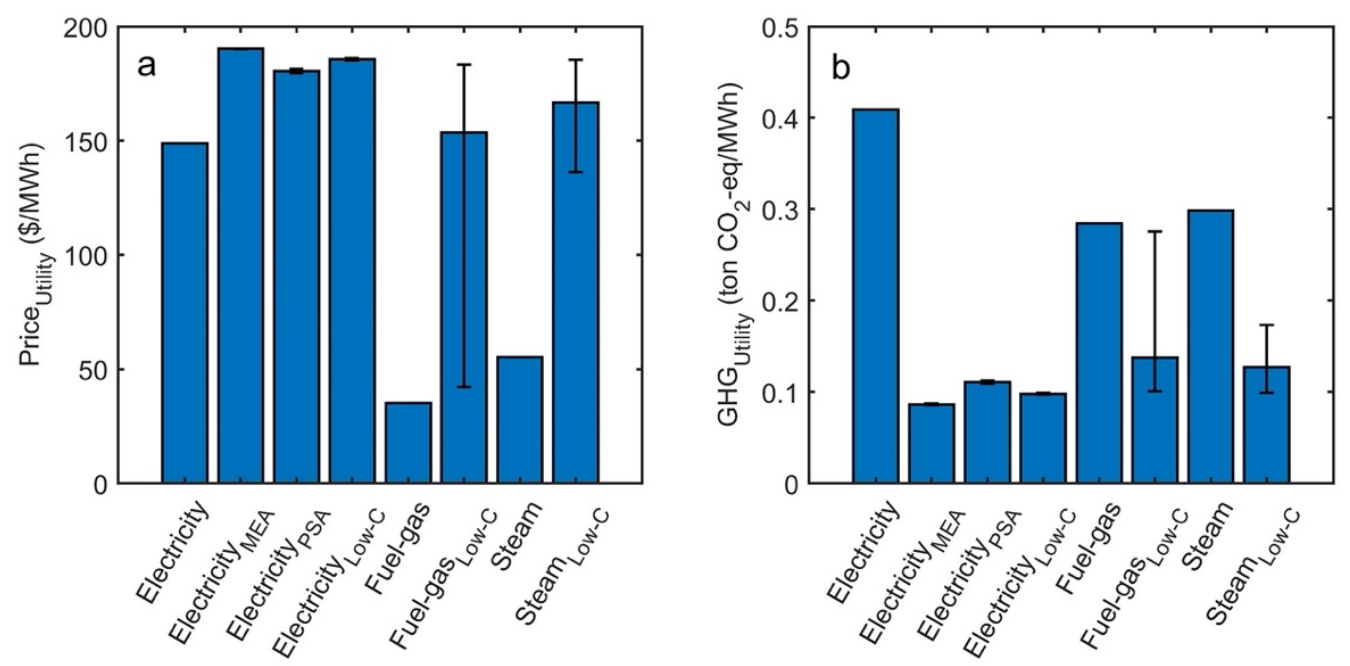

Figure S14 (a) Price of utilities. (b) GHG emissions of utilities. Clarification for the x-axis label - (1) Electricity: NG-based power plant with direct emissions; (2) Electricity ${ }_{M E A}$ : NG-based power plant coupled with MEA; (3) Electricity $_{P S A}$ : NG-based power plant coupled with PSA; (4) Electricity Low $-C_{\text {: }}$ low-carbon electricity, which is approximated by the average value between Electricity ${ }_{M E A}$ and Electricity ${ }_{P S A}$ (the cost of $\mathrm{CO}_{2}$ storage is included); (5) Fuelgas: heating provided by fuel gas; (6) Fuel-gas ${ }_{\text {Low }-C}$ : fuel-gas heating partially substituted by low-carbon electricity; (7) Steam: heating provided by steam; (8) Steam Low-C $_{\text {: steam }}$ heating partially substituted by low-carbon electricity.

\section{References}

1. IECM, Integrated Environmental Control Model (IECM) Version 11.4 (Carnegie Mellon University), https://www.cmu.edu/epp/iecm/index.html, accessed: 2020-08-01. 
2. Z. Hao, C. Zhang and A. Lapkin, Efficient Surrogates Construction of Chemical Processes: Case studies on Pressure Swing Adsorption and Gas-to-Liquids. ChemRxiv, 2021.

3. R. Haghpanah, A. Majumder, R. Nilam, A. Rajendran, S. Farooq, I. A. Karimi and M. Amanullah, Ind Eng Chem Res., 2013, 52, 4249-4265.

4. Z. Hao, A. Caspari, A. M. Schweidtmann, Y. Vaupel, A. A. Lapkin and A. Mhamdi, Chem Eng J., 2021, 423, 130248.

5. K.-S. Ha, J. W. Bae, K.-J. Woo and K.-W. Jun, Environ Sci Technol., 2010, 44, 14121417.

6. $\quad$ M. E. Dry, Catal Today, 2002, 71, 227-241.

7. J. R. van Ommen and J. Grievink, in Biomass as a Sustainable Energy Source for the Future, 2014, pp. 525-546.

8. Y. H. Kim, K.-W. Jun, H. Joo, C. Han and I. K. Song, Chem Eng J., 2009, 155, 427432.

9. C.-J. Lee, Y. Lim, H. S. Kim and C. Han, Ind Eng Chem Res., 2009, 48, 794-800.

10. B. Bao, M. M. El-Halwagi and N. O. Elbashir, Fuel Process Technol., 2010, 91, 703713.

11. I. C. Yates and C. N. Satterfield, Energy Fuel, 1991, 5, 168-173.

12. C. G. Visconti, L. Lietti, E. Tronconi, P. Forzatti, R. Zennaro and E. Finocchio, Appl Catal A: Gen., 2009, 355, 61-68.

13. P. Kaiser, R. B. Unde, C. Kern and A. Jess, Chem Ing Tech., 2013, 85, 489-499.

14. H. Jouhara, N. Khordehgah, S. Almahmoud, B. Delpech, A. Chauhan and S. A. Tassou, Therm Sci Eng Prog., 2018, 6, 268-289.

15. P. F. Fleming and B. J. Church, in Plant Engineer's Reference Book (Second Edition), ed. D. A. Snow, Butterworth-Heinemann, Oxford, 2002, pp. 13-11 13-35.

16. AspenTech, Aspen Plus Methanol Synthesis Model, 2018. The methanol synthesis model can be downloaded from esupport.aspentech.com. Alternatively, for Aspen Plus V11 and higher version, the model file can be accessed in C:IProgram

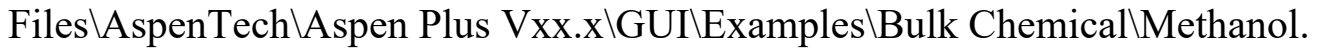

17. K. M. V. Bussche and G. F. Froment, J Catal., 1996, 161, 1-10.

18. A. Zimmermann, L. Müller, Y. Wang, T. Langhorst, J. Wunderlich, A. Marxen, K. Armstrong, G. Buchner, A. Kätelhön and M. Bachmann, Techno-Economic Assessment \& Life Cycle Assessment Guidelines for CO2 Utilization (Version 1.1), 2020.

19. D. Weisser, Energy, 2007, 32, 1543-1559.

20. K. Roh, A. S. Al-Hunaidy, H. Imran and J. H. Lee, AIChE J., 2019, 65, e16580.

21. R. M. Cuéllar-Franca, P. García-Gutiérrez, S. F. R. Taylor, C. Hardacre and A. Azapagic, Faraday Discuss, 2016, 192, 283-301.

22. I. Muñoz, K. Flury, N. Jungbluth, G. Rigarlsford, L. M. i Canals and H. King, The Int J Life Cycle Ass., 2014, 19, 109-119.

23. Eurostat, Natural gas price statistics, https://ec.europa.eu/eurostat/statisticsexplained/index.php?title=Natural_gas_price_statistics\#Natural_gas_prices_for_nonhousehold consumers, accessed: 2021-08-01.

24. A. Boulamanti and J. A. Moya, Renew Sust Energy Reviews, 2017, 68, 1205-1212.

25. Methanex, Methanex Methanol Price Sheet, https://www.methanex.com/ourbusiness/pricing, accessed: 2021-08-01.

26. European-Commission, Weekly Oil Bulletin, https://ec.europa.eu/energy/dataanalysis/weekly-oil-bulletin en, accessed: 2021-08-01.

27. P. Brandl, M. Bui, J. P. Hallett and N. Mac Dowell, Int J Greenh Gas Con., 2021, 105, 103239. 
28. ICIS, ICIS Europe Chemicals Outlooks - 2019, https://www.icis.com/explore/resources/europe-chemical-outlook-2019/, accessed: 2021-08-01.

29. TLV, Calculator: Steam Unit Cost, https://www.tlv.com/global/UK/calculator/steamunit-cost.html. accessed: 2021-08-01. 